ROGÉRIO MASSANORI SAKAHARA

\title{
ESTUDO DA FORMAÇÃO DA FASE CRISTALINA BETA NOS COMPÓSITOS DE POLIPROPILENO CONTENDO ANIDRIDO MALÉICO E CARBONATO DE CÁLCIO.
}

São Paulo

2012 
ROGÉRIO MASSANORI SAKAHARA

\title{
ESTUDO DA FORMAÇÃO DA FASE CRISTALINA BETA NOS COMPÓSITOS DE POLIPROPILENO CONTENDO ANIDRIDO MALÉICO E CARBONATO DE CÁLCIO.
}

\author{
Dissertação apresentada à Escola Politécnica da Universidade \\ de São Paulo como parte dos requisitos para a obtenção do \\ título de mestre em ciência e engenharia de materiais.
}

Área de concentração: Engenharia de materiais Orientadora: Profa. Dra. Wang Shu Hui

São Paulo

2012 
Este exemplar foi revisado e alterado em relação à versão original, sob responsabilidade única do autor e com a anuência de seu orientador.

São Paulo, 14 de dezembro de 2012.

Assinatura do autor

Assinatura do orientador

FICHA CATALOGRÁFICA

Sakahara, Rogério Massanori

Estudo da formação da fase cristalina beta nos compósitos de polipropileno contendo anidrido maléico e carbonato de cálcio / R.M. Sakahara. -- ed.rev. -- São Paulo, 2012.

$120 \mathrm{p}$.

Dissertação (Mestrado) - Escola Politécnica da Universidade de São Paulo. Departamento de Engenharia Metalúrgica e de Materiais.

1. Polímeros (Materiais) 2. Materiais compósitos poliméricos I. Universidade de São Paulo. Escola Politécnica. Departamento de Engenharia Metalúrgica e de Materiais II. t. 
À Samara e Leticinha...

Estou muito feliz por cada segundo com vocês..

e aproveito intensamente cada sentimento envolvido a essa felicidade... 
À minha mãe Taeko e minhas irmãs, Solange e Shirley, que sempre me motivaram com muito carinho e sempre me deram e me dão um grande prazer para meu desenvolvimento em vida.

Ao meu pai Mário Seiti, meus tios, meus avós paternos e maternos que de alguma forma, em qualquer lugar em que estejam, sinto a presença de suas forças que direcionam e iluminam o meu caminho. 


\section{AGRADECIMENTOS}

- À pessoa de maior importância deste trabalho: Profa. Dra. Wang Shu Hui. Pela motivação, paciência, perseverança e grande apoio durante todo o trajeto. Desde a primeira conversa de escolha do tema, direcionamento nos resultados e nos artigos escritos... enfim, até a última palavra escrita aqui. Por dedicar seu tempo precioso para me orientar... Por sempre ter acreditado no meu potencial.

- Aos professores da banca de qualificação e dissertação: Prof. Dr. Hélio Wiebeck, Profa. Dra. Ticiane S. Valera Prof. Dr. Luiz Claudio de Santa-Maria e Prof. Dr. José Augusto Agnelli que reservaram um tempo precioso neste assunto.

- Aos amigos: Lilian Lacerda, Fábio Sakata, Fábio Conte, Douglas, Walker, Vinícius Freire, João Luís, Quental, Adair, Barbara, Marcia Pires, Luciane, Farah, Fabiane, Mauro, Cristóvão, Lucas, C.Neves, Ana Moreira, Ana Paula Azeredo, Camilo, Marcia Santos e Adriane pelo auxílio, suporte experimental, inspiração, motivação e grande amizade.

- A todos os especialistas e técnicos da escola politécnica e das empresas: Dow, Styron e Braskem.

- Aos meus amigos Luiz Henriques, David Celoto e Almir Rosário pelo profissionalismo e amizade ao longo dos vários anos de trabalho em conjunto na empresa.

- Aos líderes e amigos que direcionam e apoiam o meu crescimento profissional: Luiz Henriques, David, Ruiz, Raphael Miranda, Cristino Santos, Lana Spencer, Tina Kilebrew, Ricardo Homma, Tim Pope, Adriana Simanke, Antônio Quental e Fábio Lamon pelo trabalho de orientação e motivação.

- Aos grandes amigos Kátia, Almir e Selma por me auxiliarem em alguns passos muito importantes deste trabalho.

- Aos queridos: Cleusa, Dirce, Yassushi, Priscila Yukie, Yoshimi, Sayuri, Mayumi, Kenji, Toshi, Mikie, Simone P.F., Fábio e Priscila, Digo e Érika, Shindy, Toshiko, Nelson, Henrique, Elan, Maurício, Ronaldo, Marquinho e Vera, Katia, Almir, Manoel Anjos, Elaine, Karen, Rosenthal, Marcos, Ricardo B., Armando, Romão, Yoiti e Márcia, Moisés, Rogério, Mário, Maurício, Sandrinho, Namie e Michael, Shizumi, Sérgio e Renato, Edu e Ju, Marrie e Ago. Obrigado por sempre me acompanharem e por me trazerem tantos momentos de alegria que estão guardados comigo profundamente pela eternidade...

Por fim, à todos os meus amigos que fiz durante a vida. Sinto a energia da torcida de cada um de vocês. Uma energia forte e pulsante que abastece positivamente minha vida... Agradeço de coração a cada um de vocês... 


\section{Sumário}

AGRADECIMENTOS

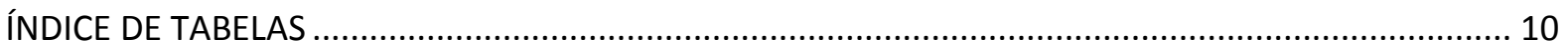

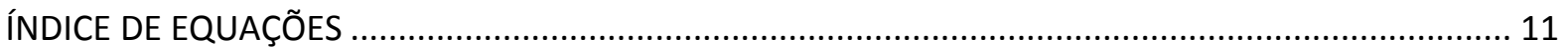

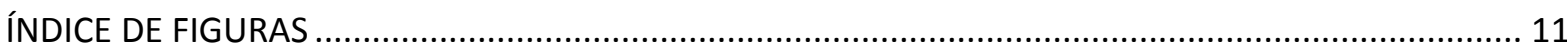

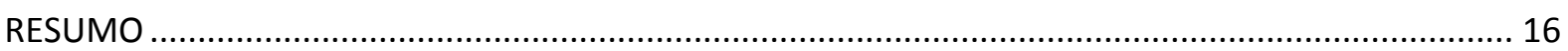

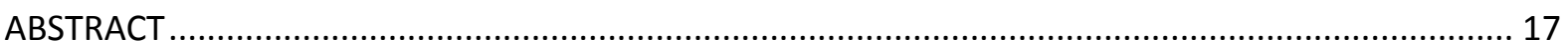

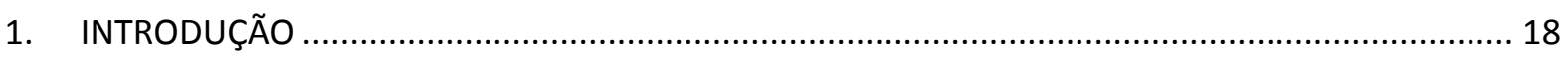

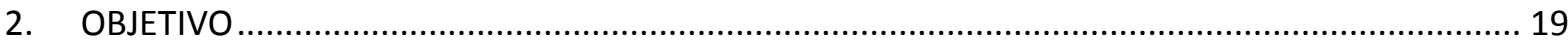

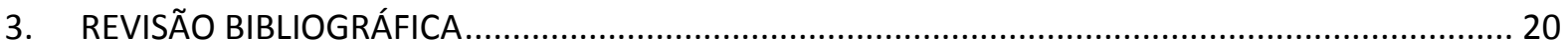

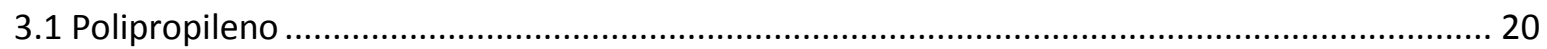

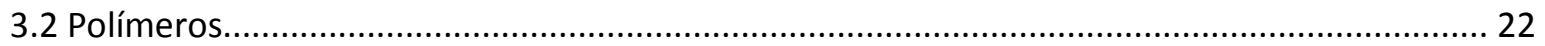

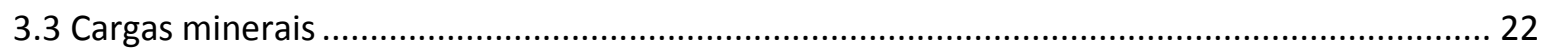

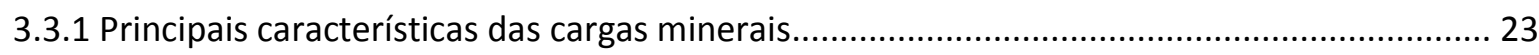

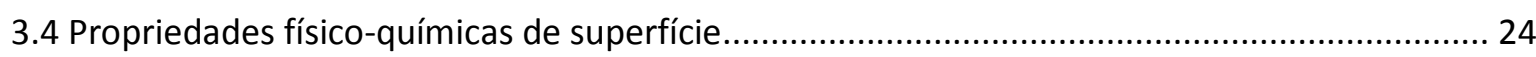

3.5 Granulometria e área de superfície específica............................................................................ 24

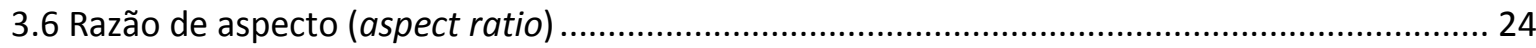

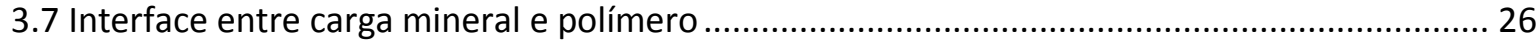

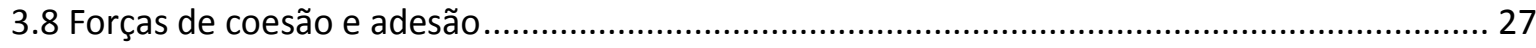

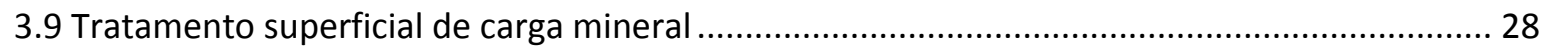

3.10 Efeitos da carga mineral nas propriedades físicas e químicas do compósito ........................... 30

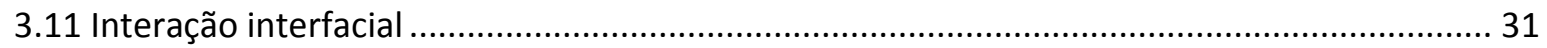

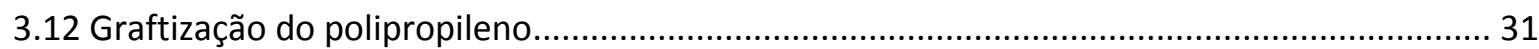

3.13 Estrutura do polipropileno e algumas considerações quanto à sua fase cristalina beta.......... 36

3.14 Utilização do $\mathrm{CaCO}_{3}$ como nucleante para cristalinidade beta do polipropileno. .................... 38

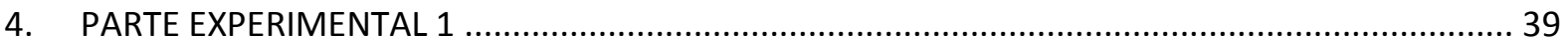

(enfoque no estudo comparativo da graftização de anidrido maléico em polipropileno utilizando

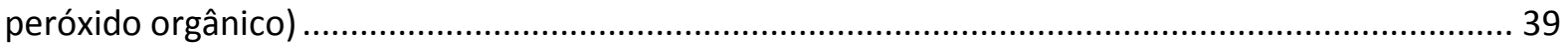

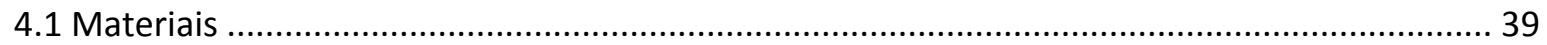


4.3 Obtenção do polipropileno graftizado com anidrido maléico (PP-g-MA) .................................. 41

4.3.1 Procedimento para graftização em balão de reação ............................................................. 41

4.3.2 Procedimento para graftização pelo método da extrusão .................................................... 42

4.3.3 Estudo comparativo dos processos de graftização do polipropileno com anidrido maléico 42

4.4 Obtenção dos filmes para curva de calibração do percentual de graftização com anidrido maléico através de análise de espectroscopia no infra vermelho

5. RESULTADOS E DISCUSSÕES 1 (enfoque no estudo comparativo da graftização de anidrido maléico em polipropileno utilizando peróxido orgânico)

5.1 Análise comparativa dos dois métodos de graftização para obtenção do

5.1.1 Análise de dados de DSC (Varredura diferencial de calorimetria) 44

5.1.2 Análise dos resultados Índice de fluidez (MFI - melt flow index) 47

5.1.3 Análise dos resultados de TGA (Análise termogravimétrica) 48

5.1.4 Análise dos resultados de microscopia eletrônica de varredura (MEV ou SEM) 51

5.1.5 Análise dos resultados de espectroscopia de energia dispersiva (EDS - Energy Dispersive Spectroscopy)

5.1.6 Análise dos resultados de espectroscopia no Infravermelho (FTIR) .................................. 53

5.2 Comparação entre os dois métodos de graftização 59

6. PARTE EXPERIMENTAL 2 (enfoque para as amostras dos compósitos produzidos com $\mathrm{CaCO}_{3}$ ) 60

6.1 Preparação das amostras de compósitos com $\mathrm{CaCO}_{3}$.

7. RESULTADOS E DISCUSSÕES 2 (enfoque para as amostras dos compósitos produzidos com $\left.\mathrm{CaCO}_{3}\right)$

7.1 Análise das propriedades mecânicas

7.1.1 Análise dos resultados de resistência à tração 64

7.1.2 Análise de dados dos resultados de módulo na flexão ....................................................... 71

7.1.3 Análise dos resultados de resistência ao impacto a $23{ }^{\circ} \mathrm{C}$ e a $-40{ }^{\circ} \mathrm{C}$..................................... 78

7.2 Análise da influência do PP-g-MA no comportamento mecânico das amostras produzidas .... 91

7.3 Análise das propriedades de resistência mecânica (resistência à tração e módulo na flexão) em comparação com os resultados de resistência ao impacto dos compósitos produzidos

7.4 Análise da fase cristalina beta dos compósitos

7.4.1 Análise da fase cristalina beta através do ensaio de DSC (Varredura diferencial de calorimetria)

7.4.2 Análises do percentual de fase cristalina beta por difração de Raios-X (WAXD). 99

7.5 Análise da influência do tamanho de partícula dos carbonatos de cálcio inseridos nas amostras e sua influência no percentual de fase cristalina beta 
7.6 Análise da aderência superficial entre o $\mathrm{PP}_{\text {e }} \mathrm{CaCO}_{3}$ e sua influência no percentual de fase cristalina beta

7.7 Análise de resultados de MEV (microscopia eletrônica de varredura) .................................... 111

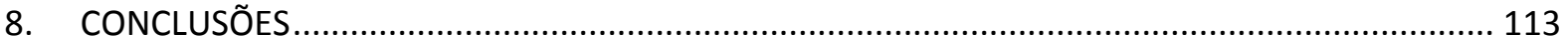

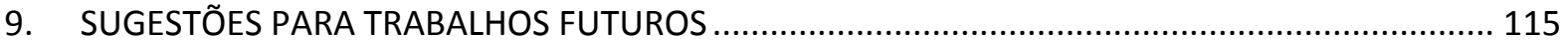

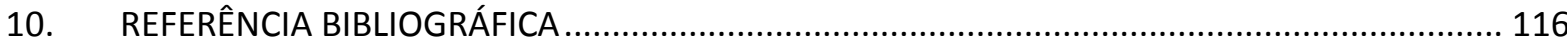




\section{ÍNDICE DE TABELAS}

Tabela 1: Propriedades gerais do polipropileno.

Tabela 2: Principais características físicas e químicas de minerais usados como carga em polímeros.

Tabela 3: Substâncias químicas e matérias primas utilizadas no trabalho experimental. 39

Tabela 4: Equipamentos utilizados no trabalho experimental. 40

Tabela 5: valores $\Delta \mathrm{Hf}$ em J/g obtidos pelos resultados de DSC e percentual de cristalinidade das amostras graftizadas

Tabela 6: Resultados das temperaturas iniciais e finais de degradação das amostras analisadas 51

Tabela 7: Resultados numéricos de infravermelho das amostras com proporção padronizadas de $0,20 \%, 0,25 \%, 0,30 \%, 0,35 \%, 0,40 \%, 0,45 \%, 0,50 \%, 0,55 \%, 0,60 \%, 0,65 \%, 0,70 \%, 0,75 \%, 0,80 \%$ e $1,0 \%$ de graftização para obtenção da curva de calibração . .58

Tabela 8: Masterbatchs para produção das amostras. 61

Tabela 9: Descrição dos compósitos de $\mathrm{CaCO}_{3}$ e seus respectivos percentuais finais

Tabela 10: Parâmetros de injeção utilizados para preparação dos corpos de prova

Tabela 11: Resultados compilados das propriedades mecânicas: $\sigma$ (resistência à tração), E (módulo na flexão), e resistência ao Impacto Izod (a $23^{\circ} \mathrm{C}$ e $-40{ }^{\circ} \mathrm{C}$ ).

Tabela 12: Resultados numéricos de resistência à tração e valores de incremento com a utilização do PP-g-MA no compósito. 69

Tabela 13: Resultados de módulo na flexão e valores de incremento com a utilização do PP-g-MA no compósito. 76

Tabela 14: Resultados de resistência ao impacto a $23{ }^{\circ} \mathrm{C}$ e valores de incremento com a utilização do PP-g-MA no compósito.

Tabela 15: Resultados de resistência ao impacto a $-40{ }^{\circ} \mathrm{C}$ e valores de incremento com a utilização do PP-g-MA no compósito.

Tabela 16: Resultados comparativos do incremento em \% nas propriedades em função da inserção de PP-g-MA nas amostras.

Tabela 17: Resultados numéricos combinados de resistência à tração, módulo na flexão e resistência ao impacto Izod a $23{ }^{\circ} \mathrm{Ce}-40{ }^{\circ} \mathrm{C}$ das amostras MAT, MA8, MAC e MA2. 95

Tabela 18: Resultados do valor de fase cristalina beta gerada (K) e os respectivos valores para iniciais utilizados para seu cálculo.

Tabela 19: Correlação de todas as propriedades e o percentual de fase cristalina formada nas amostras produzidas com PP $+\mathrm{CaCO}_{3}+\mathrm{PP}-\mathrm{g}-\mathrm{MA}$. 
Tabela 20: Resultados numéricos da formação da fase cristalina beta de acordo com a correlação do tamanho de partícula do $\mathrm{CaCO}_{3}$, com e sem a utilização de 5\% de PP-g-MA (0,05\% de anidrido maléico graftizado) 106

\section{ÍNDICE DE EQUAÇÕES}

Equação 1: grau de incorporação em massa de MA ao PP utilizando-se dados de Infra vermelho.... 43

Equação 2: Percentual de cristalinidade por entalpia de fusão. 46

Equação 3: Cálculo para obtenção do grau de incorporação em massa do anidrido maléico ao PP. . 57 Equação 4: Equação empírica da quantificação da fase cristalina beta por dados de difração de Raios$\mathrm{X}$

\section{ÍNDICE DE FIGURAS}

Figura 1 - Ilustração de experiências (forças de coesão e adesão). Fonte: Navarro (1997).

Figura 2: Fórmula geral dos organossilanos

Figura 3: Reação de liberação de $\mathrm{H}_{2} \mathrm{O}$ dos silanos.

Figura 4: Esquema de reação do silano com a argila (Plueddemann, 1974). 30

Figura 5: Substâncias mais utilizadas em reações de graftização. 32

Figura 6: Anidrido maléico.

Figura 7: Peróxido de benzoíla.

Figura 8: Esquema do mecanismo de decomposição de peróxido de benzoíla.

Figura 9: Esquema de mecanismo de reações químicas de graftização de MA em PP [1]. 35

Figura 10: Curva DSC e demais informações obtidos do PP puro. 45

Figura 11: Curva DSC e demais informações obtidos da amostra de PP graftizado com anidrido maléico a partir de peróxido de benzoíla feito pelo método da extrusora. 
Figura 12: Curva DSC e demais informações obtidos da amostra de PP graftizado com anidrido maléico a partir de peróxido de benzoíla feito pelo método de balão

Figura 13: Resultados (em gramas por 10 minutos) de índice de fluidez (MFI - melt flow index) ISO $1133\left(230^{\circ} \mathrm{C} / 2,16 \mathrm{~kg}\right)$

Figura 14: Curva termogravimétrica indicando a temperatura de degradação do PP Puro.

Figura 15: Curva termogravimétrica indicando a temperatura de degradação da amostra extrusada

Figura 16: Curva termogravimétrica indicando a temperatura de degradação da amostra produzida pelo método do balão volumétrico. 50

Figura 17: Micrografias de MEV do PP virgem e das amostras de PP graftizados com anidrido maléico.

Figura 18: Resultados de EDS do PP puro e das amostras graftizadas com anidrido maléico. 53

Figura 19: Resultados de espectroscopia no infravermelho das amostras com proporções definidas de $0,20 \%, 0,25 \%, 0,30 \%, 0,35 \%, 0,40 \%, 0,45 \%, 0,50 \%, 0,55 \%, 0,60 \%, 0,65 \%, 0,70 \%, 0,75 \%, 0,80 \%$ e $1,0 \%$ de graftização para obtenção da curva de calibração.

Figura 20: Resultados de espectroscopia no infravermelho (próximo ao pico $1156 \mathrm{~cm}^{-1}$ ) das amostras com proporções definidas de $0,20 \%, 0,25 \%, 0,30 \%, 0,35 \%, 0,40 \%, 0,45 \%, 0,50 \%, 0,55 \%$, $0,60 \%, 0,65 \%, 0,70 \%, 0,75 \%, 0,80 \%$ e 1,0\% de graftização para obtenção da curva de calibração.... 55

Figura 21: Resultados de espectroscopia no infravermelho (próximo ao pico $1785 \mathrm{~cm}^{-1}$ ) das amostras com proporções definidas de $0,20 \%, 0,25 \%, 0,30 \%, 0,35 \%, 0,40 \%, 0,45 \%, 0,50 \%, 0,55 \%$, $0,60 \%, 0,65 \%, 0,70 \%, 0,75 \%, 0,80 \%$ e 1,0\% de graftização para obtenção da curva de calibração.... 56

Figura 22: Gráfico da curva de calibração para: I(g\%) x percentual de graftização.

Figura 23: Gráfico dos resultados de resistência à tração das amostras dos compósitos de PP + $\mathrm{CaCO}_{3}$ 64

Figura 24: Gráfico dos resultados de resistência à tração comparativa das amostras produzidas com $\mathrm{PP}+\mathrm{CaCO}_{3}(\mathrm{PP}=\mathrm{PP}$ Puro, $\mathrm{PPT}=\mathrm{PP}+5 \%$ Mickhart $8 \mathrm{~T}, \mathrm{PP} 8=\mathrm{PP}+5 \%$ Mickhart 08, PP2 $=\mathrm{PP}+5 \%$ Mickhart 2, $P P C=P P+5 \%$ Mickhart $C)$.

Figura 25: Gráfico dos resultados de resistência à tração das amostras de PP $+5 \% \mathrm{CaCO}_{3}+5 \% \mathrm{PP}-\mathrm{g}$ MA.

Figura 26: Gráfico dos resultados de resistência à tração (tensão de escoamento) comparativa das amostras produzidas com PP $+\mathrm{CaCO}_{3}$ Mickhart 08T.

Figura 27: Gráfico dos resultados de resistência à tração (tensão de escoamento) comparativa das amostras produzidas com PP $+\mathrm{CaCO}_{3}$ Mickhart 08. 
Figura 28: Gráfico dos resultados de resistência à tração (tensão de escoamento) comparativa das amostras produzidas com $\mathrm{PP}+\mathrm{CaCO}_{3}$ Mickhart $\mathrm{C}$.

Figura 29: Gráfico dos resultados de resistência à tração (tensão de escoamento) comparativa das amostras produzidas com PP $+\mathrm{CaCO}_{3}$ Mickhart 2 .

Figura 30: Resultados gráficos de resistência à tração e valores de incremento com a utilização do PP-g-MA no compósito.

Figura 31: Resultados de Módulo na flexão comparativa das amostras produzidas 71

Figura 32: Gráfico dos resultados de Módulo na flexão comparativa das amostras produzidas com PP

$+\mathrm{CaCO}_{3}$ 72

Figura 33: Gráfico dos resultados de Módulo na flexão comparativa das amostras produzidas com PP

$+\mathrm{CaCO}_{3}$ 73

Figura 34: Gráfico dos resultados de módulo na flexão comparativa das amostras produzidas com PP

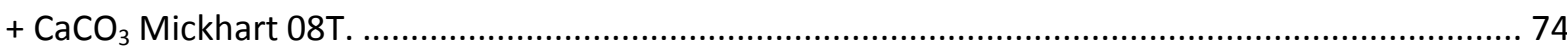

Figura 35: Gráfico dos resultados de módulo na flexão comparativa das amostras produzidas com PP

$+\mathrm{CaCO}_{3}$ Mickhart 08. 74

Figura 36: Gráfico dos resultados de módulo na flexão comparativa das amostras produzidas com PP

$+\mathrm{CaCO}_{3}$ Mickhart $\mathrm{C}$. 75

Figura 37: Gráfico dos resultados de módulo na flexão comparativa das amostras produzidas com PP

$+\mathrm{CaCO}_{3}$ Mickhart 2 . 75

Figura 38: Gráfico dos resultados de módulo na flexão e visualização do incremento com a utilização do PP-g-MA nos compósitos.

Figura 39: Gráfico dos resultados de resistência ao impacto a $23^{\circ} \mathrm{C}$ de todas as amostras dos compósitos de $\mathrm{PP}+\mathrm{CaCO}_{3}$.

Figura 40: Gráfico dos resultados de resistência ao impacto a $23^{\circ} \mathrm{C}$ comparativa das amostras produzidas com $\mathrm{PP}+\mathrm{CaCO}_{3}$

Figura 41: Gráfico dos resultados de resistência ao impacto a $23^{\circ} \mathrm{C}$ das amostras de $\mathrm{PP}+5 \% \mathrm{CaCO}_{3}+$ 5\% PP-g-MA.

Figura 42: Gráfico dos resultados de resistência ao impacto Izod a $23^{\circ} \mathrm{C}$ comparativo das amostras produzidas com $\mathrm{PP}+\mathrm{CaCO}_{3}$ Mickhart $08 \mathrm{~T}$.

Figura 43: Gráfico dos resultados de resistência ao impacto Izod a $23^{\circ} \mathrm{C}$ comparativo das amostras produzidas com $\mathrm{PP}+\mathrm{CaCO}_{3}$ Mickhart 08 .

Figura 44: Gráfico dos resultados de resistência ao impacto Izod a $23^{\circ} \mathrm{C}$ comparativo das amostras produzidas com $\mathrm{PP}+\mathrm{CaCO}_{3}$ Mickhart $\mathrm{C}$. 
Figura 45: Gráfico dos resultados de resistência ao impacto Izod a $23^{\circ} \mathrm{C}$ comparativo das amostras produzidas com $\mathrm{PP}+\mathrm{CaCO}_{3}$ Mickhart 2 .

Figura 46: Gráfico dos resultados visuais de resistência ao impacto a $23^{\circ} \mathrm{C}$ e valores de incremento com a utilização do PP-g-MA no compósito.

Figura 47: Gráfico dos resultados de resistência ao impacto a $-40{ }^{\circ} \mathrm{C}$ de todas as amostras dos compósitos de $\mathrm{PP}+\mathrm{CaCO}_{3}$.

Figura 48: Gráfico dos resultados de resistência ao impacto a $-40{ }^{\circ} \mathrm{C}$ comparativa das amostras produzidas com $\mathrm{PP}+\mathrm{CaCO}_{3}$.

Figura 49: Gráfico dos resultados de resistência ao impacto a $-40{ }^{\circ} \mathrm{C}$ das amostras de $\mathrm{PP}+5 \% \mathrm{CaCO}_{3}$

$+5 \%$ PP-g-MA. 86

Figura 50: Gráfico dos resultados de resistência ao impacto Izod a $-40{ }^{\circ} \mathrm{C}$ comparativo das amostras produzidas com $\mathrm{PP}+\mathrm{CaCO}_{3}$ Mickhart 08T

Figura 51: Gráfico dos resultados de resistência ao impacto Izod a $-40{ }^{\circ} \mathrm{C}$ comparativo das amostras produzidas com PP $+\mathrm{CaCO}_{3}$ Mickhart 08 . 88

Figura 52: Gráfico dos resultados de resistência ao impacto Izod a $-40{ }^{\circ} \mathrm{C}$ comparativo das amostras produzidas com $\mathrm{PP}+\mathrm{CaCO}_{3}$ Mickhart $\mathrm{C}$. 88

Figura 53: Gráfico dos resultados de resistência ao impacto Izod a $-40{ }^{\circ} \mathrm{C}$ comparativo das amostras produzidas com $\mathrm{PP}+\mathrm{CaCO}_{3}$ Mickhart 2 .

Figura 54: Gráfico dos resultados de resistência ao impacto a $-40{ }^{\circ} \mathrm{C}$ e valores de incremento com a utilização do PP-g-MA no compósito.

Figura 55: Gráfico dos resultados comparativos do incremento em \% nas propriedades em função da inserção de PP-g-MA nas amostras.

Figura 56: Resultados gráficos combinados de resistência à tração e módulo na flexão das amostras MAT, MA8, MAC E MA2.

Figura 57: Resultados de resistência ao impacto Izod a $23^{\circ} \mathrm{C} \mathrm{e}-40{ }^{\circ} \mathrm{C}$ das amostras MAT, MA8, MAC e MA2. 94

Figura 58: Resultados combinados de resistência à tração, módulo na flexão e resistência ao impacto Izod a $23{ }^{\circ} \mathrm{C}$ e $-40{ }^{\circ} \mathrm{C}$ das amostras MAT, MA8, MAC e MA2.

Figura 59: Gráfico radar dos resultados combinados de resistência à tração, módulo na flexão e resistência ao impacto Izod a $23{ }^{\circ} \mathrm{Ce}-40{ }^{\circ} \mathrm{C}$ das amostras MAT, MA8, MAC e MA2.

Figura 60: Resultado das curvas de aquecimento por DSC para as amostras de: PP (referência), MA2, MAC, MA8 e MAT. 98

Figura 62: Difratogramas de raios-x para todas as amostras de $\mathrm{CaCO}_{3}$ produzidas. 99 
Figura 63: Difratogramas de raios-x extratificados com pontos adaptados e convertidos apenas das amostras MAT, MA8, MAC e MA2 para melhor visualização.

Figura 64: Gráfico dos resultados percentuais de fase cristalina beta gerado nas amostras estudadas.

Figura 65: Gráfico dos resultados percentuais de fase cristalina beta gerada nas amostras produzidas com PP-g-MA. 102

Figura 66: Gráfico dos resultados percentuais de fase cristalina beta gerada nas amostras produzidas sem PP-g-MA. 102

Figura 67: Gráfico da correlação de todas as propriedades e o percentual de fase cristalina formada nas amostras produzidas com PP $+\mathrm{CaCO}_{3}+\mathrm{PP}-\mathrm{g}-\mathrm{MA}$

Figura 68: Gráfico da correlação tridimensional de todas as propriedades e o percentual de fase cristalina formada nas amostras produzidas com PP $+\mathrm{CaCO}_{3}+\mathrm{PP}-\mathrm{g}-\mathrm{MA}$.

Figura 69: Gráfico radar da correlação de todas as propriedades e o percentual de fase cristalina formada nas amostras produzidas com PP $+\mathrm{CaCO}_{3}+\mathrm{PP}-\mathrm{g}-\mathrm{MA}$. 105

Figura 70: Microscopias das amostras de PP $+\mathrm{CaCO}_{3}+\mathrm{PP}-\mathrm{g}-\mathrm{MA}$. 


\section{RESUMO}

Este trabalho estuda a influência do carbonato de cálcio $\left(\mathrm{CaCO}_{3}\right)$ nas propriedades mecânicas e na formação da fase cristalina beta do polipropileno (PP). Com o intuito de produzir amostras para o estudo, foi feita uma análise preliminar sobre o enxerto do anidrido maléico no polipropileno, porque este material graftizado (PP-g-MA) contribui significativamente em blendas e compósitos ao melhorar a adesão superficial entre o PP e $\circ \mathrm{CaCO}_{3}$. Foram estudados dois métodos de obtenção deste produto (PP-g-MA) utilizando-se peróxido orgânico e os produtos obtidos foram caracterizados e comparados. Apesar dos resultados das análises feitas por calorimetria diferencial exploratória (DSC), análise termogravimétrica (TGA), microscopia eletrônica de varredura (MEV) e espectroscopia de energia dispersiva (EDS) indicarem importantes diferenças entre os dois métodos, a análise por espectroscopia no infravermelho (FTIR) trouxe conclusões sobre a eficácia dos métodos de graftização. Duas séries de compósitos a base de PP contendo $\mathrm{CaCO}_{3}$ foram produzidos por mistura intensiva em fusão (misturador Drais), uma contendo PP-g-MA e a outra sem. Quatro tipos de $\mathrm{CaCO}_{3}$ foram utilizados, diâmetros de $0,9 \mu \mathrm{m}, 2,5 \mu \mathrm{m}$ e $3 \mu \mathrm{m}$, sendo que o $\mathrm{CaCO}_{3} 0,9 \mu \mathrm{m}$ apresentou-se com superfície tratada e não-tratada. A concentração de $\mathrm{CaCO}_{3}$ foi mantida em $5 \% \mathrm{e}$ a de PP-g-MA em $5 \%$ quando presente. Os compósitos foram submetidos a testes de resistência à tração, módulo na flexão e resistência ao impacto em duas temperaturas. As amostras contendo menores tamanhos de partículas de $\mathrm{CaCO}_{3}$ e PP-g-MA apresentaram melhora sinérgica na resistência mecânica, em que aumentos da resistência a impacto e da resistência a flexão foram observados. A análise da fase cristalina beta nestas amostras foi feita utilizando-se DSC e difratometria de raios-x. Também foi analisada a influência da adesão superficial entre a carga e a matriz de PP, quanto maior a adesão superficial e menor o tamanho de partícula do $\mathrm{CaCO}_{3}$, maior a formação da fase cristalina beta, o que contribuiu para a sinergia entre todas as propriedades mecânicas avaliadas neste trabalho. 


\begin{abstract}
This study aimed at improving the comprehension of the influence of calcium carbonate $\left(\mathrm{CaCO}_{3}\right)$ in the formation of the beta crystalline phase of polypropylene (PP), as well as the changes in the mechanical properties of this polymer. A preliminary analysis of the grafting of the maleic anhydride in the polypropylene was carried out in order to produce specimens for the study, owing to the fact that this grafted polypropylene (PP-g-MA) contributes substantially to change the polarity of the polymer and therefore, enhance the superficial adhesion between PP and $\mathrm{CaCO}_{3}$. Two grafting methods using organic peroxide were studied. The grafted copolymers were analyzed by DSC, TGA, SEM, EDS, and FTIR. Two series of PP composites containing $\mathrm{CaCO}_{3}$ were produced by intensive melt mixing (Drais mixer), one of them having MA-g-PP. Four types of $\mathrm{CaCO}_{3}$ were used, which diameters were $0.9 \mu \mathrm{m}$, $2.5 \mu \mathrm{m}$ and $3 \mu \mathrm{m}$, though the $\mathrm{CaCO}_{3} 0.9 \mu \mathrm{m}$ was surface-treated and non-treated. The concentration of $\mathrm{CaCO}_{3}$ was maintained at $5 \%$ and PP-g-MA at $5 \%$ also, when present. The composites were tested for tensile strength, flexural modulus and impact strength (at two temperatures). Samples containing smaller particle sized $\mathrm{CaCO}_{3}$ and PP-g-MA showed synergistic improvement in the mechanical strength, and increases in the impact resistance and flexural strength were observed. Analysis of the beta crystal phase in these samples was performed using DSC and x-ray diffractometry. The influence of superficial adhesion between $\mathrm{CaCO}_{3}$ and PP was also analyzed, higher concentration of the beta crystalline phase was observed for better surface adhesion and smaller $\mathrm{CaCO}_{3}$ particle size, which contributed to the synergy between all the mechanical properties evaluated in this work.
\end{abstract}




\section{INTRODUÇÃO}

O polipropileno é um termoplástico semicristalino que tem se destacado em muitos segmentos de aplicações devido à sua versatilidade de processamento e ótimo balanço de propriedades mecânicas, aliado ao baixo custo envolvido comparado com outros polímeros de aplicação tecnológica. Sendo assim, incrementar a sua aplicabilidade no contexto brasileiro pode trazer vantagens econômicas devido à necessidade de novos polímeros com características de resistência melhores que, entretanto, apresentam sérias restrições no mercado nacional devido ao seu alto custo, tornando-os muitas vezes inviáveis. Vários estudos já foram feitos no intuito de melhorar as propriedades do polipropileno, utilizando-o como matriz de compósitos contendo cargas inorgânicas, melhorando assim, consideravelmente as suas aplicações.

Quanto aos minerais, eles foram inseridos nos polímeros, inicialmente, com o intuito de abaixar o custo destes materiais, devido principalmente à crise do petróleo. A partir deste momento, a utilização dos minerais nos polímeros vem aumentando substancialmente. Nestes últimos anos, temos acompanhado uma evolução desta união, o qual o mineral tem se tornado o principal meio de melhorar as propriedades mecânicas dos polímeros. Esta evolução se deve também ao melhoramento dos processos de mistura, bem como na melhora da tecnologia de produção de matérias primas cerâmicas com menores tamanhos de partículas. Isto tudo é amparado também pela descoberta de novos aditivos que podem alterar a morfologia da matriz polimérica e influir na interface matriz- minerais incorporados.

Este trabalho torna-se importante e relevante, pois atualmente existe a consciência de que é possível ainda incrementar as propriedades do polipropileno e com isso ampliar as suas aplicações tecnológicas. A descoberta de diferentes fases cristalinas do PP impulsionou um enorme direcionamento para estudos e novas aplicações para este polímero.

Uma das descobertas marcantes está relacionada à fase cristalina beta. Diferentemente da fase cristalina alfa mais comum, a fase beta eleva as propriedades de tenacidade (por exemplo, impacto) sem que haja perdas consideráveis da resistência mecânica (por exemplo: resistência à tração, módulo e dureza). A utilização de um mineral como nucleante desta fase é uma estratégia sensata, pois se considera que a pequena perda de resistência mecânica gerada pelo incremento do 
aumento da fase cristalina beta seria compensada pelo aumento da rigidez proporcionada pela inserção da carga mineral.

Vários estudos [52, 58-63] indicam a utilização do $\mathrm{CaCO}_{3}$ como carga mineral no compósito de matriz de PP devido ao aumento sinérgico das propriedades da resina. Devido a este indício, foi estudado neste trabalho diferentes compósitos produzidos a partir da inserção de diferentes $\mathrm{CaCO}_{3}$ correlacionando-os com a fase cristalina beta e com as propriedades mecânicas geradas.

\section{OBJETIVO}

O objetivo deste trabalho foi o estudo da influência do carbonato de cálcio nas propriedades físicas, bem como na formação da fase cristalina beta do polipropileno. Para que isso fosse viabilizado de forma consistente, o trabalho foi dividido em duas etapas distintas coligadas a objetivos específicos que seguem descritas abaixo:

1. Obtenção e estudo da graftização do polipropileno com anidrido maleico (PP-g-MA). O objetivo desta primeira etapa é estudar dois métodos visando conhecer as facilidades, dificuldades e eficácia comparativa, tendo como finalidade principal produzir amostras de PP-g-MA para a utilização nos compostos com $\mathrm{CaCO}_{3}$.

2. Produção de compósitos de PP com a inserção de diferentes $\mathrm{CaCO}_{3}$ objetivando a análise das propriedades mecânicas e a influência da incorporação do PP-g-MA.

Esta segunda etapa ainda contempla a análise comparativa das amostras produzidas visando estabelecer a influência do tamanho de partícula dos $\mathrm{CaCO}_{3}$ introduzidos e b) a adesão interficial entre esta carga $\left(\mathrm{CaCO}_{3}\right)$ e a matriz de PP. A análise da influência destes dois fatores nos compósitos foi feita pela medição das suas propriedades mecânicas e pela determinação qualitativa e quantitativa da fase cristalina beta. 


\section{REVISÃO BIBLIOGRÁFICA}

\subsection{Polipropileno}

O Polipropileno ou polipropeno é um polímero termoplástico com características fisicoquímicas balanceadas aliado a boa processabilidade e baixo custo comparado com outros polímeros.

A sua forma molecular é $\left(\mathrm{C}_{3} \mathrm{H}_{6}\right) \mathrm{x}$.

Suas principais propriedades são:

> elevada resistência química e a solventes;

$>$ fácil moldagem;

> fácil coloração;

> alta resistência à fratura por flexão ou fadiga comparado com os polímeros convencionais;

$>$ boa resistência ao impacto acima de $15^{\circ} \mathrm{C}$;

$>$ boa estabilidade térmica.

Suas aplicações são vastas e incluem:

> autopeças (pára-choques, pedais, carcaças de baterias, lanternas, ventoinhas, ventiladores, peças diversas do interior do veículo);

$>$ peças para máquinas de lavar.

> carcaças para eletrodomésticos;

$>$ brinquedos;

> copos plásticos;

$>$ recipientes para alimentos,

$>$ embalagens de remédios,

$>$ embalagem de produtos químicos;

$>$ sacarias (ráfia);

> filmes orientados;

$>$ tubos para cargas de canetas esferográficas; 
$>$ carpetes;

$>$ seringas de injeção;

$>$ material hospitalar esterilizável.

Tabela 1: Propriedades gerais do polipropileno.

\begin{tabular}{|l|l|}
\hline \multicolumn{2}{|c|}{ Polipropileno } \\
\hline Nome IUPAC & poli(1-metiletileno) \\
\hline Outros nomes & $\begin{array}{l}\text { Polipropileno; Polipropeno; } \\
\text { Polipropene 25 [USAN];Polímero do propeno; } \\
\text { Polímero do propileno; Homopolímero do propeno }\end{array}$ \\
\hline Número CAS & $9003-07-0$ \\
\hline $\begin{array}{l}\text { Fórmula } \\
\text { molecular }\end{array}$ & \begin{tabular}{l}
$\left(\mathrm{C}_{3} \mathrm{H}_{6}\right)_{\mathrm{x}}$ \\
\hline Densidade
\end{tabular} \\
\hline $\begin{array}{l}\text { Ponto de } \\
\text { fusão }\end{array}$ & $0,85 \mathrm{~g} / \mathrm{cm}^{3}$, amorfo \\
\hline
\end{tabular}

Devido às suas boas propriedades mecânicas aliadas ao seu baixo preço [3] e ótima combinação de propriedades mecânicas [4], o PP apresenta-se como um dos termoplásticos mais importantes do mercado atual. A expansão de suas aplicações como polímero de engenharia em componentes de blendas ou compósitos exigem sua funcionalização, para melhorar sua baixa compatibilidade com outros materiais, devido à natureza apolar de sua estrutura [5]. A característica apolar do PP define propriedades como baixa higroscopicidade, dificuldade de impressão e pintura e baixa dispersão das cargas inorgânicas [1]. A modificação de PP com grupamentos polares, além de melhorar a compatibilidade em misturas com outros polímeros, aumenta a adesão entre o polímero e superfícies metálicas ou camadas decorativas [2].

A mistura de PP com $\mathrm{CaCO}_{3}$ é utilizada como método eficiente para melhorar algumas propriedades do PP com o intuito de aumentar as aplicações de engenharia. 
Apesar de o estudo estar direcionado especificamente para os compostos de polipropileno, a seguir, estão inseridos alguns aspectos muito importantes sobre polímeros de um modo geral, bem como, as influências das cargas minerais e sua interação com os polímeros (interface).

\subsection{Polímeros}

Polímeros são materiais compostos por macromoléculas cujas cadeias são formadas pela repetição de uma unidade básica chamada mero.

A palavra polímero é de origem grega, sendo poli (muitos) e mero (unidade de repetição).

Propriedades dos polímeros

As principais propriedades dos polímeros dividem-se em físicas, químicas e físico-químicas. Todas estas propriedades dependem de vários fatores, por exemplo: forças de interação intermolecular, tipo das ligações primárias da cadeia principal, tipo da unidade básica principal (mero), a distribuição de peso molecular do polímero, entre outros.

As propriedades físicas são aquelas que não envolvem modificações estruturais dos polímeros, em nível molecular. São as propriedades mecânicas, térmicas, elétricas, ópticas, densidade e estabilidade dimensional. Dentre as propriedades químicas mais importantes dos materiais poliméricos, diretamente relacionadas às suas aplicações, estão resistência à oxidação, à degradação térmica, às radiações ultravioleta, à água, aos ácidos e às bases e aos solventes e a reagentes de maneira geral, além da inflamabilidade.

\subsection{Cargas minerais}

Segue aqui algumas informações genéricas sobre este assunto.

Carga mineral corresponde a minerais, ou rochas, que são encontrados na natureza, tais como o calcário (calcita, dolomita), o filito, a mica (muscovita, flogopita, biotita), sílica (quartzo, zeólita), talco, pirofilita (agalmatolito), gesso, barita, wolastonita, esmectita (bentonita, montmorilonita, hectorita, saponita) e ilita [44]. 
Neste trabalho, carga mineral é o termo empregado para definir o uso de determinados pós minerais em misturas com polímeros. Chamamos de compósito esta mistura de polímero com carga mineral, desde que haja uma interação adequada ou satisfatória que permita a transferência de esforços entre o polímero (matriz, fase contínua) e a carga mineral (reforço, fase dispersa).

Em compósitos com polímeros, as cargas minerais são usadas devido a várias razões: redução de custo, melhorar o processamento, controle de densidade, efeitos óticos, controle da expansão térmica, retardamento de chama, modificações no que se refere às propriedades de condutividade térmica, resistência elétrica e susceptibilidade magnética, além de melhora de propriedades mecânicas, tais como a dureza e a resistência ao rasgamento. Por exemplo, a metacaulinita é usada como carga de plásticos de revestimento de cabos elétricos para fornecer refratariedade elétrica; outros, como a muscovita, são usados em compósitos como retardadores de chama $[45,46]$.

\subsubsection{Principais características das cargas minerais}

As principais características consideradas no desempenho de uma carga mineral para produção de um compósito são: propriedades mineralógicas (composição química, estrutura cristalina, propriedades ópticas, clivagem e dureza, densidade, brilho, cor e propriedades físicoquímicas de superfície), granulometria, área de superfície específica e razão de aspecto (aspect ratio). 


\subsection{Propriedades físico-químicas de superfície}

As propriedades de uma interface entre duas fases colocadas em contato serão afetadas pelas características físicas e químicas de cada uma das fases envolvidas. As propriedades físicoquímicas de superfície, neste caso, dizem respeito à composição química, à estrutura cristalina/molecular, às ligações químicas e à tensão superficial de cada fase (carga mineral e polímero), os quais afetam o tipo de interação (ligação química covalente, iônica, por pontes de hidrogênio, por forças de van der Walls, etc) que podem se estabelecer entre as diferentes fases.

\subsection{Granulometria e área de superfície específica}

A granulometria é um importante parâmetro que também deve ser sempre considerada. As cargas minerais utilizadas em compósitos com polímeros apresentam granulometria sempre com dimensões inferiores a $45 \mu \mathrm{m}$, sendo que, à medida que a granulometria se torna mais fina, a área de superfície específica da carga mineral aumenta exponencialmente.

A área de superfície específica diz respeito à área exposta das partículas que, uma vez devidamente dispersas, interage com o polímero. Quanto menor o tamanho das partículas maior é a área de superfície específica e de interação entre a carga mineral e o polímero e, com o aumento da ação das forças de van der Walls, maior a dificuldade de dispersão e adesão da carga mineral dentro da massa do polímero.

\subsection{Razão de aspecto (aspect ratio)}

A relação de aspecto é um dos parâmetros mais comumente empregado e relevante na seleção de cargas minerais. Ela refere-se à razão entre o maior e menor diâmetro de uma partícula.

Minerais que apresentam elevados valores de relação de aspecto são os que possuem maiores áreas superficiais por unidade de volume; o que, em termos de dispersão, significará maior área de contato com o polímero ao qual serão misturados. 
Principais minerais utilizados como carga em polímero são: talco, pirofilita, calcita, dolomita, caulinita, esmectita, muscovita, quartzo, wolastonita e barita correspondem aos principais minerais utilizados como cargas em polímeros no Brasil [47, 48, 64 ].

Estes minerais são utilizados porque são facilmente encontrados em abundância na natureza. São minerais que apresentam baixos custos de extração e estão disponíveis no mercado a preços relativamente baixos.

As composições químicas, sistemas cristalinos, grupos espaciais e principais propriedades físicas destes minerais são apresentados na Tabela 2. 
Tabela 2: Principais características físicas e químicas de minerais usados como carga em polímeros.

\begin{tabular}{|c|c|c|c|c|c|c|c|c|c|c|}
\hline & Talco & Pirofilita & Caulinita & Esmectita & Muscovita & Calcita & Dolomita & Quartzo & Holertunit. & Barita \\
\hline $\begin{array}{l}\text { Fórmula } \\
\text { química }\end{array}$ & $\begin{array}{c}\mathrm{Mg}_{6}\left(\mathrm{Si}_{8} \mathrm{D}_{20}\right] \\
(\mathrm{OH})_{4}\end{array}$ & $\begin{array}{l}\left(\mathrm{Si}_{4} \mathrm{O}_{10}\right] \\
\mathrm{Al}_{2}(\mathrm{OH})_{2}\end{array}$ & $\begin{array}{c}\mathrm{Al}_{2} \mathrm{Si}_{2} \mathrm{O}_{5} \\
\left(\mathrm{O} \mathrm{H}_{4}\right.\end{array}$ & $\begin{array}{c}(\mathrm{Mg}, \mathrm{Ca}) \mathrm{O} \\
\mathrm{Al}_{2} \mathrm{O}_{3} \mathrm{Si}_{5} \mathrm{O}_{10} \\
\mathrm{nH}_{2} \mathrm{O}\end{array}$ & $\begin{array}{c}\mathrm{KAl}_{2} \mathrm{Si}_{3} \mathrm{AlO}_{10} \\
(\mathrm{O}, \mathrm{H}, \mathrm{F})_{2}\end{array}$ & $\mathrm{CaCO}_{3}$ & $\mathrm{CaMg}\left(\mathrm{CO}_{3}\right)_{2}$ & $\mathrm{SiO}_{2}$ & $\mathrm{CaSiO}_{3}$ & $\mathrm{BaSO}_{4}$ \\
\hline Composição & $\begin{array}{c}31,88 \% \mathrm{MgO} \\
63,37 \% \mathrm{SiO}_{2} \\
4,75 \% \mathrm{H}_{2} \mathrm{O}\end{array}$ & $\begin{array}{c}28,3 \% \mathrm{Al}_{2} \mathrm{O}_{3} \\
66,7 \% \mathrm{Si}_{2} \\
5,0 \% \mathrm{H}_{2} \mathrm{O}\end{array}$ & $\begin{array}{c}39,5 \% \mathrm{Al}_{2} \mathrm{D}_{3} \\
46,5 \% \mathrm{SiO}_{2} \\
14 \% \mathrm{H}_{2} \mathrm{O}\end{array}$ & $\begin{array}{c}0,60 \% \mathrm{~K}_{2} \mathrm{O} \\
2,37 \% \mathrm{Na}_{2} \mathrm{O} \\
2,15 \% \mathrm{CaO} \\
39,01 \% \mathrm{Al}_{2} \mathrm{O}_{3} \\
45,97 \% \mathrm{SiO}_{2} \\
9,19 \% \mathrm{H}_{2} \mathrm{O}\end{array}$ & $\begin{array}{c}11,82 \% \mathrm{~K}_{2} \mathrm{O} \\
38,38 \% \mathrm{Al}_{2} \mathrm{O}_{3} \\
45,23 \% \mathrm{SiO}_{2} \\
4,29 \% \mathrm{H}_{2} \mathrm{O}\end{array}$ & $\begin{array}{l}53,0 \% \mathrm{CaO} \\
44,0 \% \mathrm{CO}_{2}\end{array}$ & $\begin{array}{c}30,4 \% \mathrm{Ca}, \\
21,7 \% \mathrm{MgO}, \\
47,7 \% \mathrm{CO}_{2}\end{array}$ & $\begin{array}{l}46,74 \% \mathrm{Si} \\
53,26 \% \mathrm{\square}\end{array}$ & $\begin{array}{c}48,28 \% \mathrm{CaO} \\
51,71 \% \mathrm{SiO}_{2}\end{array}$ & $\begin{array}{l}34,4 \% \mathrm{SO}_{3} \\
65,7 \% \mathrm{BaO}\end{array}$ \\
\hline $\begin{array}{l}\text { Sistema } \\
\text { cristalino }\end{array}$ & $\begin{array}{c}\text { pseudo- } \\
\text { hexagonal }\end{array}$ & Monoclínico & $\begin{array}{c}\text { pseudo- } \\
\text { hexagonal }\end{array}$ & monoclínico & $\begin{array}{c}\text { pseudo- } \\
\text { hexagonal }\end{array}$ & trigonal & trigonal & trigonal & triclínico & ortorrômbico \\
\hline $\begin{array}{l}\text { Propriedades } \\
\text { ópticas }\end{array}$ & biaxial - & biaxial - & biaxial - & biaxial - & biaxial - & uniaxial - & uniasial - & uniaxial + & biarial - & biasial + \\
\hline Hábito & Micáceo & Prismático & micáceo & $\begin{array}{c}\text { massas micro } \\
e \\
\text { criptocristalina } \\
s\end{array}$ & micáceo & $\begin{array}{c}\text { prismático, } \\
\text { escalenoédr } \\
\text { ico, } \\
\text { romboédrico }\end{array}$ & romboédrico & $\begin{array}{c}\text { granular, } \\
\text { prismático, } \\
\text { compacto }\end{array}$ & $\begin{array}{l}\text { tabular ou } \\
\text { maciço }\end{array}$ & $\begin{array}{l}\text { tabular, } \\
\text { prismático }\end{array}$ \\
\hline Clivagem & $\begin{array}{l}\text { Perfeita em } \\
\text { (001) }\end{array}$ & perfeita (001) & $\begin{array}{l}\text { perfeita em } \\
\text { (001) }\end{array}$ & perfeita (001) & $\begin{array}{l}\text { perfeita em } \\
\text { (001) }\end{array}$ & $\begin{array}{l}\text { perfeita } \\
\text { (1011) }\end{array}$ & $\begin{array}{l}\text { Perfeita } \\
\text { (1011) }\end{array}$ & $\begin{array}{c}\text { imperfeita } \\
\text { (1011) ou } \\
\text { (0111] }\end{array}$ & $\begin{array}{c}\text { perfeita em } \\
\text { (100), boa em } \\
\text { (001) }\end{array}$ & $\begin{array}{c}\text { perfeita em } \\
\text { (001), boa em } \\
\text { [110]. } \\
\text { imperfeita em } \\
\text { [010] }\end{array}$ \\
\hline Dureza Mohs & 1 & $1 \mathrm{a} 2$ & $2 a 2,5$ & $1 a 2$ & $2 a 2,5$ & 3 & $3 a 4$ & 7 & 5,5 & $3 a 3,5$ \\
\hline Densidade & 2.7 & 2,8 & 2,6 & $2 a 2,7$ & 2,76 a 3,1 & 2,72 & 2,85 & 2,65 & $2,8 a 2,9$ & $4,3 a 4,6$ \\
\hline Brilho & perláceo & Perláceo & terroso & lustroso & perolado & Leitoso & $\begin{array}{c}\text { vítreo a } \\
\text { nacarado }\end{array}$ & vitreo & $\begin{array}{c}\text { vítreo a } \\
\text { nacarado }\end{array}$ & vítreo \\
\hline Cor & $\begin{array}{l}\text { verde pálido, } \\
\text { amarelo }\end{array}$ & $\begin{array}{c}\text { branco, } \\
\text { verde, cinza }\end{array}$ & $\begin{array}{l}\text { branco, } \\
\text { variando em } \\
\text { funçẫo da } \\
\text { impureza }\end{array}$ & branco, cinza & $\begin{array}{c}\text { incolor, } \\
\text { transparente }\end{array}$ & $\begin{array}{c}\text { branco, } \\
\text { cinza, } \\
\text { vermelho }\end{array}$ & $\begin{array}{l}\text { róseo, } \\
\text { branco }\end{array}$ & $\begin{array}{l}\text { incolor, } \\
\text { preto, } \\
\text { branco, } \\
\text { leitoso, } \\
\text { púrpura }\end{array}$ & $\begin{array}{l}\text { incolor a } \\
\text { branco } \\
\text { cinzento }\end{array}$ & $\begin{array}{l}\text { branco, } \\
\text { amarelo, } \\
\text { marrom }\end{array}$ \\
\hline
\end{tabular}

Fontes: Dana, 1974, Betejtin, 1977 [47, 48]

\subsection{Interface entre carga mineral e polímero}

Agregados de partículas

Durante o processo de mistura entre a carga mineral e o polímero, devido às forças de adesão entre as partículas minerais e devido à tensão interfacial entre partícula e polímero, a carga pode tender a formar agregados. Devido a este fato, neste presente trabalho, tomou-se extremo cuidado para a etapa de dispersão da carga na matriz polimérica.

A presença de agregados é particularmente relevante quando da presença de partículas com granulação inferior a $20 \mu \mathrm{m}$ de diâmetro, situação em que as forças atrativas entre elas podem ser mais relevantes que o seu próprio peso. 


\subsection{Forças de coesão e adesão}

Sólidos e líquidos resistem a esforços de tração (Figura 1 abaixo), este fato revela forças de atração entre os corpúsculos (átomos ou moléculas) da parede da coluna capilar e as moléculas do líquido que compõem o corpo ensaiado; mesmo em gases e vapores, existem débeis forças de atração entre os corpúsculos (efeito Joule-Thompson). Tais forças de atração exercidas entre corpúsculos da mesma espécie química são denominadas forças de coesão. Esforços de tração crescentes aplicados a um corpo alongam-no até rompê-lo; isto demonstra que as forças de coesão diminuem rapidamente à medida que aumenta a distância entre os corpúsculos.
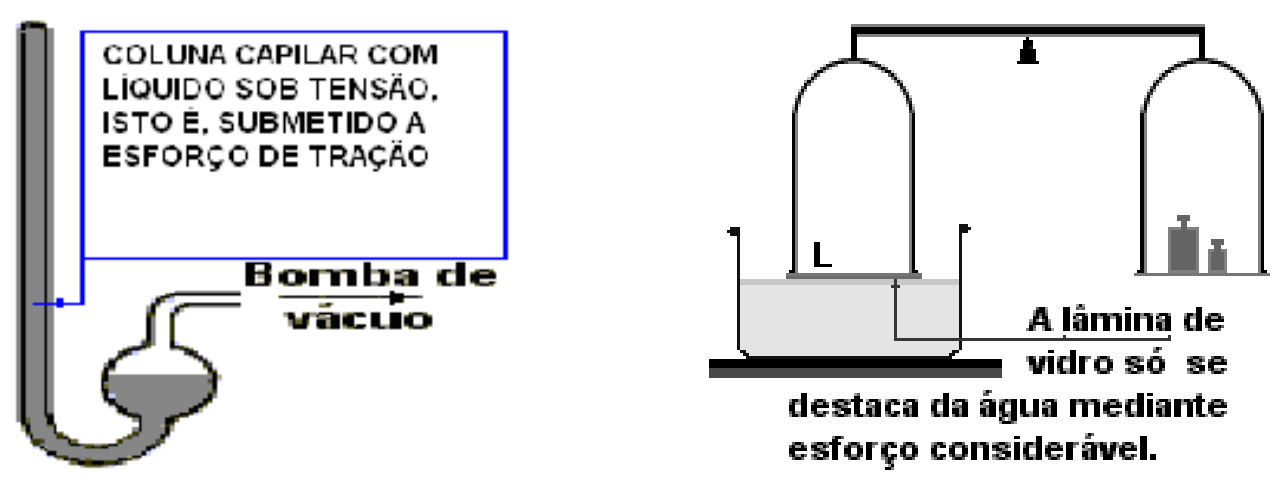

Figura 1 - Ilustração de experiências (forças de coesão e adesão). Fonte: Navarro (1997).

Forças de adesão, por sua vez, correspondem a forças de atração entre corpúsculos de espécies químicas diferentes.

Por exemplo, a água adere fortemente a uma superfície de vidro perfeitamente desengordurada. Na experiência ilustrada na Figura 1, uma carga suficientemente grande colocada no prato à direita determina o levantamento da lâmina de vidro. A inspeção desta revela estar molhada a sua face inferior. Portanto, o levantamento do vidro se dá com superação das forças de coesão, sem vencer as de adesão; assim constata-se que a adesão entre a água e o vidro é mais intensa do que a coesão entre as próprias moléculas de água. 
Para o caso de compósitos de matriz polimérica é importante que haja um método de processamento na qual a adesão entre a carga e o polímero seja potencializada. Isso, pode ser melhorado com a inserção de ligantes superficiais como o PP-g-MA.

\subsection{Tratamento superficial de carga mineral}

O tratamento superficial é necessário porque a partícula de carga mineral costuma ter a sua força de tensão superficial superior à força de tensão superficial do polímero. Se esta partícula fosse adicionada ao polímero sem o devido tratamento superficial, ela pode se aglomerar e não se dispersar porque a força de interação partícula-partícula é grande e pode ser maior do que a força de interação partícula-polímero.

Com o tratamento superficial, a força de tensão superficial da carga mineral é diminuída a valor menor do que aquele da força de tensão superficial do polímero; então a força de interação partícula-partícula sendo menor que a força de interação partícula-polímero permite que a carga se disperse mais facilmente na matriz do polímero.

Dependendo da composição química da carga e do agente de tratamento empregado, a partícula será apenas dispersa na matriz do polímero sem que haja forte interação entre ela e o polímero (ácidos graxos). Em outras situações, o agente que promove a dispersão também favorece, por algum meio, forte interação partícula-polímero (silano).

\section{Organossilanos}

Os agentes de tratamento superficial à base de organossilanos, constituídos quimicamente por compostos de silano (Figura 2), têm amplo uso por sua habilidade de interligar quimicamente polímeros orgânicos a um grupo relativamente grande de materiais inorgânicos como as cargas minerais (Figura 4). Quando os organossilanos são adicionados a estes sistemas, eles melhoram suas propriedades físicas e químicas, mesmo quando submetidos a severas condições ambientais.

O tipo de polímero e de carga mineral e os resultados esperados em termos de propriedades a serem adquiridas pelo compósito condicionam o tipo de organossilano e a técnica de tratamento. 
$\mathrm{YRSiX}_{3}$

Figura 2: Fórmula geral dos organossilanos.

$\mathrm{O}(\mathrm{Y})$ da fórmula representa a parte do organossilano que interagirá com o polímero, podendo conter grupos alquil, aril, vinil, amina, epóxi, metacrilato e outros.

$\mathrm{O}(\mathrm{X})$ na fórmula representa os grupos hidrolisáveis ligados ao silício (Si). Geralmente estes grupos são representados pelo cloro, alcóxi ou acetóxi. Em condições aquosas, estes grupos se hidrolisam para formar silanos e HX (Figura 3):

\section{$\mathrm{YRSiX}_{3} \stackrel{\mathrm{H}_{2} \mathrm{O}}{\rightarrow} \mathrm{YRSi}(\mathrm{OH})_{3}+3 \mathrm{HX}$}

Figura 3: Reação de liberação de $\mathrm{H}_{2} \mathrm{O}$ dos silanos.

$\mathrm{O}\left(-\mathrm{SiX}_{3}\right)$, ou o produto de sua reação, provocará uma interação acentuada à fase inorgânica do compósito. Os silanos reagem com os silanóis das superfícies das partículas minerais (quartzo, mica, etc.) (Figura 4) e liberam $\mathrm{H}_{2} \mathrm{O}$. Subsequentemente, a liberação da água faz com que uma camada de silanos fique ligada covalentemente à superfície da partícula. Porém, a composição química desta partícula influencia em maior ou menor grau esta ligação. 


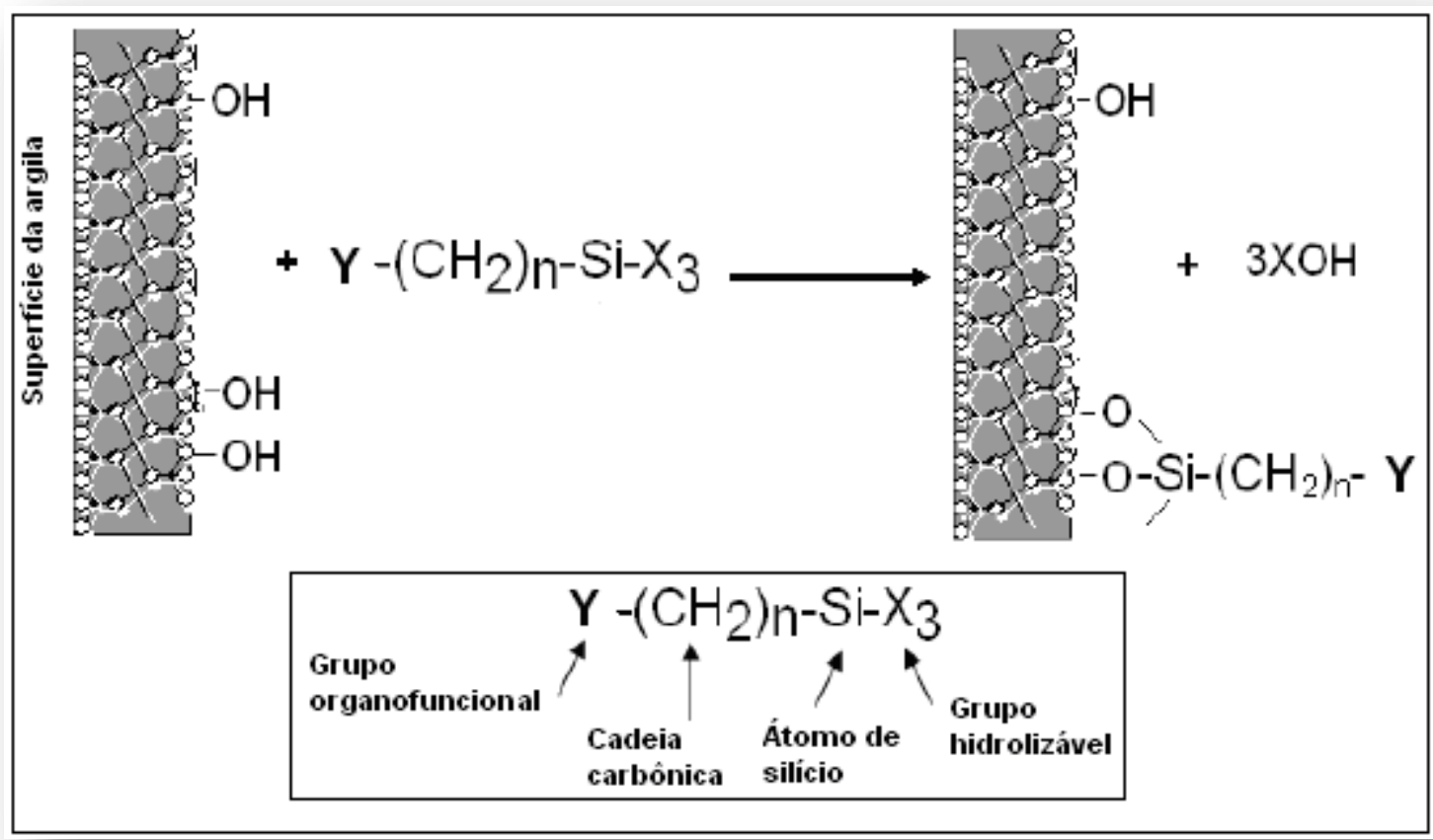

Figura 4: Esquema de reação do silano com a argila (Plueddemann, 1974).

\subsection{Efeitos da carga mineral nas propriedades físicas e químicas do compósito}

Cada uma das várias características da carga mineral (granulometria, dureza, composição química, etc.) exerce algum efeito, quer seja nas propriedades físicas, quer seja nas propriedades químicas do compósito. A aplicação do compósito é que irá nortear a escolha do tipo de carga mais adequada.

A composição química e, especialmente, a pureza da carga mineral exercem, ambos, efeitos diretos e indiretos nas possibilidades de aplicações e performances do compósito. Carga com insuficiente pureza pode levar à alteração da cor ou mesmo à descoloração do produto limitando a sua aplicação.

Um aspecto importante da distribuição granulométrica é a quantidade relativa de partículas pequenas. A tendência à agregação da carga cresce com o decréscimo do tamanho da partícula. Extensiva agregação leva à insuficiente homogeneidade, rigidez e menor resistência à compressão 
do compósito. Partículas de carga agregadas agem como iniciadores de rupturas localizadas quando o compósito sofre impacto.

Em geral, a resistência aos esforços parece aumentar com o aumento da anisotropia da partícula (razão de aspecto); cargas com a forma de placa como o talco e a mica agregam mais resistência que cargas com formato romboédrico como o $\mathrm{CaCO}_{3}$, enquanto que cargas como a fibra de vidro agregam maior valor à resistência à tração.

\subsection{Interação interfacial}

O tratamento superficial imposto à carga mineral tem como primeiro objetivo o melhoramento de sua "molhabilidade" pelo polímero. Do ponto de vista da termodinâmica, este tratamento tem o propósito de adequar as energias superficiais. Com o tratamento, a tensão superficial do polímero, que é geralmente baixa, e da carga mineral, que é geralmente mais elevada, são compatibilizadas. Com isso, a carga adsorve o polímero mais completamente e mais rapidamente porque o tratamento superficial da carga mineral reduz sua tensão superficial. A viscosidade é reduzida e a dispersão da carga é aumentada. A dispersão da carga mineral dentro da matriz do compósito é o primeiro passo importante no processo de interação carga/polímero.

As propriedades mecânicas do compósito estão intimamente relacionadas às interações que se estabelecem entre a superfície da carga tratada e o polímero.

\subsection{Graftização do polipropileno}

$\mathrm{Na}$ graftização, um homopolímero torna-se um copolímero graftizado ou enxertado, isso acontece através de ligações covalentes laterais de um polímero B (ou outra substância) na cadeia principal formada por um polímero A.

As substâncias mais utilizadas em reações de graftização estão representados na Figura 5 a seguir, sendo normalmente do tipo 1,2-dissubstituídos (a) e (b); 1-substituídos (c); 1,1-dissubstituídos (d) [6] ou (e) [16]. 


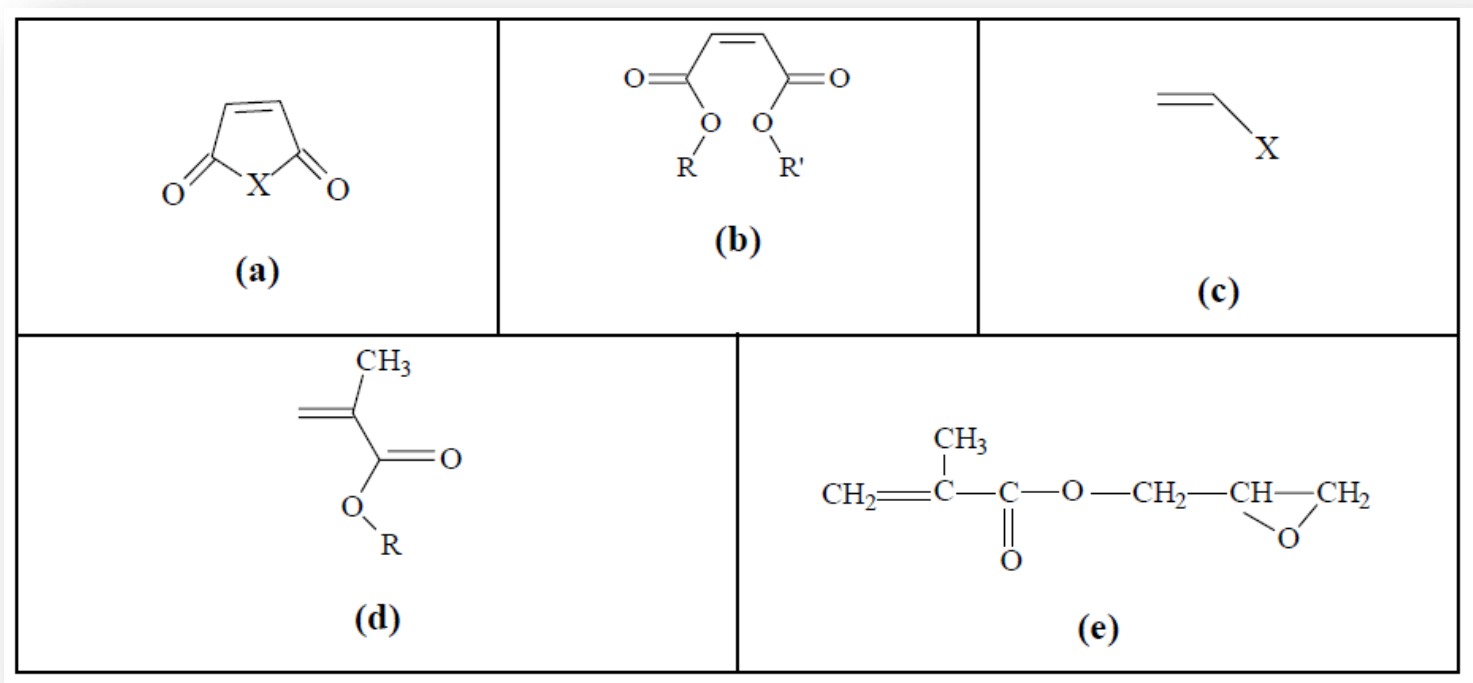

Figura 5: Substâncias mais utilizadas em reações de graftização.

Sendo:

(a) tipo 1,2-dissubstituídos (anidrido maléico, tendo $\mathrm{X}=\mathrm{O}$ )

(b) tipo 1,2-dissubstituídos, (éster maleato)

(c) 1-substituídos (ésteres acrilatos, $\mathrm{X}=\mathrm{CO} 2 \mathrm{R}$ ou vinil silanos $\mathrm{X}=\mathrm{SiOR} 3$ )

(d) 1,1-dissubstituídos (ésteres metacrilatos)

(e) 1,1-dissubstituídos (compostos contendo uma segunda funcionalidade como o metacrilato de glicidila)

Entre estas substância químicas, a mais comumente utilizada para graftização do polipropileno é o anidrido maléico (MA) (anidrido cis-butenidióico, anidrido toxílico, di-hidro-2,5dioxofurano), que é um composto orgânico com a fórmula $\mathrm{C}_{4} \mathrm{H}_{2} \mathrm{O}_{3}\left(\mathrm{C}=\mathrm{OCH}=\mathrm{CHC}=\mathrm{O}_{2}\right)$ representada pela Figura 6 que é utilizado industrialmente para a produção de diversos produtos, entre eles: plastificantes e aditivos. O polipropileno graftizado com anidrido maléico é um material largamente comercializado devido à sua combinação de baixo custo, boa processabilidade e características de aplicação atrativas. A graftização com anidrido maléico é também bastante estudada devido, principalmente, à alteração significativa na polaridade do polipropileno, tornando-o mais compatível, 
quando utilizado para a produção de compósitos e, também, quando utilizado em blendas com outros polímeros polares.

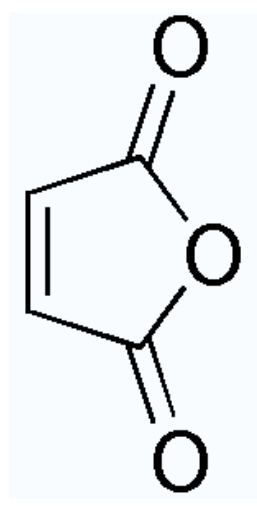

Figura 6: Anidrido maléico.

Para a graftização, é utilizado um iniciador de reação e o mais utilizado e estudado atualmente é o peróxido de benzoíla (Figura 7). É um produto utilizado em cosméticos e em terapias contra a acne devido a sua ação bacteriana e oxidativa, porém é utilizado em baixíssimas concentrações para estes fins. O peróxido de benzoíla é facilmente encontrado comercialmente e tem ótima relação custo/benefício. É uma molécula de fórmula $\mathrm{C}_{14} \mathrm{H}_{10} \mathrm{O}_{4}$, altamente reativa (conforme reação esquematizada pela Figura 8), explosiva e irritante, devendo ser utilizado com extrema precaução e com dosagens bem calculadas.<smiles>O=C(OOC(=O)c1ccccc1)c1ccccc1</smiles>

Figura 7: Peróxido de benzoíla. 
<smiles>O=C(OOC(=O)c1ccccc1)c1ccccc1</smiles>

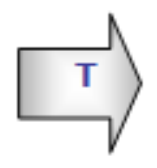<smiles>COC(=O)c1ccccc1</smiles>

aquecimento

Figura 8: Esquema do mecanismo de decomposição de peróxido de benzoíla.

Para a reação de graftização ocorra de forma adequada é importante observar a meia vida $\left(t_{1 / 2}\right.$ ) do iniciador a uma dada temperatura, que é o tempo necessário para que a sua concentração se reduza à metade. Portanto, o $\mathrm{t}_{1 / 2}$ não deve ser muito alto em relação ao tempo de residência do material dentro do equipamento de reação (extrusora ou balão de reação) para que, dessa forma, o iniciador seja completamente convertido em radicais durante a reação. No entanto, o uso de iniciadores com $t_{1 / 2}$ muito curtos pode provocar a geração de uma alta concentração de radicais livres já no início da reação, aumentando a probabilidade de ocorrência de reticulação pela combinação destes radicais, ou a limitação da graftização pela dificuldade de difusão do monômero no meio, principalmente em meios heterogêneos. Em casos em que o iniciador tenha um tempo de meia vida muito curto é importante utilizar adequados teores combinados à introdução controlada deste iniciador ao sistema em reação [6].

Devido à natureza inerte da estrutura do PP e do baixo controle de reação de radical livre, a graftização de MA envolve também reações secundárias indesejáveis, como cisão-beta, tranferência de cadeia e acoplamentos. A incorporação de MA, normalmente, é inversamente proporcional à massa molar do polímero resultante [7]. A Figura 9 apresenta o esquema do mecanismo de reações químicas de graftização do MA em PP. 
<smiles>[R]CCCC(C)(C)[C@H](C)C(C)C</smiles>

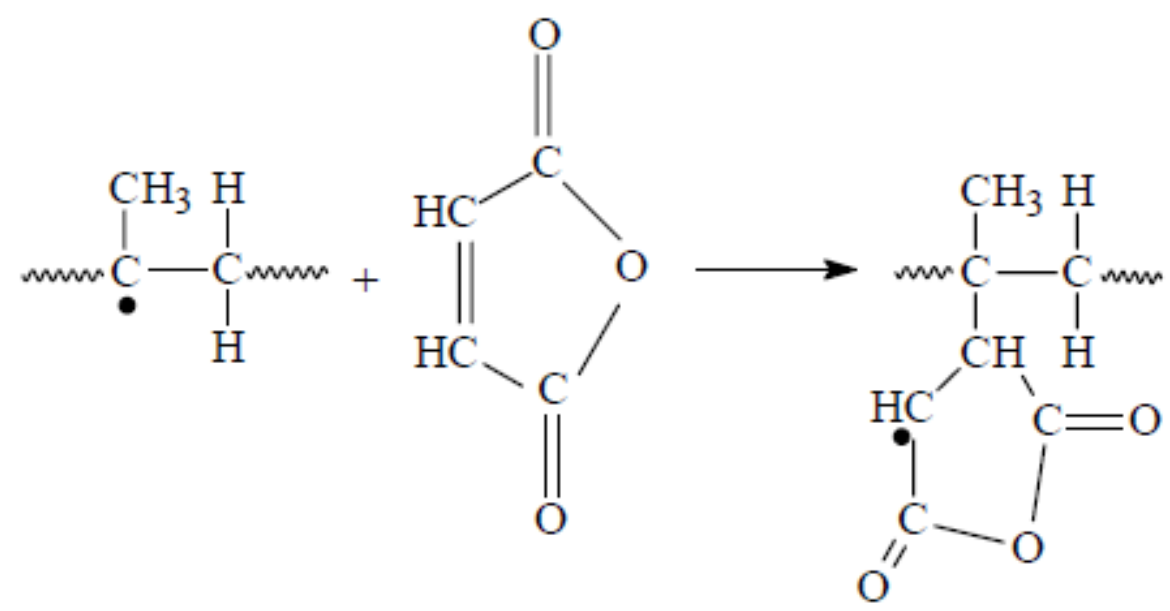<smiles>CC(C)C(C)(C)C1CC(=O)OC1=O</smiles><smiles>CC(C)[C@H](C)[C@H]1C(=O)OC(=O)[C@H]1[N+](=O)[O-]</smiles>

Figura 9: Esquema de mecanismo de reações químicas de graftização de MA em PP [1].

A razão de reatividade para homopolimerização de MA durante a reação é pequena, porque a temperatura da funcionalização normalmente ultrapassa o limite superior para a polimerização do MA e este processo exige condições muito controladas de reação, nem sempre gerando um produto uniforme [3]. Um dos fatores limitantes da graftização de MA em hidrocarbonetos é sua insolubilidade nestes compostos. 


\subsection{Estrutura do polipropileno e algumas considerações quanto à sua fase cristalina beta.}

Sabemos que o polipropileno é um polímero poliolefínico semicristalino, sendo assim, encontramos maiores resistências mecânicas na fase cristalina e por outro lado, encontramos maiores resistências ao impacto na fase amorfa [20,22].

O grande desafio é harmonizar estas propriedades opostas num mesmo produto aliando a processabilidade, baixo custo e possível melhora para o processo de reciclagem dos produtos finais.

Estudos relativamente recentes com o polímero indicaram a formação de uma fase cristalina diferente da habitual fase alfa. Chamada de fase cristalina beta, ela se diferencia da fase alfa pelo aumento das resistências ao impacto sem que haja perda consideráveis em propriedades opostas, como: módulo de flexão e resistência à tração.

De um modo geral, o percentual de cristalinidade de um polímero é induzida pela inserção de substâncias que direcionam a formação de núcleos cristalinos. Estas substâncias chamadas de agentes nucleantes podem ser produtos como benzoato de sódio, sais organofosforados e sorbitóis. Com a presença deles em determinada concentração, a formação inicial dos núcleos aumenta, o que direciona o aumento da quantidade de esferulitos. Com isso, há um favorecimento da probabilidade do aumento percentual cristalino do polímero e também favorece a velocidade de cristalização do material fundido [20, 22].

O polimorfismo do polipropileno com a formação de duas fases cristalinas ainda é pouco utilizada pela indústria, pois poucos agentes nucleantes de fase beta são conhecidos atualmente. Além disso, os agentes nucleantes beta conhecidos não formam esta fase cristalina de modo estável termodinamicamente. Portanto, o grande desafio é a descoberta de um nucleante que torne a fase cristalina beta menos metaestável.

Estudos atuais indicam que uma determinada deformação em sua estrutura ou esforço mecânico pode converter os cristais beta para cristais de fase alfa e esta transformação gera microvazios (microvoids) advindos da diferença do fator de empacotamento entre as duas fases. Esta é a explicação de alguns autores [15] para o aumento de resultados de impacto sem que haja 
perdas significativas de outras propriedades mecânicas (resistência à tração, dureza e módulo na flexão).

Podemos acrescentar que a fase cristalina beta é menos compacta que a fase cristalina alfa e, portanto, menos densa. Assim sendo, a fase cristalina beta tem um ponto de fusão diferente e mais baixo que o ponto de fusão da fase alfa. Em termos quantitativos, o ponto de fusão pode variar entre 12 e $15{ }^{\circ} \mathrm{C}$ mais baixo e sua densidade pode diminuir aproximadamente $10 \%$ em comparação com a fase cristalina alfa mais comum [15].

Em termos de processamento, a fase cristalina beta pode melhorar significativamente 0 processo de termoformagem especificamente, pois as propriedades inerentes a este processo são melhoradas de modo sinérgico quando comparadas novamente com a fase alfa. Inclusive, em termos de contração, o polipropileno com maior percentual de fase cristalina beta contribui para que não haja diferenças bruscas de volume de material fundido para o volume de material sólido durante a solidificação.

Uma das características, entretanto, que deve ser levada em consideração é que a fase cristalina beta é menos transparente devido aos microvazios formados durante a sua cristalização. Esta peculiar característica, ao mesmo tempo, é altamente concebível no caso do produto final ser pintado, pois estes minúsculos poros oferecem fendas para que a tinta possa ser espalhada melhor na superfície e assim, aderir à superfície.

Portanto, no atual momento do polipropileno, a fase cristalina beta deve ser um dos caminhos muito procurados para a melhora significativa deste polímero. Quando melhor entendida, melhor estudada e melhor controlada, a indústria e a sociedade como um todo serão beneficiadas em diversos campos de sua aplicabilidade. 


\subsection{Utilização do $\mathrm{CaCO}_{3}$ como nucleante para cristalinidade beta do polipropileno.}

A estrutura cristalina beta do polipropileno foi descoberta e reportada nos finais de 1950 [52]. Em 1967, Leugering identificou uma quinacridona específica a qual fornecia uma relativa quantidade de fase cristalina beta no polipropileno. Desde então, várias investigações foram direcionadas, e diversos nucleantes beta foram identificados, entre eles podemos citar: ortoftalato de sódio, alguns ácidos isoftálicos e tereftálicos [53], wollastonitas, alguns ácidos pimélicos e compostos de aril amidas [54, 55-57], entre outros incluindo o $\mathrm{CaCO}_{3}$.

No caso específico deste último, muitos pesquisadores [52,58-63] estudaram-no com mais detalhamento, pois, além de ser utilizado como carga mineral de reforço na matriz polimérica, determinados tipos deste mineral com tratamentos superficiais específicos geravam compósitos com uma combinação superior de propriedades mecânicas [52,58-61].

Sabe-se que a carga mineral é utilizada para melhora de algumas propriedades mecânicas, tais como: resistência à tração, rigidez e dureza; em grande detrimento de propriedades que exigem tenacidade.

Como já descrito anteriormente, sabe-se que a fase cristalina beta tem um fator de empacotamento maior que a fase cristalina alfa mais comum. Quando há uma solicitação de deformação muito rápida do material já solidificado, os cristais betas são transformados em cristais alfa formando microvazios (microvoids) que aumentam a capacidade de absorção de energia favorecendo a tenacidade do material [15].

Este trabalho torna-se relevante devido ao estudo e à observação do aumento de propriedades de resistência mecânica gerada pela utilização do $\mathrm{CaCO}_{3}$ combinada sinergicamente com o aumento da tenacidade gerada pela formação da fase cristalina beta com a própria utilização deste mineral. 


\section{PARTE EXPERIMENTAL 1 \\ (enfoque no estudo comparativo da graftização de anidrido maléico em polipropileno utilizando peróxido orgânico)}

\subsection{Materiais}

Os materiais e substâncias utilizadas neste trabalho são apresentados na Tabela 3 abaixo. De um modo resumido, tratam-se: do polipropileno, Carbonatos de Cálcio e demais substâncias químicas que foram utilizados conforme recebidos dos fornecedores.

Tabela 3: Substâncias químicas e matérias primas utilizadas no trabalho experimental.

\begin{tabular}{|c|c|c|}
\hline $\begin{array}{l}\text { Matéria prima } \\
\text { utilizada }\end{array}$ & Fornecedor/Fonte & Características/Propriedades \\
\hline Peróxido de benzoíla & Quimibrás & Pureza $65 \%$ de $\mathrm{C}_{14} \mathrm{H}_{10} \mathrm{O}_{4}$ \\
\hline Anidrido maléico & Elekeiróz & Pureza $99,5 \%$ de $\mathrm{C}_{4} \mathrm{H}_{2} \mathrm{O}_{3}$ \\
\hline o-xileno & Labsynth & grau A.C.S. \\
\hline Mickhart 08T & $\begin{array}{l}\text { Adexim-Comexim / } \\
\text { Provençale }\end{array}$ & $\begin{array}{c}\mathrm{CaCO}_{3} \text { tratado superficialmente de tamanho de } \\
\text { partícula } 900 \mathrm{~nm} \text { ou } 0,9 \mu \mathrm{m} \text { (este é um produto } \\
\text { comercial e o tratamento superficial não foi } \\
\text { disponibilizado e nem mencionado) }\end{array}$ \\
\hline Mickhart 08 & $\begin{array}{l}\text { Adexim-Comexim / } \\
\text { Provençale }\end{array}$ & $\begin{array}{l}\mathrm{CaCO}_{3} \text { sem tratamento de tamanho de partícula } \\
\qquad 900 \mathrm{~nm} \text { ou } 0,9 \mu \mathrm{m}\end{array}$ \\
\hline Mickhart C & $\begin{array}{l}\text { Adexim-Comexim / } \\
\text { Provençale }\end{array}$ & $\begin{array}{l}\mathrm{CaCO}_{3} \text { sem tratamento de tamanho de partícula } \\
\qquad 2.5 \mu \mathrm{m}\end{array}$ \\
\hline Mickhart 2 & $\begin{array}{l}\text { Adexim-Comexim / } \\
\text { Provençale }\end{array}$ & $\begin{array}{c}\mathrm{CaCO}_{3} \text { sem tratamento de tamanho de partícula } \\
3 \mu \mathrm{m}\end{array}$ \\
\hline $\begin{array}{l}\text { Polipropileno } \\
\text { HP500N }\end{array}$ & Braskem & $\begin{array}{c}\text { PP homopolímero de } \\
\text { MFI } 230^{\circ} \mathrm{C} / 2,16 \mathrm{~kg}=11 \mathrm{~g} / 10 \mathrm{~min}\end{array}$ \\
\hline Polibond 3200 & Chemtura & $\begin{array}{l}\text { Polipropileno graftizado com anidrido maléico. } \\
\text { (PP-g-MA) Índice de graftização: } 1 \%\end{array}$ \\
\hline
\end{tabular}




\subsection{Equipamentos utilizados}

Os equipamentos de caracterização e também os equipamentos de processamento das amostras poliméricas estão apresentados na Tabela 4 a seguir.

Tabela 4: Equipamentos utilizados no trabalho experimental.

\begin{tabular}{|c|c|}
\hline $\begin{array}{l}\text { Equipamento } \\
\text { utilizado }\end{array}$ & Informações relevantes \\
\hline Aparelho de DSC & $\begin{array}{c}\text { TA Instruments - modelo: Universal V4.2E - software: Q1000 V9.8 } \\
\text { Build } 296\end{array}$ \\
\hline Aparelho universal & $\begin{array}{c}\text { Instron - modelo } 5566 \text { - célula de carga } 10 \mathrm{kN} \text { - software acoplado: } \\
\text { Blue Hill } 2009\end{array}$ \\
\hline Aparelho de Impacto & Aparelho de impacto Ceast - modelo Resil impactor 6967 \\
\hline $\begin{array}{l}\text { Aparelho de } \\
\text { infravermelho }\end{array}$ & FTIR - Nicolet iS10 - Charis Technologies \\
\hline $\begin{array}{l}\text { Aparelho de } \\
\text { medição de índice } \\
\text { de fluidez }\end{array}$ & Plastômetro de extrusão - Tinius Olsen - Modelo MP993 \\
\hline $\begin{array}{l}\text { Extrusora } \\
\text { laboratorial }\end{array}$ & $\begin{array}{c}\text { Miotto - rosca simples } \mathrm{L} / \mathrm{D}=25 \text { e } \mathrm{D}=25 \mathrm{~mm} \text { com ajuste de } \\
\text { temperatura em } 3 \text { zonas de aquecimento sem sistema de } \\
\text { degasagem [65] }\end{array}$ \\
\hline $\begin{array}{l}\text { Equipamentos } \\
\text { laboratoriais para } \\
\text { reação }\end{array}$ & $\begin{array}{l}\text { Balão de reação, sistemas de vazão contínuo de nitrogênio gasoso } \\
\text { para purga, capela, bico de Bunsen, balança, etc. }\end{array}$ \\
\hline $\begin{array}{l}\text { Homogeneizador de } \\
\text { laboratório tipo } \\
\text { "Banbury-drays" }\end{array}$ & $\begin{array}{l}\text { MH equipamentos - modelo MH-600 - misturador de alta velocidade } \\
\text { mono rosca - potência } 18,5 \mathrm{~kW} \text { - rotação } 1800 \mathrm{rpm} \text { [50] }\end{array}$ \\
\hline Prensa hidraulica & $\begin{array}{l}\text { MH equipamentos - modelo MH-8-MT - Equipamento hidráulico para } \\
\text { produção controlada de filmes poliméricos - capacidade } 2 \mathrm{~kg} \text {-área } \\
\text { de prensagem } 200 \times 200 \mathrm{~mm}-2700 \mathrm{~kW} \text { de potência de aquecimento } \\
\text { - temp. máxima } 300^{\circ} \mathrm{C}[51]\end{array}$ \\
\hline $\begin{array}{l}\text { Injetora de corpos } \\
\text { de prova }\end{array}$ & $\begin{array}{l}\text { Battenfeld modelo FB 1400/450 - Capacidade de fechamento } 400 \\
\text { ton }\end{array}$ \\
\hline
\end{tabular}




\subsection{Obtenção do polipropileno graftizado com anidrido maléico (PP-g-MA)}

As matérias primas utilizadas para o estudo foram: polipropileno homopolímero (PP), HP 500N da Braskem (MFI $230{ }^{\circ} \mathrm{C} / 2,16 \mathrm{~kg}=11 \mathrm{~g} / 10 \mathrm{~min}$ ); peróxido de benzoíla da Quimibrás $\mathrm{C}_{14} \mathrm{H}_{10} \mathrm{O}_{4}$; anidrido maléico $99,5 \%$ da Elekeiróz, $\mathrm{C}_{4} \mathrm{H}_{2} \mathrm{O}_{3}$; o-xileno da Labsynth, grau A.C.S. A quantidade percentual utilizada para os dois métodos de graftização foram: $91,2 \%$ de $\mathrm{PP}, 7,4 \%$ de anidrido maléico e $1,4 \%$ de peróxido de benzoíla. Esta proporção ideal foi estudada detalhadamente pelo grupo de ciência de los Materiales da Universidade de Antioquia [8].

\subsubsection{Procedimento para graftização em balão de reação}

Montou-se o balão de reação sob um sistema coligado de fluxo contínuo de gás nitrogênio. Este sistema foi montado em ambiente seco e inerte em capela de exaustão. Esta adaptação foi feita com o intuito de minimizar possíveis reações indesejadas com outros gases. Dessa forma, foram inseridos primordialmente $91,2 \mathrm{~g}$ de PP no balão de reação, seguidos de $5 \mathrm{ml}$ de xileno, adicionados em intervalos de 10 em 10 minutos, para facilitar a homogeneização. Após aproximadamente 2 horas e 40 minutos, foi obtida uma mistura viscosa e homogênea. Neste momento, 7,4 g de anidrido maléico foram adicionados à mistura no balão e homogeneizados por mais 25 minutos. Em seguida, inseriram-se mais $3 \mathrm{ml}$ de xileno. Após 5 minutos foram adicionados $1,4 \mathrm{~g}$ de peróxido de benzoíla. $\mathrm{O}$ aquecimento foi desligado após 15 minutos de reação. O produto obtido foi purificado por extração por 8 horas, utilizando-se um sistema de extração Sohxlet. Para esta última etapa, utilizou-se o etanol como solvente. 


\subsubsection{Procedimento para graftização pelo método da extrusão}

Foi utilizada uma extrusora de rosca simples ( $L / D=25$ e $D=25 \mathrm{~mm}$ ) com ajute de temperatura em 3 zonas de aquecimento, $Z 1=130{ }^{\circ} \mathrm{C}, \mathrm{Z} 2=150{ }^{\circ} \mathrm{C}$ e $\mathrm{Z} 3=180{ }^{\circ} \mathrm{C}$ [65]. A mistura de $912 \mathrm{~g}$ de PP, $74 \mathrm{~g}$ de anidrido maléico e $14 \mathrm{~g}$ de peróxido de benzoíla foi devidamente pesada e misturada fisicamente antes de ser inserida no funil de alimentação. O tempo de residência (do funil de alimentação até a saída) da mistura na extrusora foi de três minutos estimados (estes três minutos foram previamente medidos com a utilização do PP com e sem masterbatch para visualização da cronometragem). O produto extrusado foi resfriado em água e após secagem foi utilizado um moinho para obtenção das amostras em pellets.

\subsubsection{Estudo comparativo dos processos de graftização do polipropileno com anidrido maléico}

Com o intuito de comparar os dois processos de graftização as amostras foram submetidas às seguintes análises: DSC, FTIR, EDS e MEV. A partir dos resultados destas análises foi possível verificar qual é o método mais eficaz desta graftização especificamente e possível utilização do produto final (PP-g-MA) como terceiro componente e matéria prima para os compostos de polipropileno com $\mathrm{CaCO}_{3}$ referentes ao objetivo final deste trabalho.

\subsection{Obtenção dos filmes para curva de calibração do percentual de graftização com anidrido maléico através de análise de espectroscopia no infra vermelho}

Foram preparadas amostras misturando-se o Polipropileno HP 500N com o Polibond 3200, que é um PP-g-MA comercial com 1,0\% de anidrido maléico graftizado. Isso foi necessário, pois o Polibond 3200 é um produto de referência no mercado, mantendo a proporção de anidrido maléico muito próxima a $1 \%$ em todos os lotes recebidos. Além disso, este grade em específico da empresa fabricante (Chemtura) é o que contém o maior teor de graftização, fato que explica a escolha do produto.

As amostras consistiram em misturas destas duas matérias primas para geração das respectivas proporções padronizadas de percentual graftizado: $0,20 \%, 0,25 \%, 0,30 \%, 0,35 \%, 0,40 \%$, 
$0,45 \%, 0,50 \%, 0,55 \%, 0,60 \%, 0,65 \%, 0,70 \%, 0,75 \%, 0,80 \%$ e $1,0 \%$. Esta faixa de concentração foi escolhida com o intuito de aproximar ao máximo à faixa provável que seriam encontradas nas amostras graftizadas neste trabalho. Estas amostras foram submetidas à prensagem aquecida a 165 ${ }^{\circ} \mathrm{C}$.(os detalhes da preparação destes filmes estão descritos no item 5.1.5) Utilizou-se uma célula de espessura padronizada com geração de filmes de $0,3 \mathrm{~mm}$. Estes filmes foram analisados por espectroscopia no infravermelho.

A relação entre as áreas dos picos $1785 \mathrm{~cm}^{-1}(\mathrm{Aa})$, característica de absorção do grupamento carbonila do anidrido, e $1156 \mathrm{~cm}^{-1}(\mathrm{Ab})$, utilizada como banda de referência do PP foi utilizada para análise da concentração relativa de anidrido maléico (MA) em PP. A curva de calibração é necessária para análise do teor de anidrido maléico incorporado ao PP nos dois processos de graftização (os detalhes da obtenção desta curva de calibração estão descritos no item 5.1.5). A concentração é determinada utilizando a Equação 1 obtida experimentalmente.

Equação 1: grau de incorporação em massa de MA ao PP utilizando-se dados de Infra vermelho.

$$
I(g \%)=1,677 \times(\mathrm{Aa} / \mathrm{Ab})
$$

Onde:

I $(g \%)=$ grau de incorporação em massa de MA ao PP;

$\mathrm{Aa}=$ área do pico de absorção a $1785 \mathrm{~cm}^{-1} \mathrm{e}$

$\mathrm{Ab}=$ área do pico de absorção a $1156 \mathrm{~cm}^{-1}$ 


\section{RESULTADOS E DISCUSSÕES 1 (enfoque no estudo comparativo da graftização de anidrido maléico em polipropileno utilizando peróxido orgânico)}

\subsection{Análise comparativa dos dois métodos de graftização para obtenção do PP-g-MA}

\subsubsection{Análise de dados de DSC (Varredura diferencial de calorimetria)}

O DSC foi utilizado neste trabalho para observação do percentual cristalino das amostras em comparação com o PP puro, mantido como referência. Foi utilizado a Equação 2 utilizando-se o valor de entalpia de fusão obtido em literatura de entalpia de fusão $(\Delta \mathrm{H})$ para o PP 100\% cristalino, $209 \mathrm{~J}$ g-1 [13].

Os valores de entalpia de fusão $(\Delta \mathrm{Hf})$ das amostras foram obtidas através das Figuras 10,11 e 12, que são as curvas de DSC obtidas a partir do segundo aquecimento. Ou seja, as amostras foram primeiramente aquecidas a $10{ }^{\circ} \mathrm{C}$ por minuto até $230{ }^{\circ} \mathrm{C}$ com o intuito de padronização da história térmica de todos os materiais e depois resfriadas até $-40{ }^{\circ} \mathrm{C}$ a $10{ }^{\circ} \mathrm{C}$ por minuto. As curvas ilustradas (Figuras 10,11 e 12) foram obtidas a partir de um segundo aquecimento $10{ }^{\circ} \mathrm{C}$ por minuto até $200^{\circ} \mathrm{C}$.

Existem outras informações que podem ser analisadas e estudadas através destas curvas [912], porém deixamos como sugestão para trabalhos futuros. 


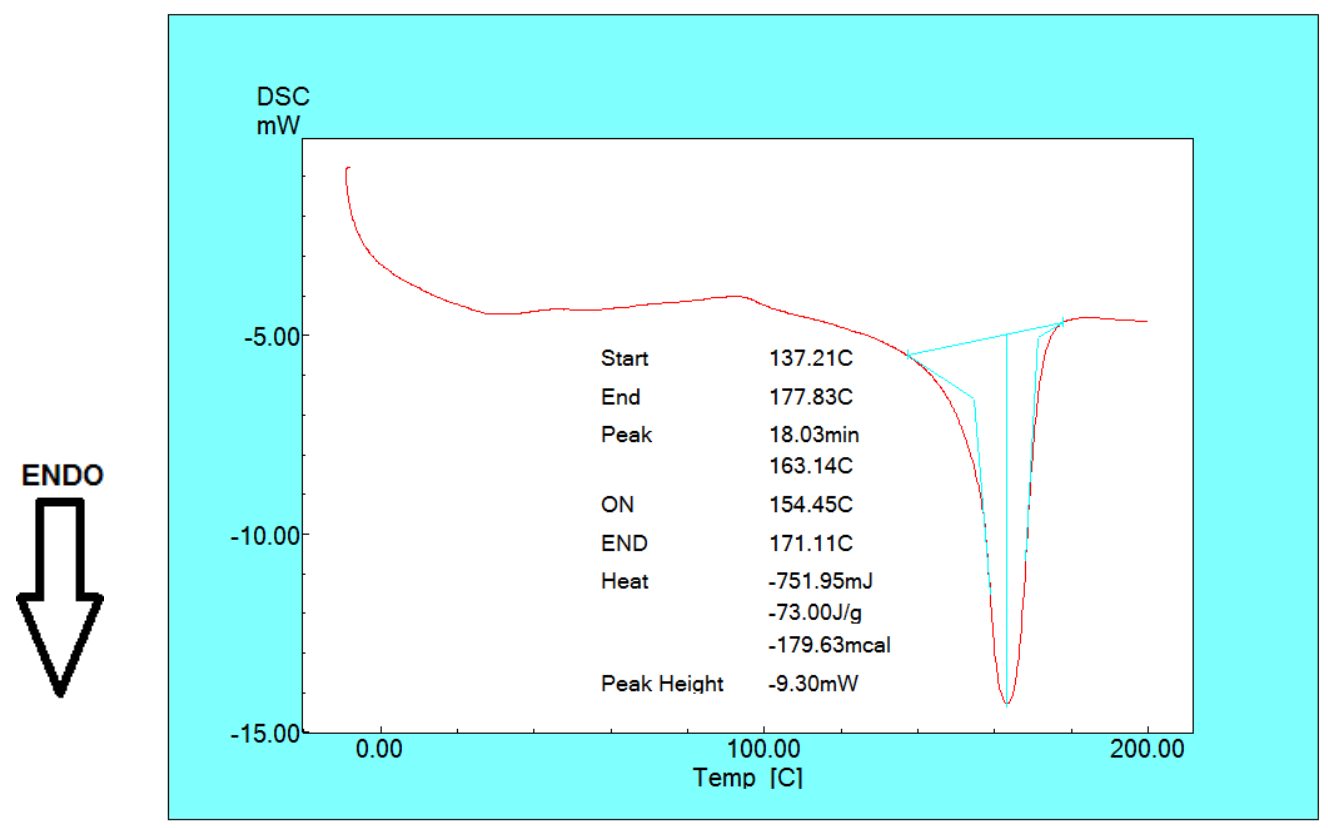

Figura 10: Curva DSC e demais informações obtidos do PP puro.

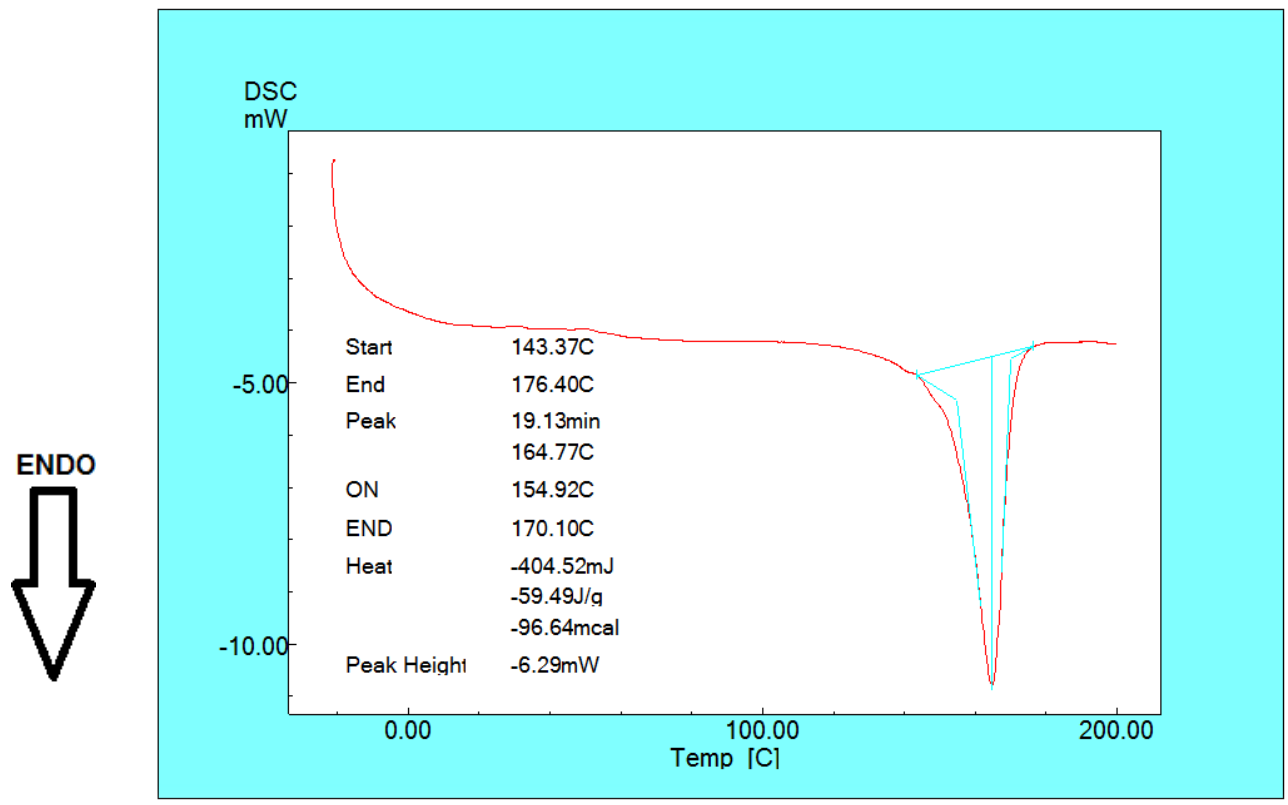

Figura 11: Curva DSC e demais informações obtidos da amostra de PP graftizado com anidrido maléico a partir de peróxido de benzoíla feito pelo método da extrusora. 


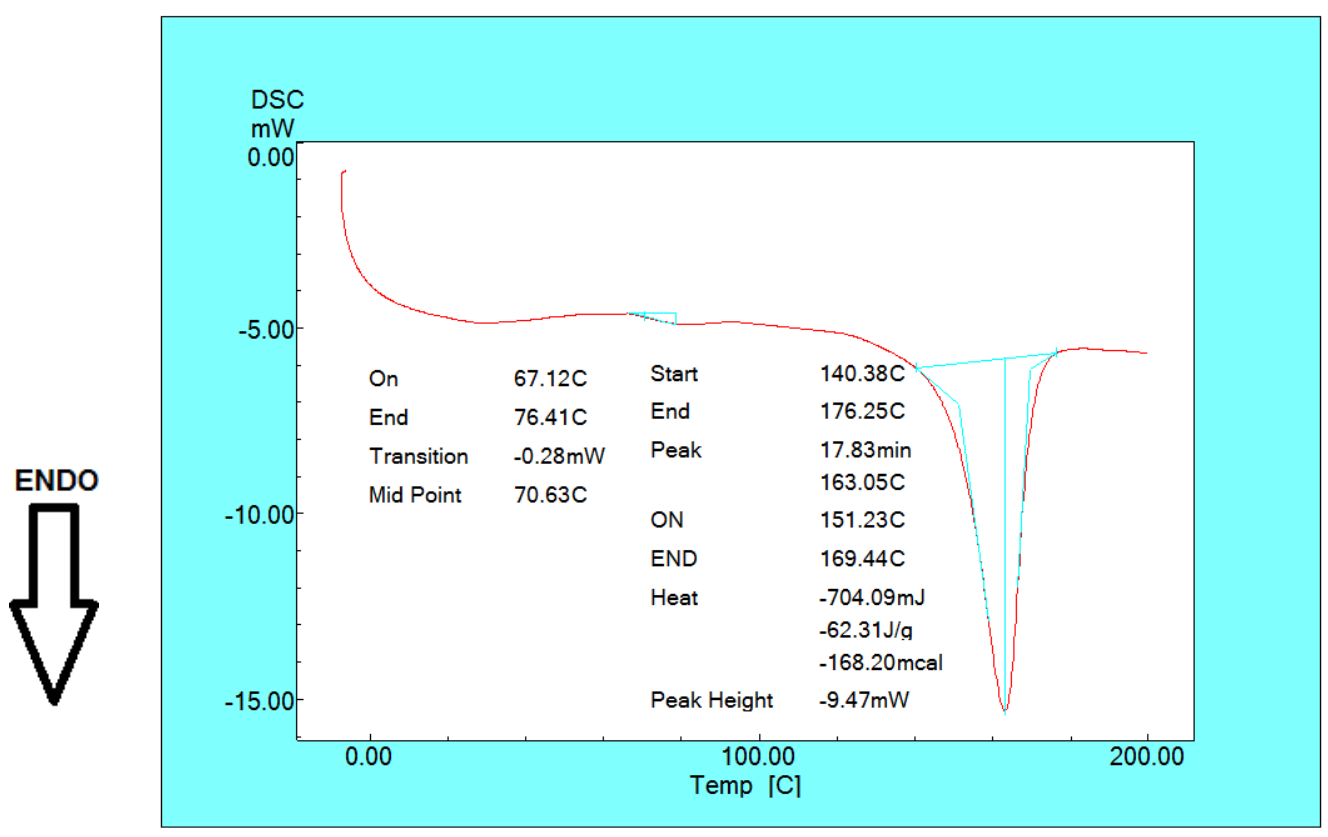

Figura 12: Curva DSC e demais informações obtidos da amostra de PP graftizado com anidrido maléico a partir de peróxido de benzoíla feito pelo método de balão.

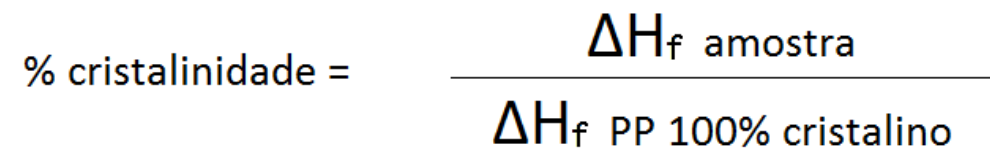

Equação 2: Percentual de cristalinidade por entalpia de fusão.

A Tabela 5 mostra os valores de entalpia de fusão $(\Delta \mathrm{Hf})$ das amostras, bem como o percentual de cristalinidade calculado. 
Tabela 5: valores $\Delta \mathrm{Hf}$ em J/g obtidos pelos resultados de DSC e percentual de cristalinidade das amostras graftizadas

\begin{tabular}{|cccc|}
\hline & PP & extrusora & balão de \\
& puro & & reaçäo \\
\hline AHf amostra & 73 & 59.49 & 62.31 \\
\hline total de \% cristalina & 34.9 & 28.5 & 29.8 \\
\hline
\end{tabular}

Observa-se, por estes resultados, que a amostra produzida em extrusora sofreu uma queda acentuada em sua cristalinidade. Isto seria um indício de que a probabilidade de ocorrência de graftização tenha ocorrida com mais eficiência, porém foi necessário um cruzamento de análise somados aos ensaios de índice de fluidez e de Infravermelho que são mostrados a seguir, pois além de reação de graftização, ocorrem também inúmeras reações de quebra de cadeia, que contribuem para a queda de cristalinidade.

\subsubsection{Análise dos resultados Índice de fluidez (MFI - melt flow index)}

Com esta técnica, observou-se uma indicação se houve quebra de cadeia durante a graftização das amostras produzidas. A Figura 13 mostra os resultados deste ensaio nas condições de temperatura $230{ }^{\circ} \mathrm{C}$ com peso de 2,16 $\mathrm{kg}$ padronizados através da norma ISO 1133 . 


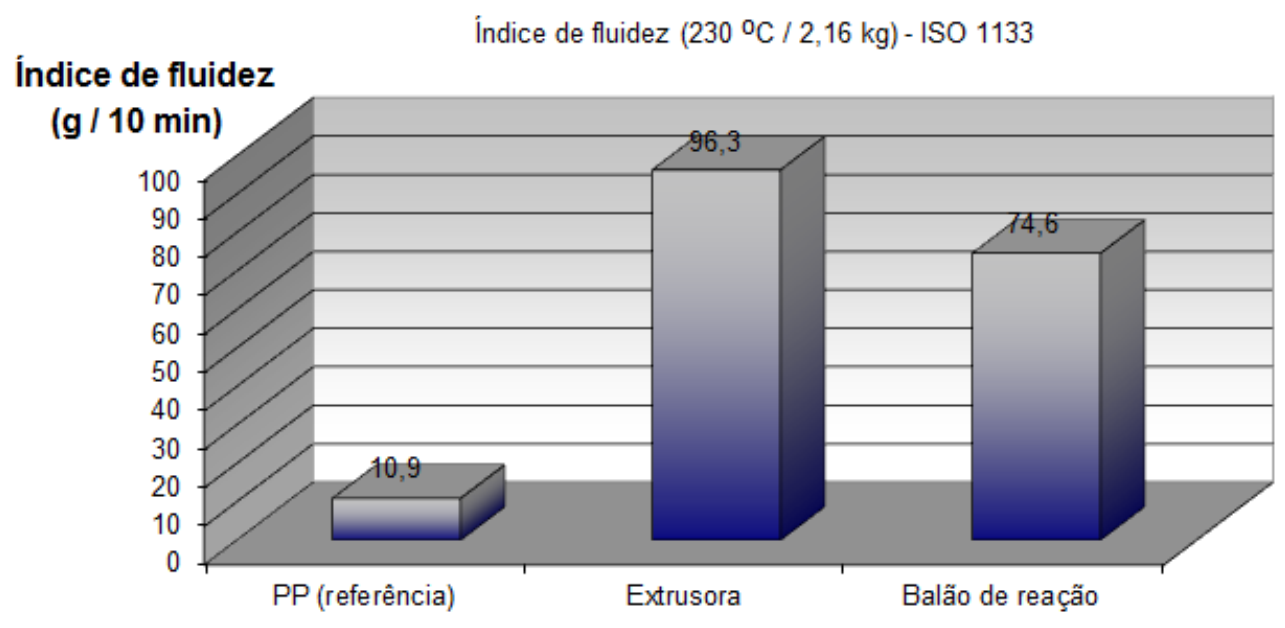

Figura 13: Resultados (em gramas por 10 minutos) de índice de fluidez (MFI - melt flow index) ISO 1133 $\left(230^{\circ} \mathrm{C} / 2,16 \mathrm{~kg}\right)$

Podemos concluir a partir desta análise que a amostra graftizada pelo método de extrusão reativa apresentou um grande aumento em seu índice de fluidez, que pode indicar a grande probabilidade da diminuição da sua massa molecular em função de reações de quebra de cadeia.

\subsubsection{Análise dos resultados de TGA (Análise termogravimétrica)}

É uma técnica de análise térmica muito empregada em polímeros, pois pode estudar uma grande faixa de temperatura usando vários programas de temperatura, utilizando-se amostras em qualquer forma física (sólida, líquida ou gel)

$\mathrm{Na}$ análise termogravimétrica (TGA), uma balança é usada para medir a perda de massa em função da temperatura. Aplicações típicas incluem a avaliação da estabilidade térmica e da temperatura de decomposição sob várias condições da cura de polímeros, de composições, além de algumas informações sobre distribuição de seqüência de copolímeros, da composição de polímeros carregados entre outros . 
No TGA, existe um grande número de fatores que afetam a natureza e a precisão dos resultados experimentais, sendo de natureza instrumental (taxa de aquecimento do forno, atmosfera do forno, geometria do porta-amostra e do forno, etc.) ou dependentes das características da amostra (quantidade, solubilidade dos gases envolvidos na amostra, tamanho da partícula, calor de reação, empacotamento da amostra, condutividade térmica, etc.). A análise termogravimétrica é usada para se caracterizar a decomposição e a estabilidade térmica dos materiais sob várias condições, e para analisar a cinética dos processos físico-químicos que ocorrem nas amostras. Para este trabalho, o TGA foi usado para analisar a estabilidade térmica das amostras graftizadas em comparação com o PP puro não graftizado.

O equipamento utilizado foi o analisador termogravimétrico do Departamento de Engenharia Metalúrgica e Materiais da Escola Politécnica da USP.

As análises de TGA foram realizadas a uma taxa constante de aquecimento com elevação de temperatura até $600 \stackrel{\circ}{\mathrm{C}}$.

Os resultados são mostrados na Tabela 6 e nas Figuras 14, 15 e 16.

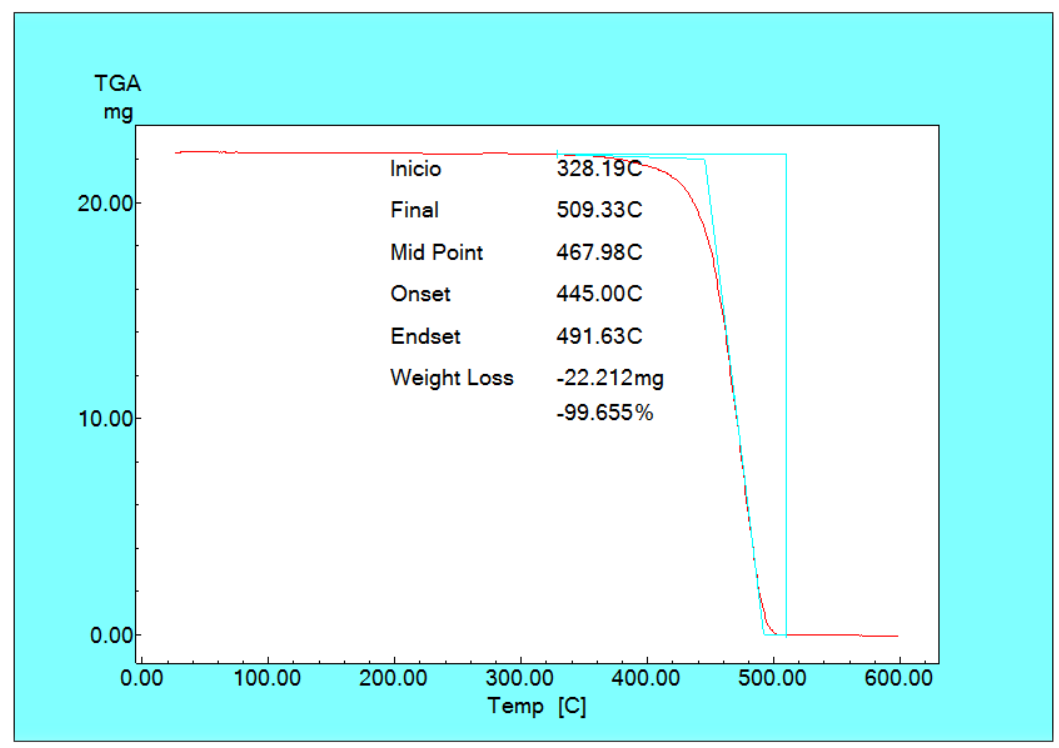

Figura 14: Curva termogravimétrica indicando a temperatura de degradação do PP Puro. 


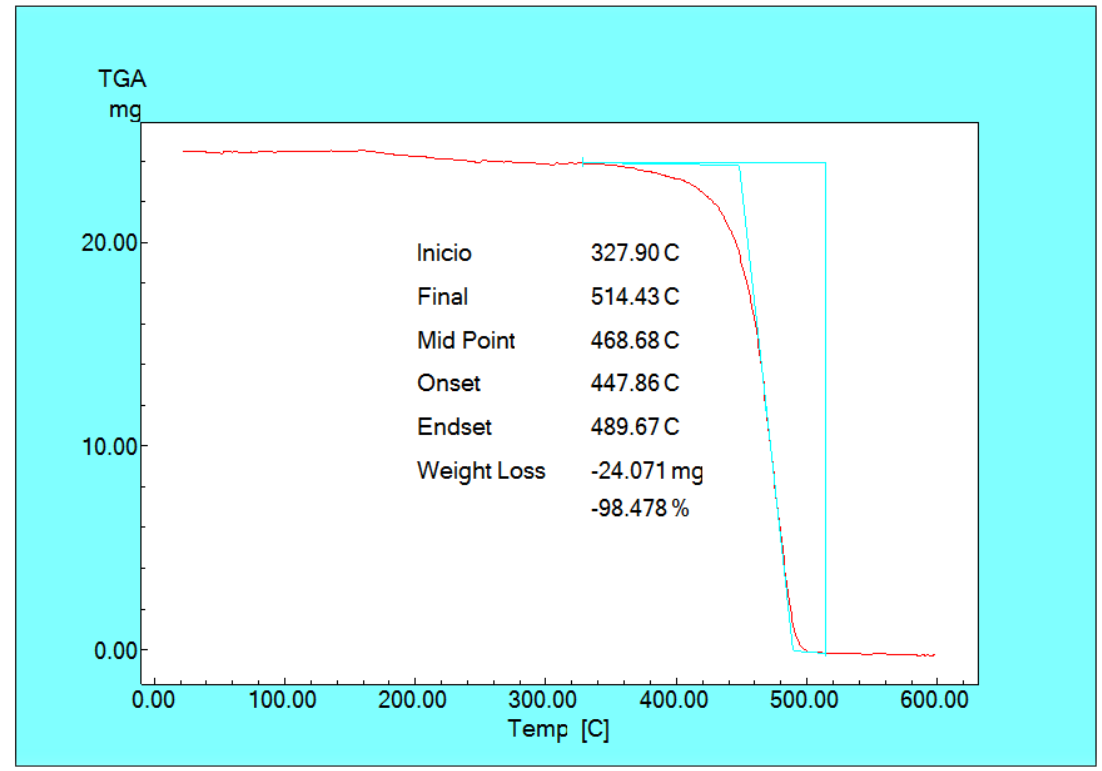

Figura 15: Curva termogravimétrica indicando a temperatura de degradação da amostra extrusada

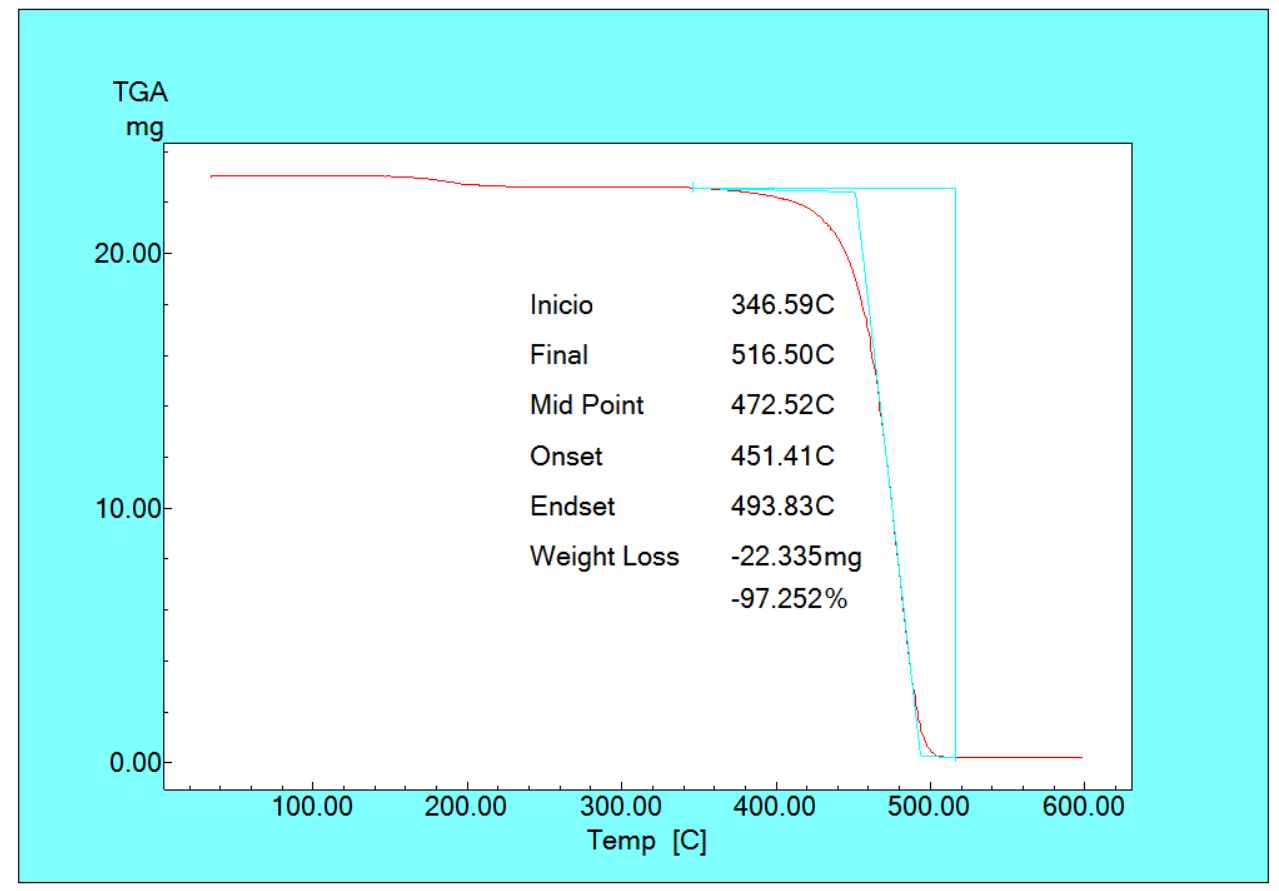

Figura 16: Curva termogravimétrica indicando a temperatura de degradação da amostra produzida pelo método do balão volumétrico 
Tabela 6: Resultados das temperaturas iniciais e finais de degradação das amostras analisadas

\begin{tabular}{|cccc|}
\hline & pp puro & Extrusão reativa & balão volumétrico \\
\hline início & 328,19 & 327,9 & 346,59 \\
\hline final & 509,33 & 514,43 & 516,5 \\
\hline
\end{tabular}

Com estes resultados observam-se dois pontos importantes. As três amostras analisadas tiveram apenas uma única etapa de degradação, indicando que não houve presença significativa de impurezas como água, solvente ou monômero residual. O outro ponto importante a ser analisado é a diferença de temperatura entre o início e o final (intervalo de reação). Quanto menor for essa diferença mais estável termicamente é o material, porém isso não ocorreu neste trabalho, pois todas as amostras apresentaram um intervalo próximo ao do PP puro não graftizado, indicando pouca alteração das estruturas químicas das amostras mesmo após o processo de graftização.

\subsubsection{Análise dos resultados de microscopia eletrônica de varredura (MEV ou SEM)}

Neste método de análise microscópica, um feixe de elétrons é focalizado na superfície da amostra e sua interação com o material analisado gera diversos tipos de sinais que são utilizados para a formação de imagens ou análise de composição.

Para os materiais poliméricos, esta é uma análise muito boa para investigação de miscibilidade de alguns tipos de blendas e polímeros carregados com cargas inorgânicas. Para o presente trabalho, esta análise também teve o caráter apenas de suporte para os outros ensaios.

Os resultados seguem compilados na Figura 17. 


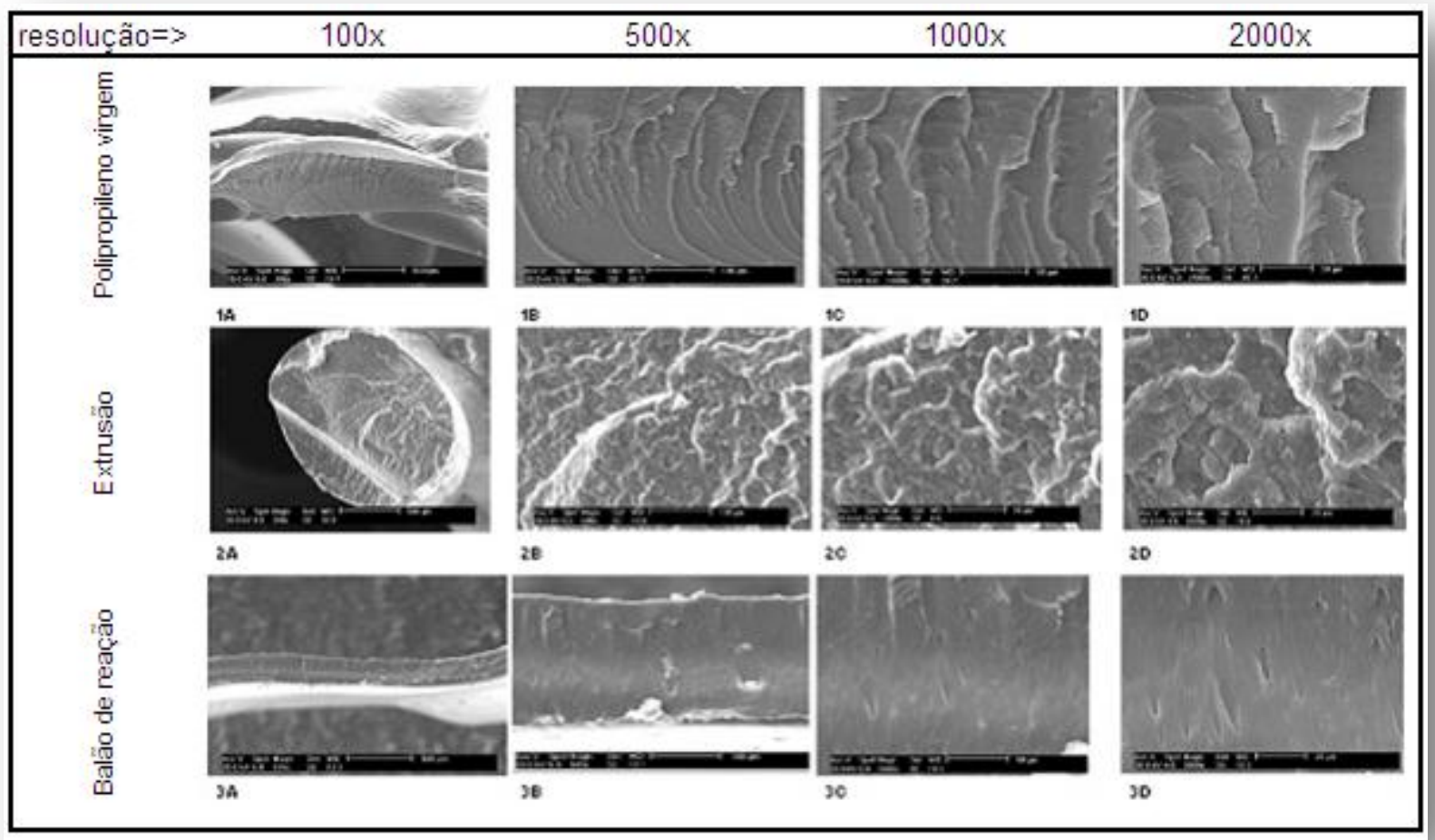

Figura 17: Micrografias de MEV do PP virgem e das amostras de PP graftizados com anidrido maléico.

As amostras distiguiram-se uma das outras apenas devido ao método com que cada amostra foi fraturada (Figura 17). Ou seja, a superfície do local a ser analisada é extremamente sensível ao manuseio e apesar do extremo cuidado tomado para a fratura criogênica (quebra após 2 horas em nitrogênio líquido) observamos estas diferenças. Outras informações diferentes e relevantes não foram identificadas por este método.

\subsubsection{Análise dos resultados de espectroscopia de energia dispersiva (EDS - Energy Dispersive Spectroscopy)}

Esta análise foi conclusiva para se comprovar a elevada presença de oxigênio na amostra extrusada (Figura 18) em comparação com as outras amostras, polipropileno virgem e após graftização em solução. 


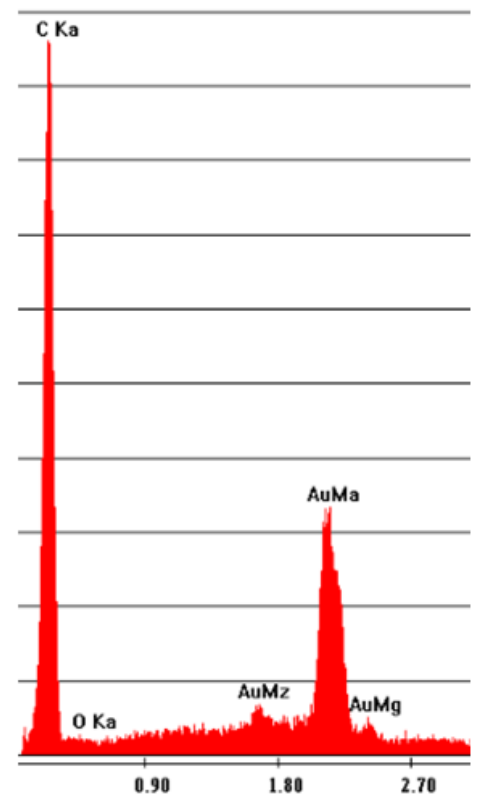

PP Puro

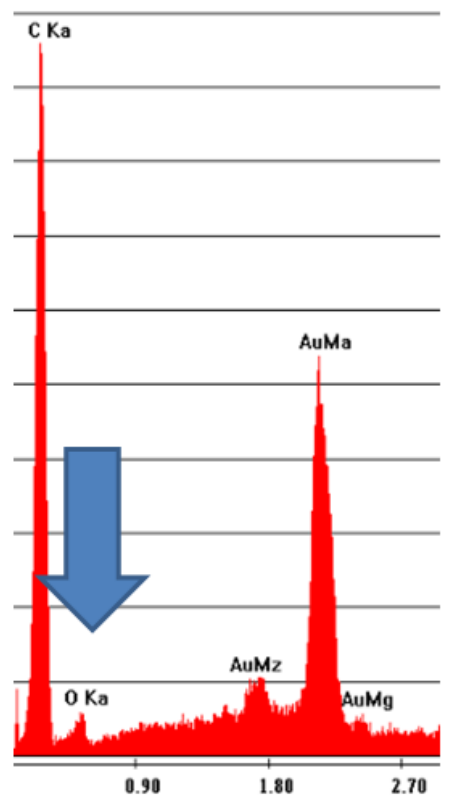

Extrusora

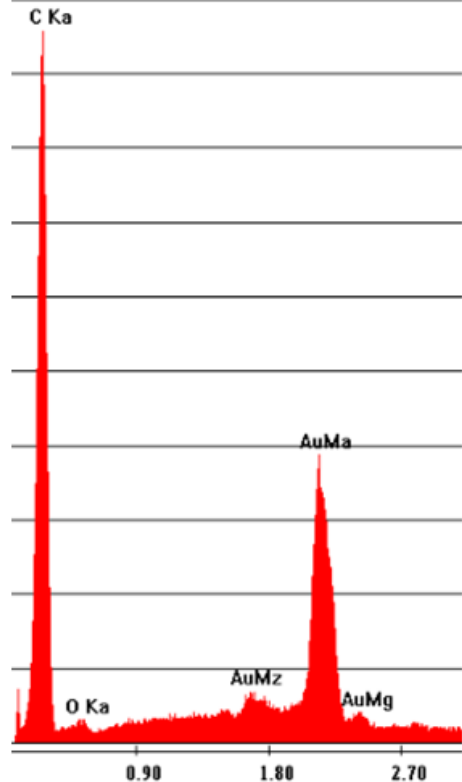

Balão de Reação

Figura 18: Resultados de EDS do PP puro e das amostras graftizadas com anidrido maléico.

Este resultado condiz com os resultados de IR, MFI, Raio-x e DSC. Existindo; portanto, um direcionamento de que houve reações indesejadas para a amostra obtida por extrusão reativa.

\subsubsection{Análise dos resultados de espectroscopia no Infravermelho (FTIR)}

Os resultados obtidos por espectroscopia no infravermelho (FTIR) foram analisados após a obtenção de uma curva de calibração.

Conforme já descrito anteriormente, foram preparadas algumas amostras com percentuais definidos de anidrido maleico graftizado. A preparação foi feita misturando-se o polipropileno HP 500 N com o Polibond 3200, que é um PP-g-MA comercial com 1,0\% de anidrido maléico graftizado. Isso foi necessário, pois o Polibond 3200 é o produto de referência no mercado com proporção de $1 \%$ em todos os lotes recebidos. Segundo o fabricante, este material tem um processo de fabricação altamente estável e controlado, fazendo com que esta proporção varie apenas na segunda casa decimal, o que o torna bastante relevante para a montagem da curva de calibração deste trabalho. 
Além disso, este grade em específico da empresa fabricante (Chemtura) é o que contém o maior teor de graftização, fato que explica a escolha do produto.

As amostras consistiram em misturas destas duas matérias primas para geração das respectivas proporções padronizadas de percentual graftizado: $0,20 \%, 0,25 \%, 0,30 \%, 0,35 \%, 0,40 \%$, $0,45 \%, 0,50 \%, 0,55 \%, 0,60 \%, 0,65 \%, 0,70 \%, 0,75 \%, 0,80 \%$ e $1,0 \%$. Esta faixa de concentração foi escolhida com o intuito de aproximar ao máximo à faixa provável que seria encontrada nas amostras graftizadas neste trabalho. Estas amostras foram submetidas a uma mistura controlada em um homogeneizador laboratorial tipo "banbury-drays" com parâmetros de 1800 rpm, $220{ }^{\circ} \mathrm{C}$ e, logo em seguida, utilizou-se uma prensa hidráulica com temperatura padronizada de placas de $165{ }^{\circ} \mathrm{C}$. Tomou-se o cuidado para que esta etapa de prensagem não ultrapassasse 30 segundos para não haver deterioração das amostras. A célula de espessura utilizada foi padronizada para que os filmes tivessem espessuras de 0,3 mm. Por fim, cada um desses filmes foram medidos criteriosamente para que tivessem a mesma espessura, dessa forma estes filmes foram analisados por infravermelho para a geração da curva de calibração. Os resultados são mostrados nas Figuras 19, 20 e 21 .

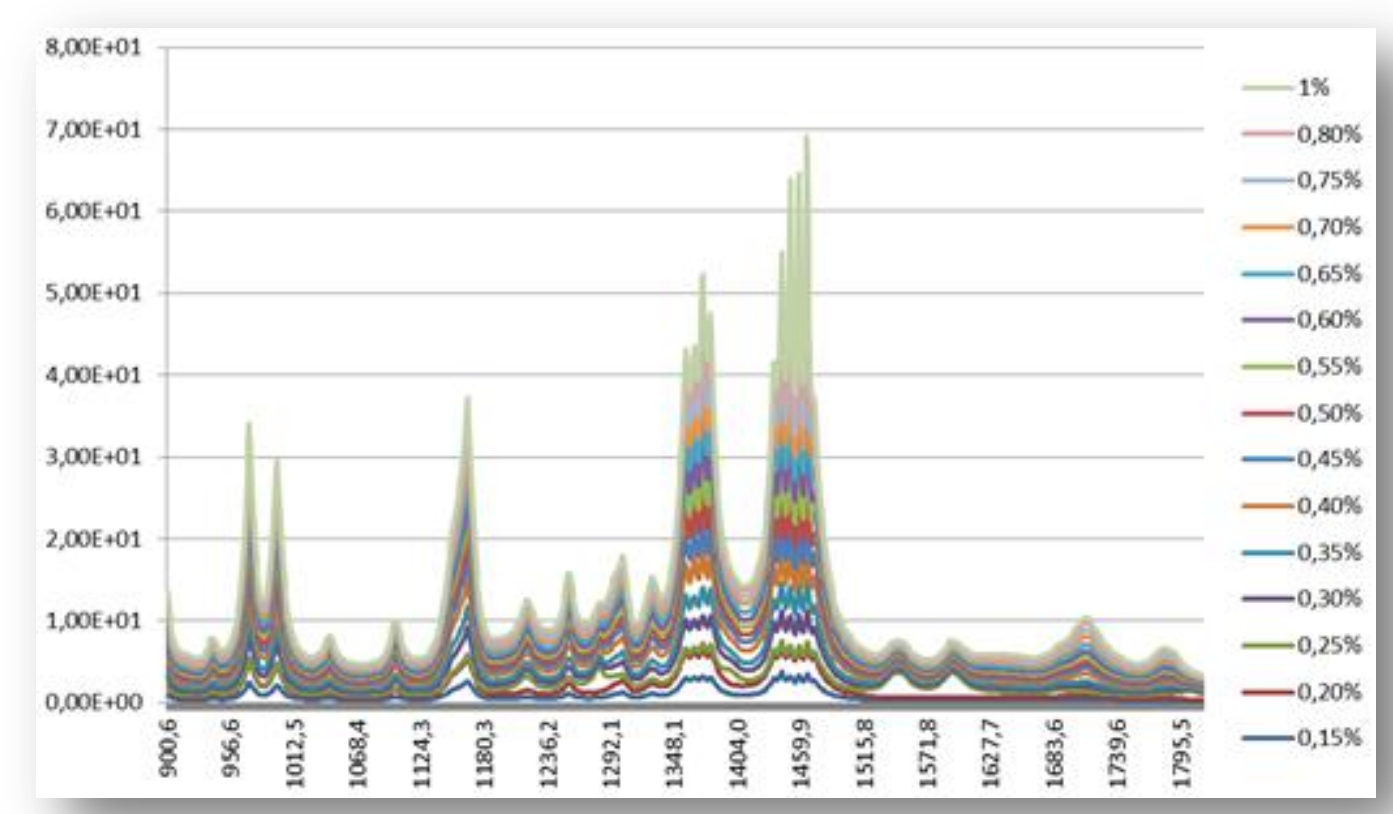

Figura 19: Resultados de espectroscopia no infravermelho das amostras com proporções definidas de 0,20\%, $0,25 \%, 0,30 \%, 0,35 \%, 0,40 \%, 0,45 \%, 0,50 \%, 0,55 \%, 0,60 \%, 0,65 \%, 0,70 \%, 0,75 \%, 0,80 \%$ e $1,0 \%$ de graftização para obtenção da curva de calibração. 


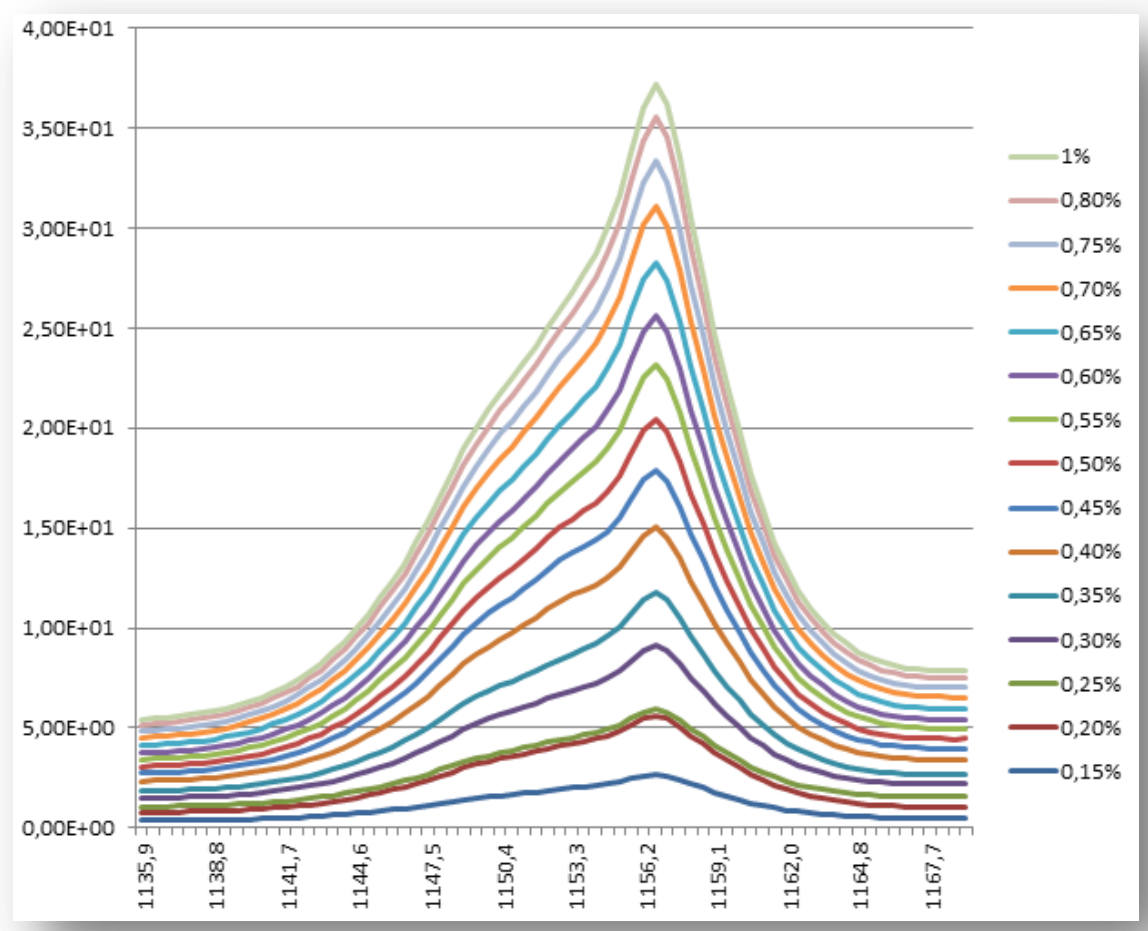

Figura 20: Resultados de espectroscopia no infravermelho (próximo ao pico $1156 \mathrm{~cm}^{-1}$ ) das amostras com proporções definidas de $0,20 \%, 0,25 \%, 0,30 \%, 0,35 \%, 0,40 \%, 0,45 \%, 0,50 \%, 0,55 \%, 0,60 \%, 0,65 \%, 0,70 \%$, 0,75\%, 0,80\% e 1,0\% de graftização para obtenção da curva de calibração. 


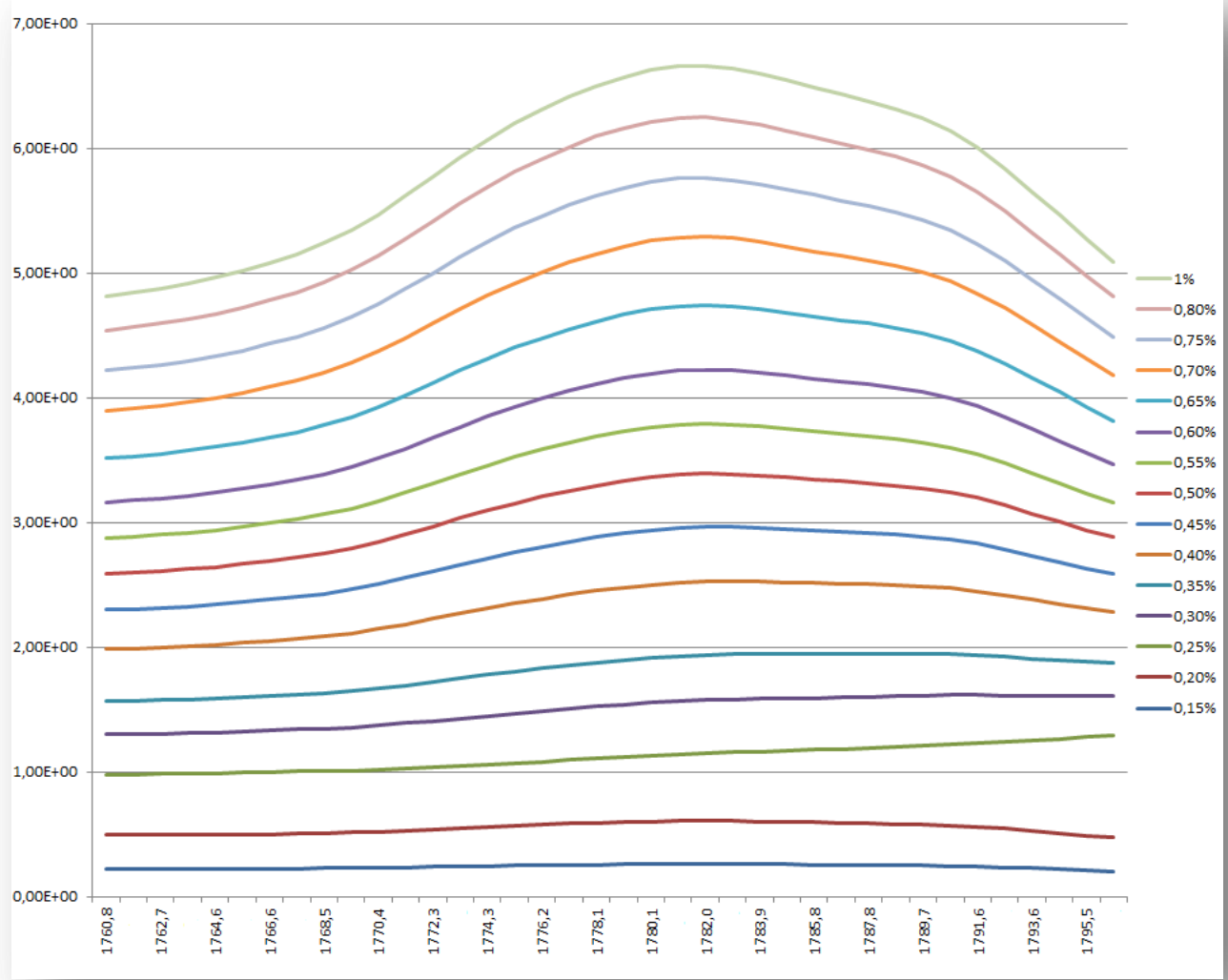

Figura 21: Resultados de espectroscopia no infravermelho (próximo ao pico $1785 \mathrm{~cm}^{-1}$ ) das amostras com proporções definidas de 0,20\%, 0,25\%, 0,30\%, 0,35\%, 0,40\%, 0,45\%, 0,50\%, 0,55\%, 0,60\%, 0,65\%, 0,70\%, $0,75 \%, 0,80 \%$ e $1,0 \%$ de graftização para obtenção da curva de calibração.

A partir destes resultados foi utilizado uma equação empírica (Equação 3) para se calcular o o grau de incorporação (I) do anidrido maléico ao PP. Esta equação permite calcular o percentual de anidrido maléico através da razão entre as áreas dos picos $1785 \mathrm{~cm}^{-1}$ (Aa), característica de absorbância do grupamento carbonila do anidrido, e $1156 \mathrm{~cm}^{-1}(\mathrm{Ab})$, utilizada como banda de referência do PP [29] e [41-43].

A curva de calibração construída é mostrada na Figura 22. Para isso foi relacionado o percentual da graftização de cada amostra com o grau de incorporação (I) de anidrido maléico ao PP. 


$$
I(g \%)=1,677 \times(A a / A b)
$$

Equação 3: Cálculo para obtenção do grau de incorporação em massa do anidrido maléico ao PP.

Onde:

I $(g \%)=$ grau de incorporação em massa de MA ao PP;

Aa = área do pico de absorção a $1785 \mathrm{~cm}^{-1} \mathrm{e}$

$\mathrm{Ab}=$ área do pico de absorção a $1156 \mathrm{~cm}^{-1}$

Figura 22: Gráfico da curva de calibração para: I(g\%) x percentual de graftização.

\section{Curva de calibração para: I(g\%) x percentual de graftização}

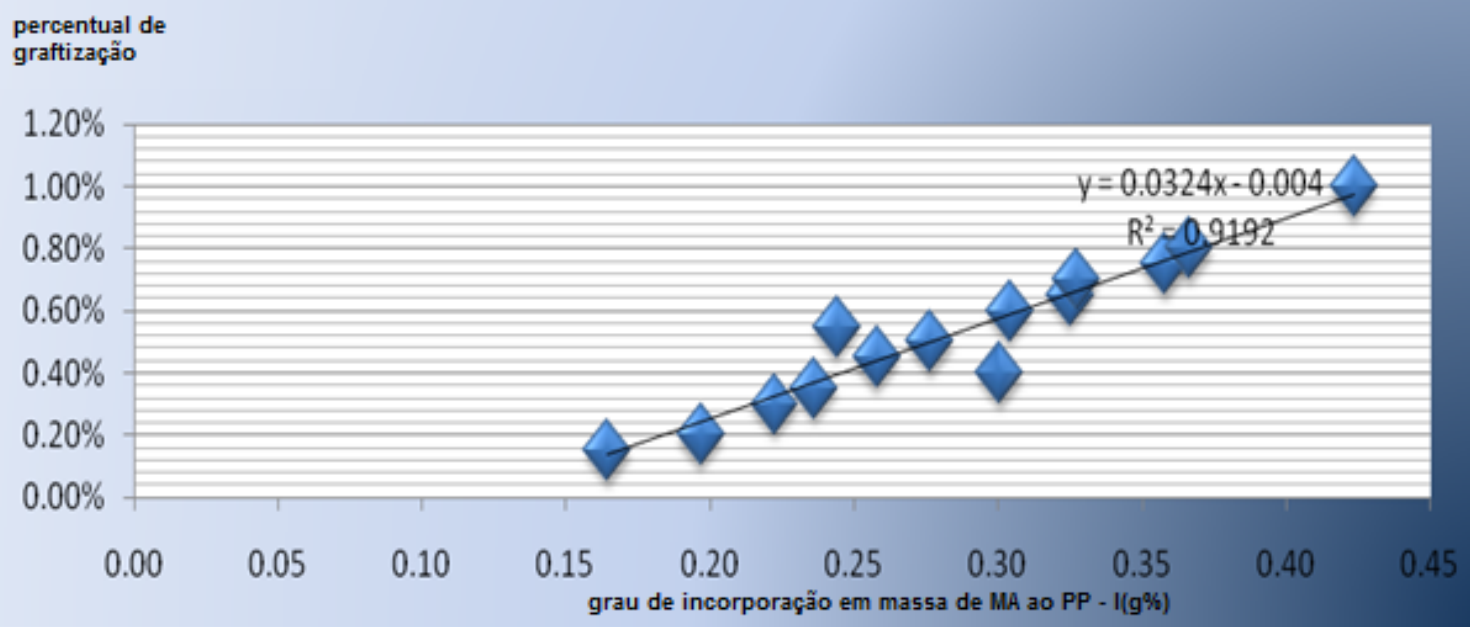

As informações utilizadas para os cálculos estão compiladas na Tabela 7. 


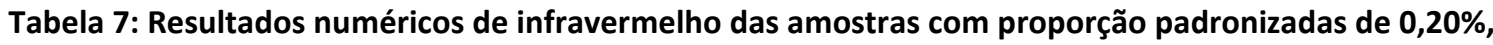
$0,25 \%, 0,30 \%, 0,35 \%, 0,40 \%, 0,45 \%, 0,50 \%, 0,55 \%, 0,60 \%, 0,65 \%, 0,70 \%, 0,75 \%, 0,80 \%$ e 1,0\% de graftização para obtenção da curva de calibração

\begin{tabular}{|c|c|c|c|c|}
\hline & Aa (área do pico $1785 \mathrm{~cm}-1$ ) & Ab (área do pico $1156 \mathrm{~cm}-1$ ) & $\mathrm{I}(\mathrm{g} \%)$ & percentual de graftização \\
\hline & 0,2618833 & 2,670234 & 0,16 & $0,15 \%$ \\
\hline & 0,3450741 & 2,941518 & 0,20 & $0,20 \%$ \\
\hline & 0,4278847 & 3,223041 & 0,22 & $0,30 \%$ \\
\hline & 0,3622383 & 2,571409 & 0,24 & $0,35 \%$ \\
\hline & 0,5886427 & 3,286011 & 0,30 & $0,40 \%$ \\
\hline & 0,4391611 & 2,858737 & 0,26 & $0,45 \%$ \\
\hline & 0,4260888 & 2,585295 & 0,28 & $0,50 \%$ \\
\hline & 0,3980792 & 2,735823 & 0,24 & $0,55 \%$ \\
\hline & 0,4383422 & 2,40786 & 0,30 & $0,60 \%$ \\
\hline & 0,5171305 & 2,670113 & 0,32 & $0,65 \%$ \\
\hline & 0,5500387 & 2,821053 & 0,33 & $0,70 \%$ \\
\hline & 0,4737404 & 2,219232 & 0,36 & $0,75 \%$ \\
\hline & 0,4843384 & 2,216989 & 0,37 & $0,80 \%$ \\
\hline & 0,4140243 & 1,639422 & 0,42 & $1,00 \%$ \\
\hline balão de reação & 0,3516299 & 0,8400518 & 0,70 & $1,86 \%$ de graftiz ação (calculado) \\
\hline extrus ora & 0,136198 & 0,8883111 & 0,28 & $0,44 \%$ de graftiz aç:ão (calculado) \\
\hline
\end{tabular}

Os valores de I(g\%) das amostras "extrusora" e "balão de reação" foram obtidos por FTIR e a porcentagem de anidrido maléico graftizado foi determinada através da equação da reta calculada pela curva de calibração.

Observou-se que a amostra de PP graftizado pelo método da extrusão reativa apresentou menor incorporação de anidrido maléico em comparação com o produto de reação em balão 0,44\% e 1,86\%, respectivamente, conforme a Tabela 7. A partir deste resultado, especula-se a possibilidade da amostra produzida por extrusão ter sofrido reações secundária, principalmente de quebra de cadeia, visto que se obteve um polímero com maior índice de fluidez (MFI) e menor grau de cristalinidade de acordo com os resultados de DSC. 


\subsection{Comparação entre os dois métodos de graftização}

Nesta parte do trabalho, onde se objetivou a comparação entre dois métodos de graftização, foi possível verificar que a graftização feita em solução em balão de reação foi mais eficaz, comprovado, principalmente, pelos resultados gerados por espectroscopia no infravermelho. Acredita-se que este resultado é devido ao uso de atmosfera de nitrogênio durante toda a reação. Dessa forma, o processo tornou-se mais direcionado e efetivo para a graftização, confirmado também pelos resultados de EDS. A grande desvantagem deste método é a dificuldade de purificação, incluindo longos tempos de extração, adicionalmente, a viscosidade e a baixa solubilidade do polipropileno dificultaram a formação de solução homogênea do fundido. A grande vantagem da extrusão reativa é a sua facilidade de execução, incluindo rapidez e pouca preparação prévia. No entanto, o método é extremamente sensível ao controle da alimentação de matéria prima no funil de alimentação. Além disso, há uma maior probabilidade de ocorrência de reações indesejadas, principalmente de quebra de cadeia, observada pelas análises conjuntas de MFI e DSC.

Neste estágio do trabalho, foi feita uma análise detalhada dos resultados obtidos visando uma produção em maior escala do polipropileno graftizado. O produto obtido por reação em balão apresentou boa qualidade com índice de graftização maior que o esperado, porém a quantidade produzida é baixa e o tempo envolvido longo. Estas desvantagens poderiam comprometer o prazo para finalização desta pesquisa. Com relação ao método da extrusão reativa, a facilidade e a rapidez de obtenção comparadas com o outro método são pontos positivos, entretanto a porcentagem de graftização baixa e as reações secundárias durante o processo são difíceis de seram contornadas. Com estes resultados, optou-se pela utilização do produto já comercializado pela Chemtura. Foi escolhido o Polibond 3200, que é um produto com homogeneidade alta, o que auxiliou a obtenção das amostras produzidas na próxima etapa, sem que houvesse problemas com esta variável. 


\section{PARTE EXPERIMENTAL 2 (enfoque para as amostras dos compósitos produzidos com $\mathrm{CaCO}_{3}$ )}

O trabalho foi direcionado a partir deste ponto para a análise dos compósitos de PP fazendo uma inserção dos diferentes $\mathrm{CaCO}_{3}$ já citados na Tabela 3 utilizando os equipamentos citados na Tabela 4.

É importante ressaltar que, neste momento do trabalho, foi decidido utilizar o Polibond 3200 (PP-g-MA industrializado da Chemtura) ao invés de produzí-lo em escala laboratorial. Devido a diversos fatores já discutidos anteriormente em "Comparação dos dois métodos de graftização".

O procedimento de produção, bem como, as análises comparativas entre as amostras são mostradas a seguir. De um modo geral, estas análises contemplam os seguintes itens: $\boldsymbol{a}$. propriedades mecânicas, $\boldsymbol{b}$. influência da incorporação do PP-g-MA nos compósitos, $\boldsymbol{c}$. influência do tamanho de partícula dos $\mathrm{CaCO}_{3}$ introduzidos, $\boldsymbol{d}$. influência da adesão superficial entre esta carga $\left(\mathrm{CaCO}_{3}\right)$ e a matriz de PP e e. a formação da fase cristalina beta do PP. 


\subsection{Preparação das amostras de compósitos com $\mathrm{CaCO}_{3}$}

Para a preparação das amostras de polipropileno com melhor incorporação do $\mathrm{CaCO}_{3}$ foi necessário, primeiramente, produzir masterbatchs de $\mathrm{PP}+\mathrm{CaCO}_{3}$ na proporção 1:1 e também Polibond $3200+\mathrm{CaCO}_{3}$, também na proporção de 1:1. Foi utilizado um homogeneizador laboratorial tipo "banbury-drays" onde o material é incorporado por batelada. Os parâmetros de processo utilizado foram: velocidade de $1800 \mathrm{rpm}$ e temperatura de $220{ }^{\circ} \mathrm{C}$.

Dessa forma, foram produzidos os seguintes masterbatchs, conforme vemos na Tabela 8.

Tabela 8: Masterbatchs para produção das amostras

\begin{tabular}{|c|c|}
\hline NOME & DESCRIÇÃO \\
\hline MB PPT & $50 \%$ Mickhart 08T + 50\% PP \\
\hline MB PP8 & $50 \%$ Mickhart 08 + 50\% PP \\
\hline MB PPC & $50 \%$ Mickhart C + 50\% PP \\
\hline MB PP2 & $50 \%$ Mickhart 2 + 50\% PP \\
\hline MB MAT & $50 \%$ Mickhart 08T + 50\% Polibond 3200 \\
\hline MB MA8 & $50 \%$ Mickhart 08 + 50\% Polibond 3200 \\
\hline MB MAC & $50 \%$ Mickhart C + 50\% Polibond 3200 \\
\hline MB MA2 & $50 \%$ Mickhart 2 + 50\% Polibond 3200 \\
\hline
\end{tabular}

Estes masterbatchs foram misturados e injetados com Polipropileno HP 500N para que o teor de $\mathrm{CaCO}_{3}$ ficasse na proporção de $5 \%$ no final. A Tabela 9 mostra as misturas que foram produzidas por injeção das misturas na proporção de $90 \% \mathrm{PP}+10 \% \mathrm{MB}$. 
Tabela 9: Descrição dos compósitos de $\mathrm{CaCO}_{3}$ e seus respectivos percentuais finais

\begin{tabular}{|c|c|}
\hline NOME & DESCRIÇÃO \\
\hline PP & Polipropileno (referência) \\
\hline PPT & $95 \%$ PP $+5 \%$ Mickhart 08T \\
\hline PP8 & $95 \%$ PP $+5 \%$ Mickhart 08 \\
\hline PPC & $95 \%$ PP $+5 \%$ Mickhart C \\
\hline PP2 & $95 \%$ PP $+5 \%$ Mickhart 2 \\
\hline MAT & $90 \%$ PP $+5 \%$ Mickhart 08T + 5\% PP-g-MA \\
\hline MA8 & $90 \%$ PP $+5 \%$ Mickhart 08 + 5\% PP-g-MA \\
\hline MAC & $90 \%$ PP + 5\% Mickhart C + 5\% PP-g-MA \\
\hline MA2 & $90 \%$ PP + 5\% Mickhart $2+5 \%$ PP-g-MA \\
\hline
\end{tabular}

A injeção dos corpos de prova a partir da mistura acima foi feita em uma máquina Battenfeld FB 1400/450 com os parâmetros descritos na Tabela 10 previamente avaliados em escala industrial como a melhor condição para este tipo de compósito.

Tabela 10: Parâmetros de injeção utilizados para preparação dos corpos de prova

\begin{tabular}{|c|c|}
\hline Parâmetro de injeção & Valor \\
\hline Temperatura de injeção & $230{ }^{\circ} \mathrm{C}$ \\
\hline Temperatura do molde & $60{ }^{\circ} \mathrm{C}$ \\
\hline Temperatura das zonas de aquecimento & $190 / 200 / 210 / 220^{\circ} \mathrm{C}$ \\
\hline Pressão de injeção & 400 psi \\
\hline Tempo de injeção & 16 segundos \\
\hline Tempo de resfriamento & 30 segundos \\
\hline
\end{tabular}




\section{RESULTADOS E DISCUSSÕES 2 (enfoque para as amostras dos compósitos produzidos com $\mathrm{CaCO}_{3}$ )}

\subsection{Análise das propriedades mecânicas}

Nesta parte do trabalho a análise iniciou-se com a comparação das propriedades mecânicas entre as amostras produzidas de PP $+\mathrm{CaCO}_{3}+$ PP-g-MA citadas na Tabela 9 (PP, PPT, PP8, PPC, PP2, MAT, MA8, MAC e MA2). As propriedades analisadas (resistência à tração, módulo na flexão e resistência ao impacto com entalhe) foram compiladas na Tabela 11. Os equipamentos utilizados foram: a. um equipamento Instron de modelo $5566 \mathrm{com}$ célula de carga $10 \mathrm{kN}$ e $\boldsymbol{b}$. um aparelho de impacto Ceast de modelo Resil impactor 6967.

Tabela 11: Resultados compilados das propriedades mecânicas: $\sigma$ (resistência à tração), E (módulo na flexão), e resistência ao Impacto Izod (a $23^{\circ} \mathrm{C}$ e $\left.-40^{\circ} \mathrm{C}\right)$.

\begin{tabular}{|c|c|c|c|c|}
\hline Amostra & $\begin{array}{c}\boldsymbol{\sigma} \\
(\mathrm{MPa})\end{array}$ & $\begin{array}{c}\mathbf{E} \\
(\mathrm{MPa})\end{array}$ & $\begin{array}{c}\text { Izod a } 23^{\circ} \mathrm{C} \\
(\mathrm{J} / \mathrm{m})\end{array}$ & $\begin{array}{c}\text { Izod a }-40^{\circ} \mathrm{C} \\
(\mathrm{J} / \mathrm{m})\end{array}$ \\
\hline PP & $31,4 \pm 0,12$ & $1282 \pm 63$ & $38,7 \pm 0,17$ & $22,6 \pm 0,11$ \\
\hline PPT & $31,7 \pm 0,14$ & $1383 \pm 62$ & $35,6 \pm 0,18$ & $22,3 \pm 0,12$ \\
\hline PP8 & $31,5 \pm 0,15$ & $1303 \pm 65$ & $35,3 \pm 0,16$ & $22,3 \pm 0,11$ \\
\hline PPC & $31,5 \pm 0,12$ & $1306 \pm 62$ & $35,1 \pm 0,16$ & $22,2 \pm 0,11$ \\
\hline PP2 & $31,6 \pm 0,11$ & $1312 \pm 67$ & $35,0 \pm 0,17$ & $21,9 \pm 0,09$ \\
\hline MAT & $34,9 \pm 0,15$ & $1884 \pm 82$ & $43,6 \pm 0,19$ & $23,9 \pm 0,11$ \\
\hline MA8 & $34,7 \pm 0,16$ & $1771 \pm 83$ & $43,1 \pm 0,18$ & $23,4 \pm 0,12$ \\
\hline MAC & $34,4 \pm 0,15$ & $1719 \pm 85$ & $42,8 \pm 0,19$ & $23,1 \pm 0,11$ \\
\hline MA2 & $32,9 \pm 0,16$ & $1578 \pm 81$ & $39,7 \pm 0,18$ & $22,8 \pm 0,12$ \\
\hline
\end{tabular}

$\sigma=$ resistência à tração (tensão de escoamento) a $23^{\circ} \mathrm{C}$ norma ISO $527-2$ - velocidade $50 \mathrm{~mm} / \mathrm{min}$; $\mathrm{E}=$ Módulo na flexão a $23{ }^{\circ} \mathrm{C}$ norma ISO 178 - velocidade $2 \mathrm{~mm} / \mathrm{min} ;$ Izod a $23{ }^{\circ} \mathrm{C}=$ resistência ao impacto com entalhe a $23^{\circ} \mathrm{C}$ norma ISO $180 / 4 \mathrm{~A}$; Izod a $-40{ }^{\circ} \mathrm{C}=$ resistência ao impacto com entalhe a $-40^{\circ} \mathrm{C}$ norma ISO $180 / 4 \mathrm{~A}$. 
Devido à complexidade de análises que podem ser geradas a partir da Tabela 11, foi dividido o estudo por cada ensaio que seguem a seguir.

\subsubsection{Análise dos resultados de resistência à tração}

$\mathrm{Na}$ Figura 23, são apresentados os resultados de resistência à tração obtida para todos os compósitos produzidos.

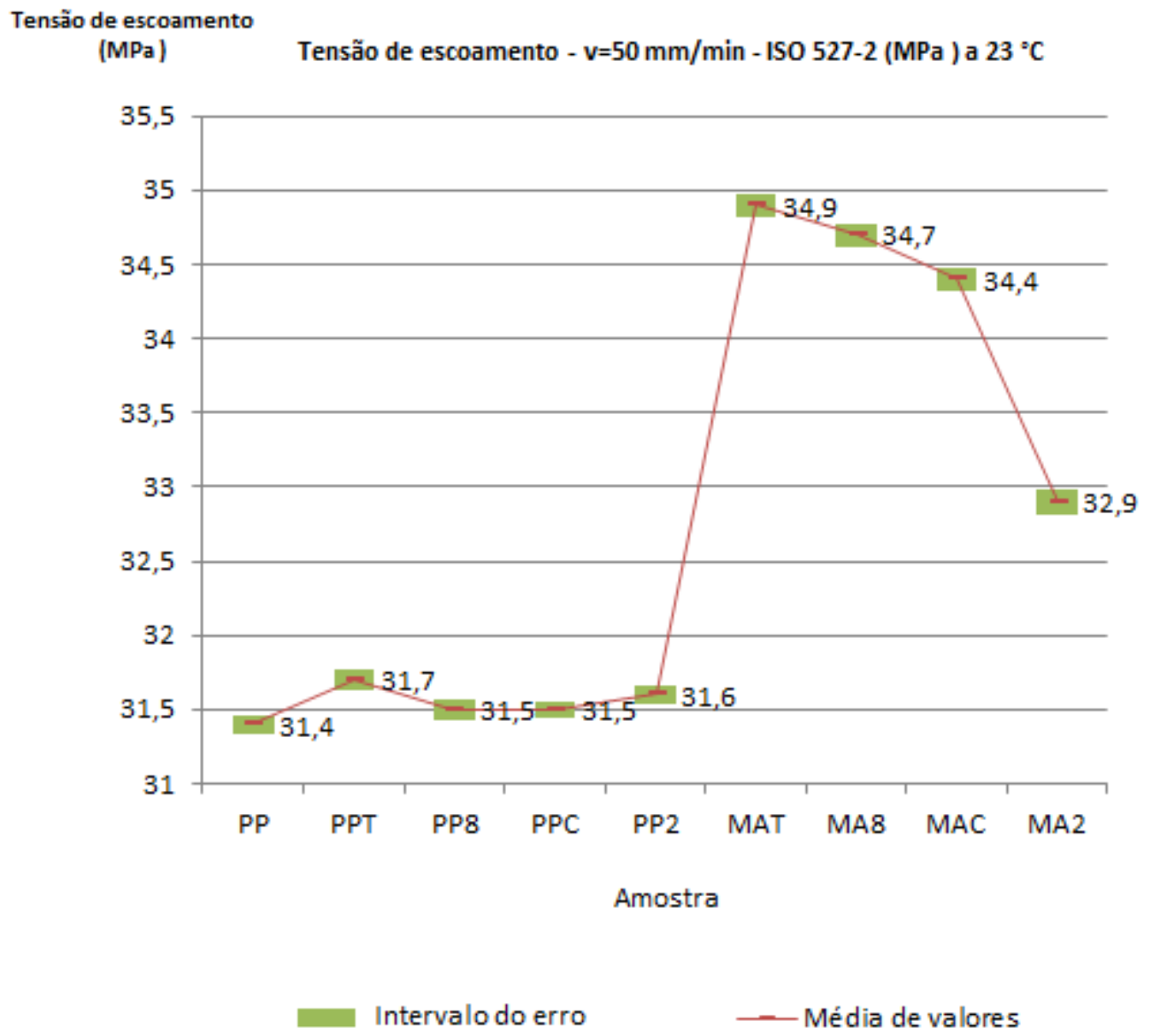

Figura 23: Gráfico dos resultados de resistência à tração das amostras dos compósitos de $\mathrm{PP}+\mathrm{CaCO}_{3}$. 
Nota-se que existe uma grande variação entre as amostras produzidas com e sem PP-g-MA. Portanto, observa-se pelas Figuras 24 e 25 os gráficos comparativos destas amostras separadas em grupos distintos para uma melhor visualização.

Tensão de escoamento - $\mathbf{v}=50 \mathrm{~mm} / \mathrm{min}$ - ISO $527-2$ (MPa) a $23{ }^{\circ} \mathrm{C}$

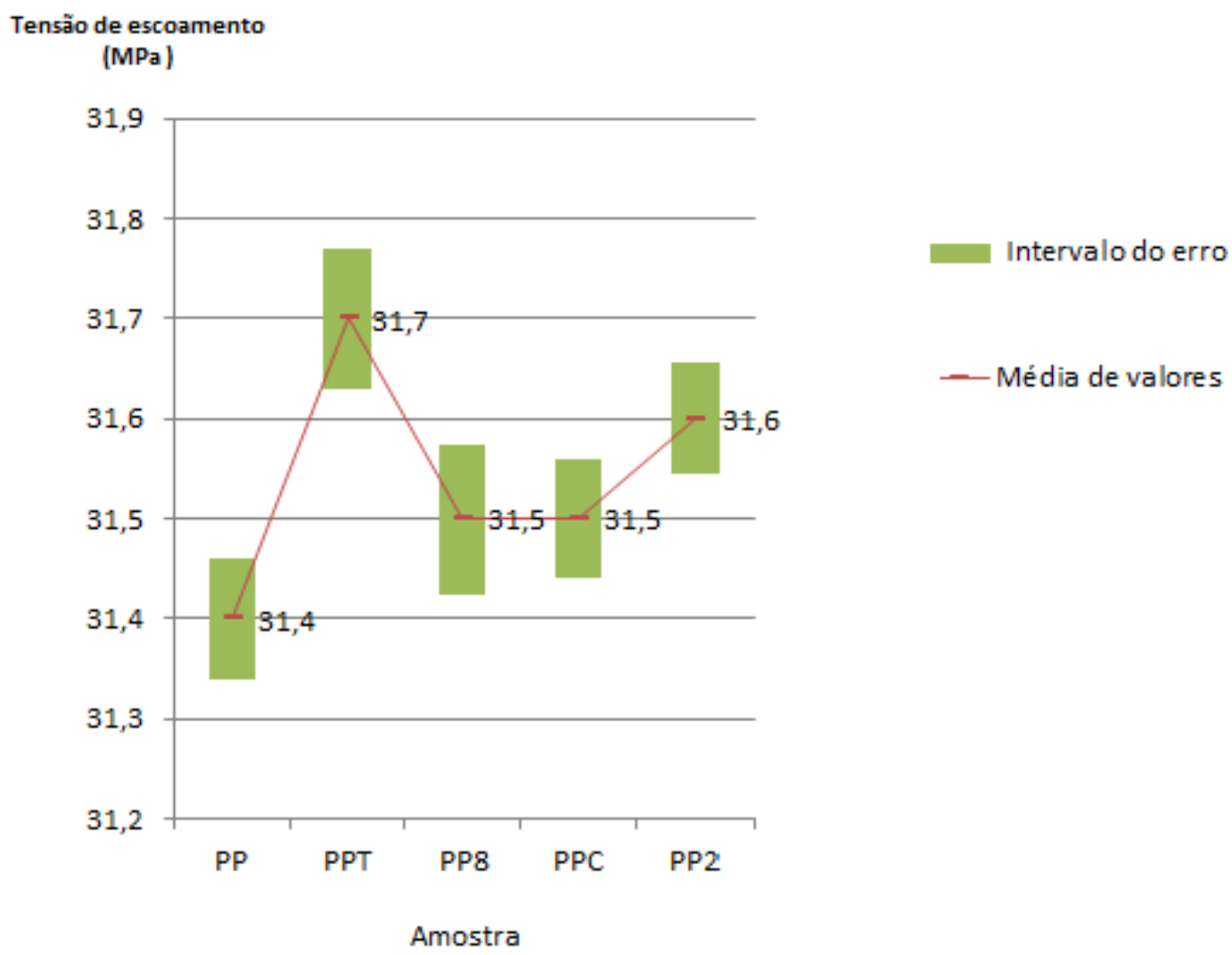

Figura 24: Gráfico dos resultados de resistência à tração comparativa das amostras produzidas com PP + $\mathrm{CaCO}_{3}(\mathrm{PP}=\mathrm{PP}$ Puro, $\mathrm{PPT}=\mathrm{PP}+5 \%$ Mickhart 8T, PP8 $=$ PP + 5\% Mickhart 08, PP2 $=$ PP + 5\% Mickhart 2, PPC $=P P+5 \%$ Mickhart $\mathrm{C})$. 


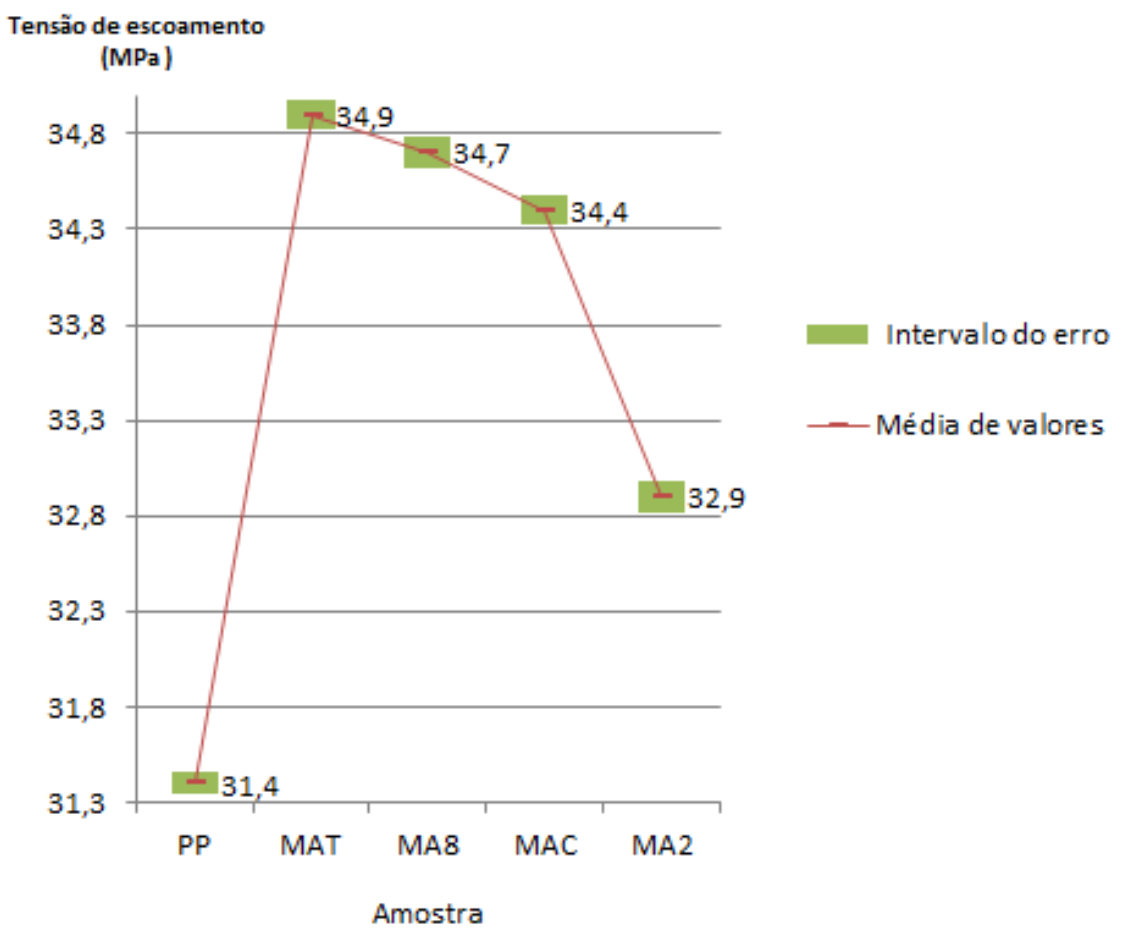

Figura 25: Gráfico dos resultados de resistência à tração das amostras de PP + 5\% $\mathrm{CaCO}_{3}+5 \%$ PP-g-MA.

Observa-se pela Figura 24 que não há diferenças significativas dos resultados de resistência à tração entre as amostras produzidas sem anidrido maléico. O maior valor (31,7 MPa) que é encontrado para a amostra PPT (PP + 5\% Mickhart 08T+5\% PP-g-MA) é de apenas de 1,59\% superior ao PP puro $(31,4 \mathrm{MPa})$. Isto se deve principalmente a quantidade pequena utilizada de $\mathrm{CaCO}_{3}(5 \%)$, ou seja, para as amostras produzidas sem PP-g-MA, a quantidade de carga utilizada não foi suficiente para melhorar esta propriedade.

Por outro lado, as amostras produzidas com anidrido maléico graftizado (Figura 25) tiveram suas propriedades de resistência à tração bastante melhoradas em comparação com o PP virgem. Resultado que mostra a importância da utilização do PP-g-MA para que haja melhora significativa na propriedade de resistência à tração destas amostras.

Estes gráficos mostraram uma grande diferença de resultados com a utilização do PP-g-MA. Desta forma, observa-se pelas Figuras 26 a 29 os resultados gráficos comparativos dos respectivos 
pares de compósitos produzidos com e sem PP-g-MA. Ou seja, PPT versus MAT, PP8 versus MA8, PP2 versus MA2 e PPC versus MAC.

Tensão de escoamento - v=50 mm/min - ISO 527-2 (MPa ) a $23{ }^{\circ} \mathrm{C}$

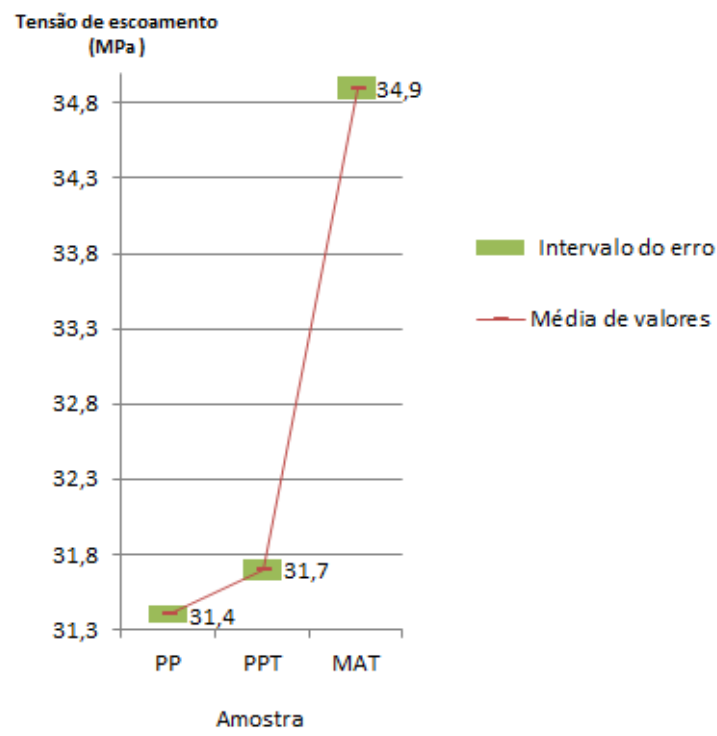

Figura 26: Gráfico dos resultados de resistência à tração (tensão de escoamento) comparativa das amostras produzidas com PP $+\mathrm{CaCO}_{3}$ Mickhart 08T.

Tensão de escoamento - $\mathrm{v}=50 \mathrm{~mm} / \mathrm{min}$ - ISO $527-2$ (MPa ) a $23{ }^{\circ} \mathrm{C}$

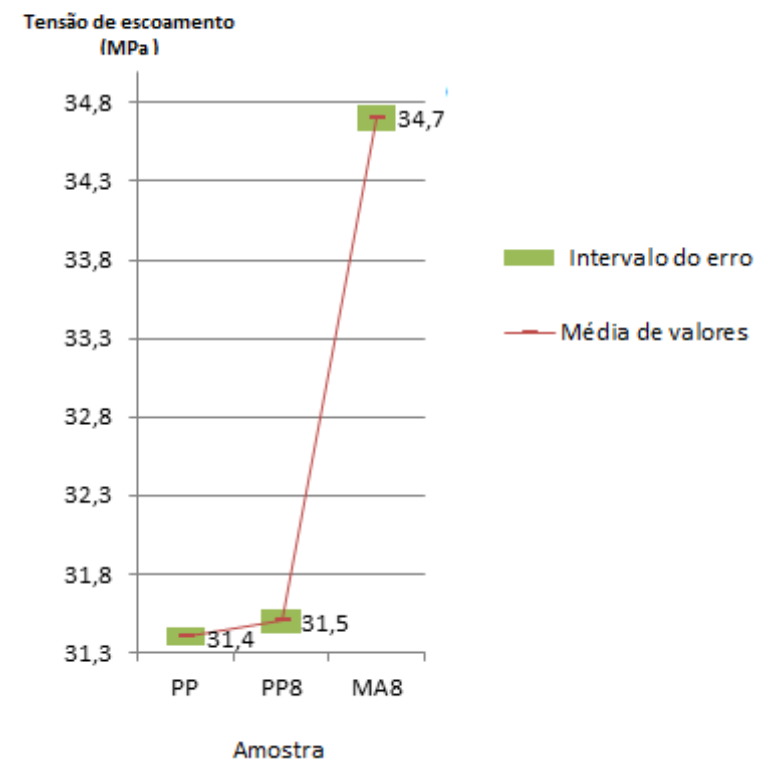

Figura 27: Gráfico dos resultados de resistência à tração (tensão de escoamento) comparativa das amostras produzidas com $\mathrm{PP}+\mathrm{CaCO}_{3}$ Mickhart 08. 


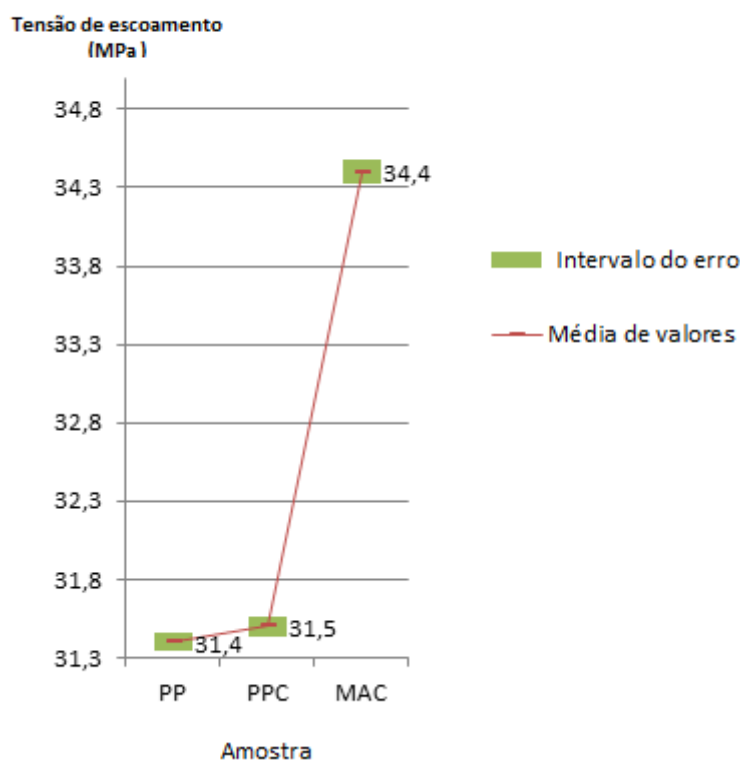

Figura 28: Gráfico dos resultados de resistência à tração (tensão de escoamento) comparativa das amostras produzidas com $\mathrm{PP}+\mathrm{CaCO}_{3}$ Mickhart $\mathrm{C}$.

Tensão de escoamento $-\mathrm{v}=50 \mathrm{~mm} / \mathrm{min}-1 \mathrm{SO} 527-2$ (MPa ) a $23^{\circ} \mathrm{C}$

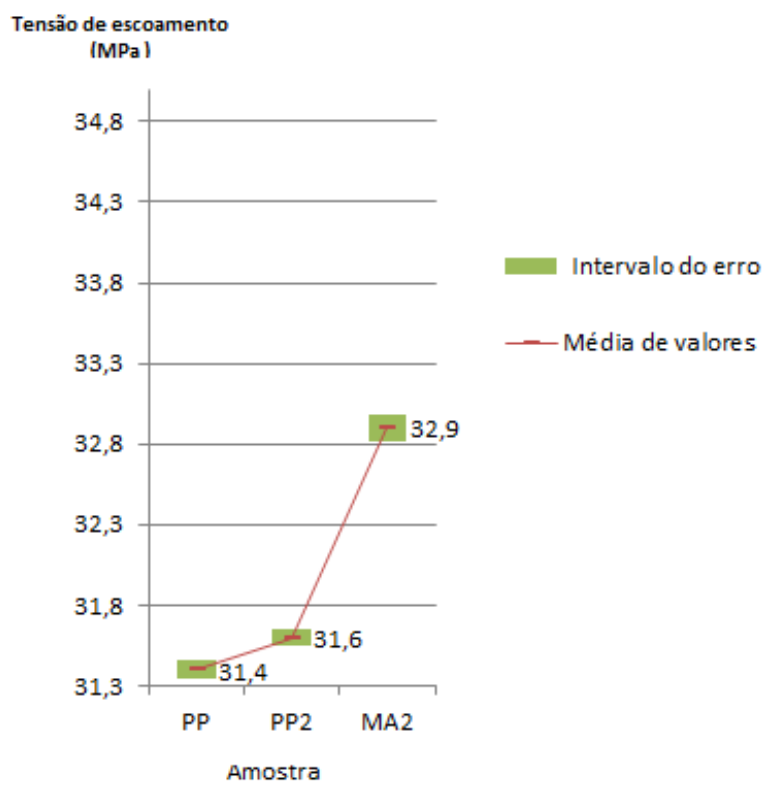

Figura 29: Gráfico dos resultados de resistência à tração (tensão de escoamento) comparativa das amostras produzidas com PP + $\mathrm{CaCO}_{3}$ Mickhart 2. 
As Figuras 26, 27, 28 e 29 mostram o aumento da resistência à tração em todas as composições contendo o copolímero PP-g-MA. Mais uma vez, observa-se que o anidrido maléico graftizado nestes compostos aumenta consideravelmente a resistência à tração do material com Carbonato de Cálcio. Esta substância é capaz de alterar a polaridade do compósito aumentando a interação entre a carga e a matriz polimérica.

Observa-se pela Tabela 12 e Figura 30 as informações do percentual de aumento na propriedade de resistência à tração compiladas de acordo com cada tipo de $\mathrm{CaCO}_{3}$ utilizado.

Tabela 12: Resultados numéricos de resistência à tração e valores de incremento com a utilização do PP-gMA no compósito.

\begin{tabular}{|c|c|c|c|}
\hline \multicolumn{3}{|c|}{ Resultado de resistência à tração (MPa) e incrementos do uso do PP-g-MA } \\
\hline tipo de $\mathrm{CaCO}_{3}$ & $\begin{array}{c}\mathrm{A}=\mathrm{PP}+5 \% \\
\mathrm{CaCO}\end{array}$ & $\mathrm{B}=\mathrm{PP}+5 \% \mathrm{CaCO}_{3}+5 \%$ PP-g-MA & Incremento em \% (B/A) \\
\hline Mickhart 08T & PPT $=31,7$ & MAT $=34,9$ & 10,1 \\
\hline Mickhart 08 & PP8 $=31,5$ & $\mathrm{MA} 8=34,7$ & 10,1 \\
\hline Mickhart C & PPC $=31,5$ & MAC $=34,4$ & 9,2 \\
\hline Mickhart 2 & PP2 $=31,6$ & MA2 $=32,9$ & 4,1 \\
\hline
\end{tabular}




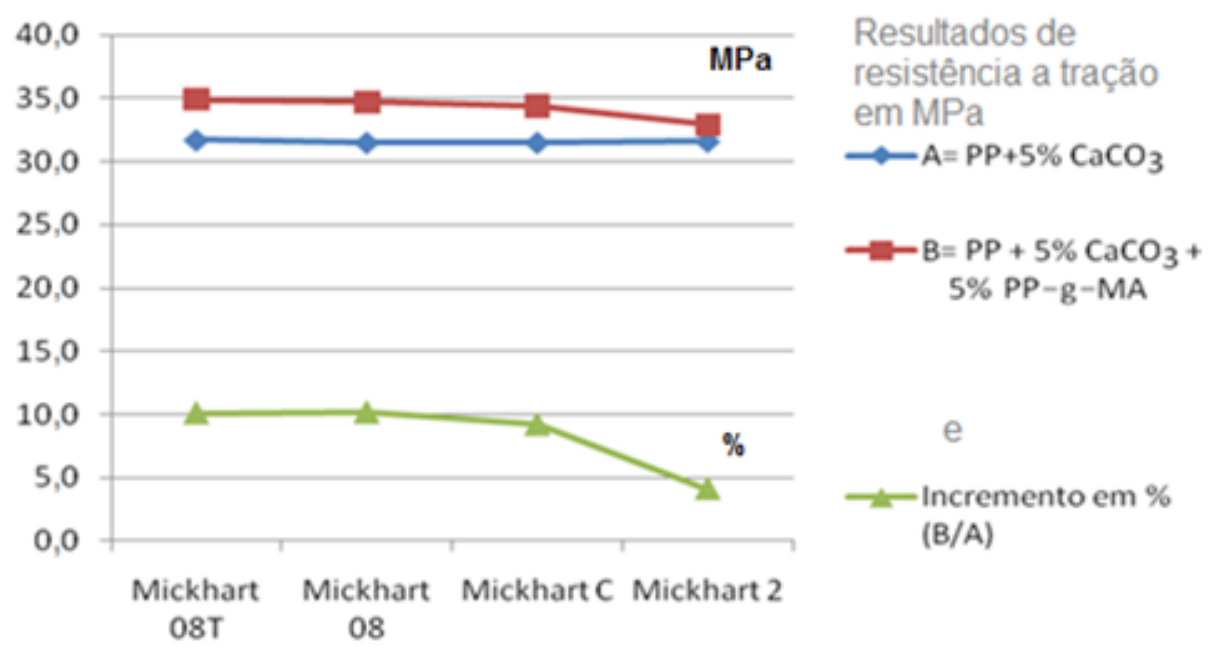

Figura 30: Resultados gráficos de resistência à tração e valores de incremento com a utilização do PP-g-MA no compósito.

Nota-se, pela Tabela 12 e Figura 30, que o tamanho de partícula da carga influi neste aumento de propriedade. Observa-se que, pelo incremento em \% (B/A), quanto menor o tamanho de partícula do $\mathrm{CaCO}_{3}$, maior o incremento na propriedade de resistência à tração. É o que constatamos na amostra feita com Mickhart 08 que tem um tamanho de partícula menor que o Mickhart $\mathrm{C}$ e este menor que o Mickhart 2. 


\subsubsection{Análise de dados dos resultados de módulo na flexão}

Pela Figura 31 podemos observar a comparação geral do resultado de módulo na flexão entre todas as amostras produzidas.

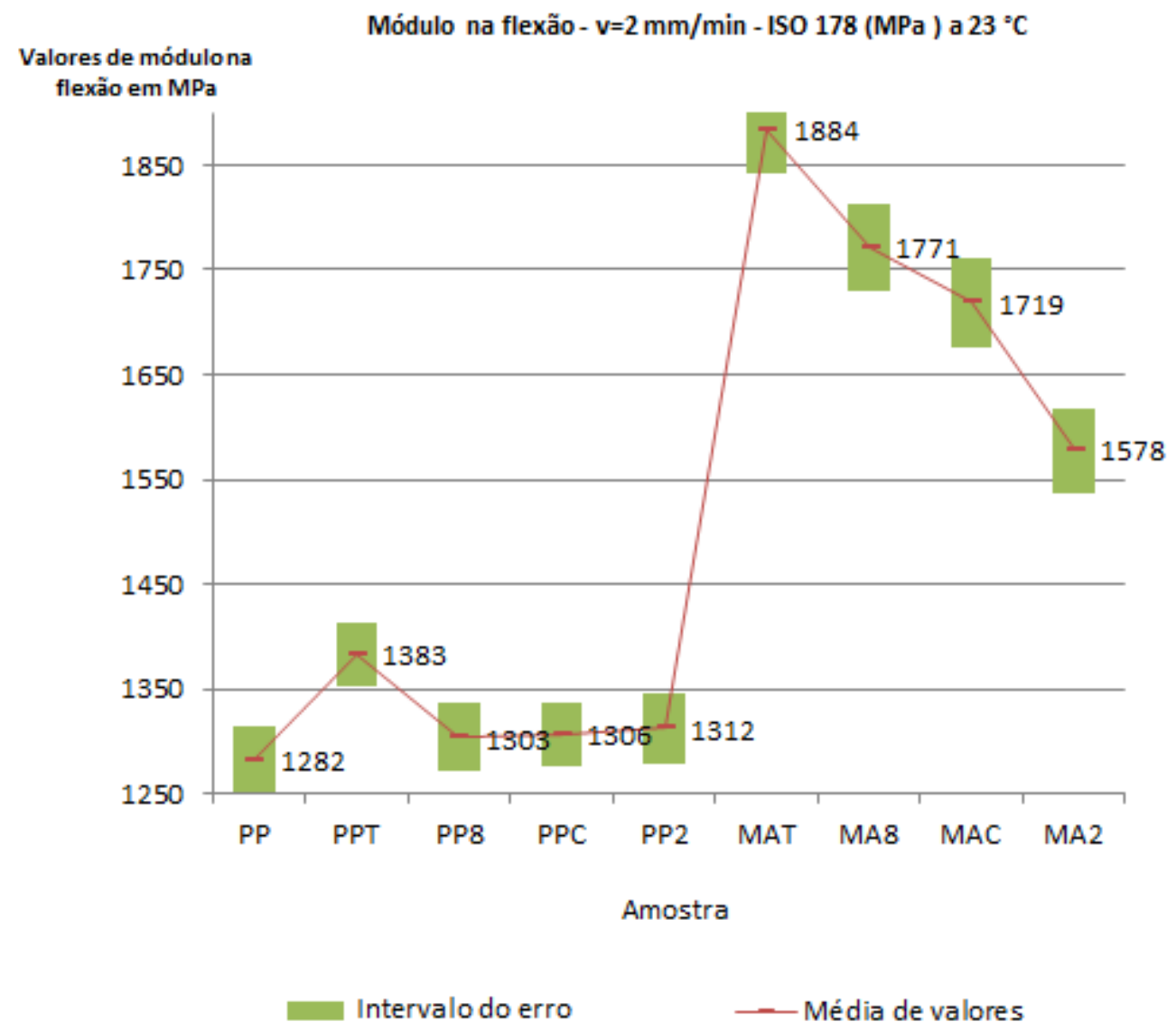

Figura 31: Resultados de Módulo na flexão comparativa das amostras produzidas. 
De forma análoga aos resultados de resistência à tração, nota-se que existe uma grande variação entre as amostras produzidas com e sem PP-g-MA. Estes resultados de módulo na flexão, portanto, foram separados em dois grupos (Figuras 32 e 33) para uma melhor visualização.

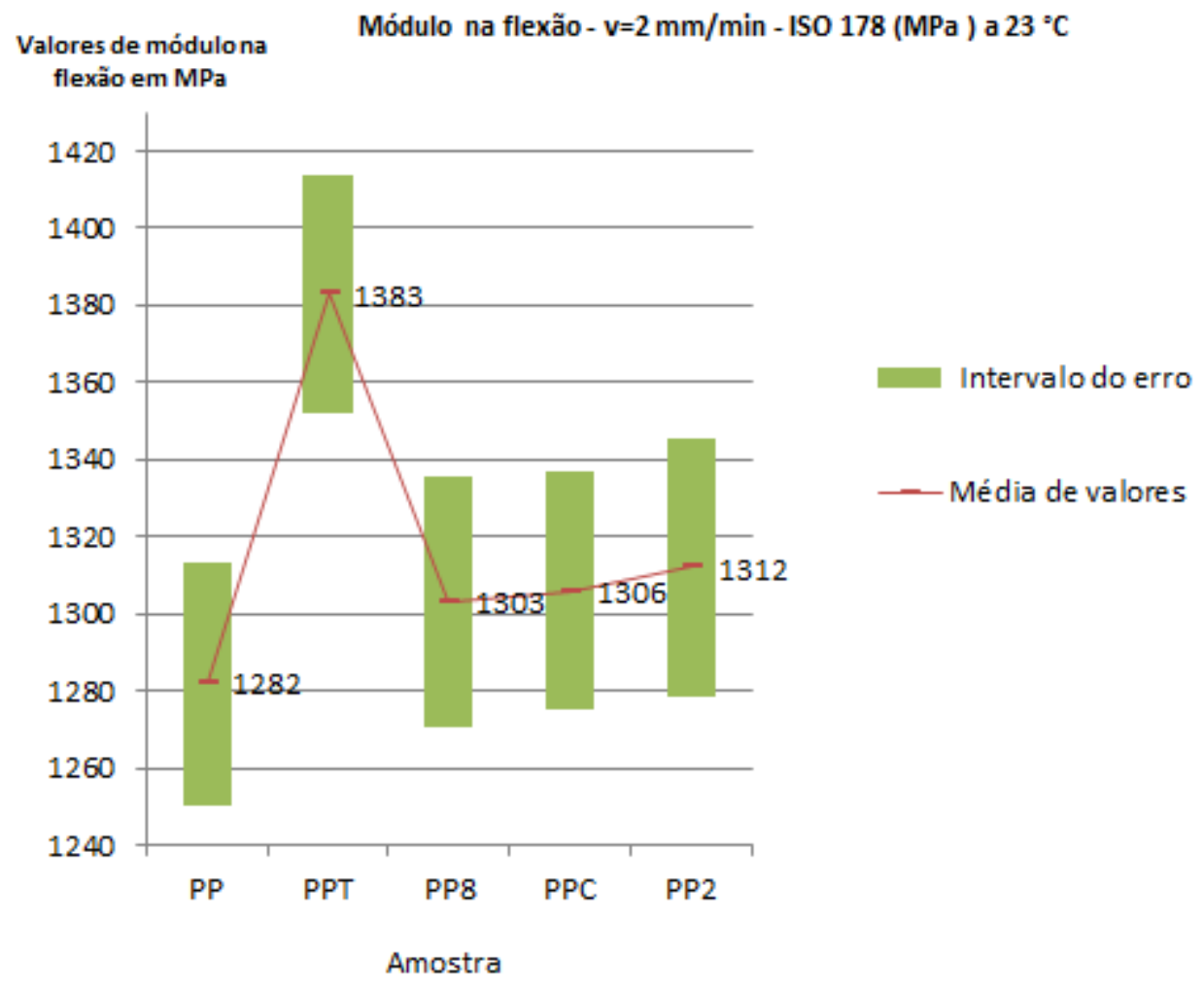

Figura 32: Gráfico dos resultados de Módulo na flexão comparativa das amostras produzidas com PP + $\mathrm{CaCO}_{3}$. 


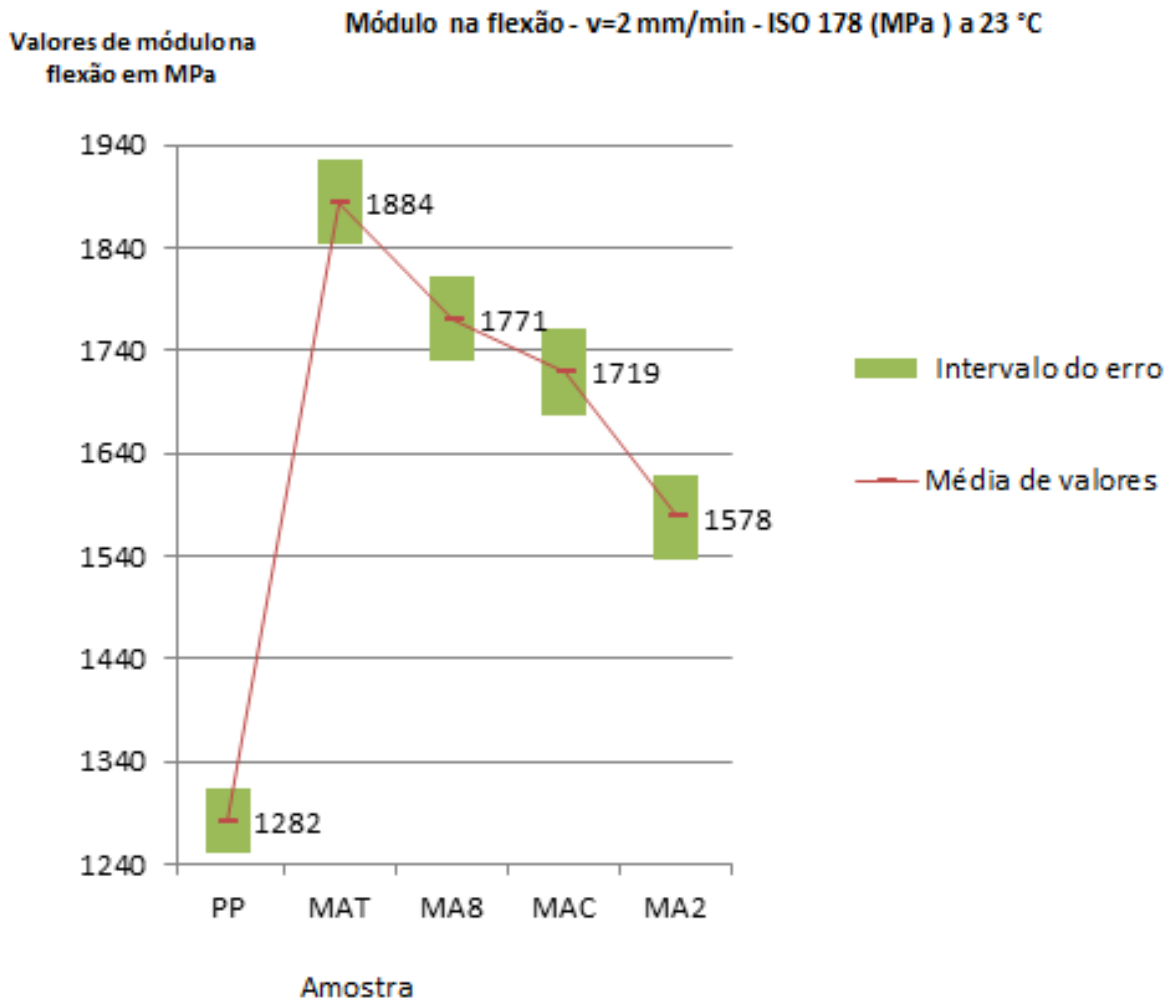

Figura 33: Gráfico dos resultados de Módulo na flexão comparativa das amostras produzidas com PP + $\mathrm{CaCO}_{3}$.

As amostras produzidas sem PP-g-MA (Figura 32) não apresentam diferenças significativas nos resultados de módulo de flexão comparados aos resultados com o PP puro. Estes resultados são consistentes em relação aos observados anteriormente de resistência à tração o que é atribuído à quantidade pequena utilizada de $\mathrm{CaCO}_{3}(5 \%)$. Porém, diferentemente dos valores de tração, o valor de módulo encontrado pela amostra PPT (PP+5\%Mickhart $08 \mathrm{~T}+5 \%$ PP-g-MA) chega a um valor bastante significativo em comparação ao PP puro. Lembrando que a amostra PPT é produzida com Mickhart $08 \mathrm{~T}, \mathrm{um} \mathrm{CaCO}_{3}$ de tamanho de partícula 0,9 $\mu \mathrm{m}$ previamente tratada pelo fornecedor. Isto é um indício de que o valor de módulo na flexão é potencializado quando há um incremento na adesão superficial entre a carga e a matriz polimérica. 
Esta potencialização no valor do módulo de flexão é ainda mais evidente quando é avaliado a série de resultados relativos às amostras produzidas com PP-g-MA. As Figuras 34 a 37 e a Tabela 13 mostram a diferença de resultados com a utilização do PP-g-MA nas amostras.

Módulo na flexão - v=2 mm/min - ISO 178 (MPa ) a $23{ }^{\circ} \mathrm{C}$

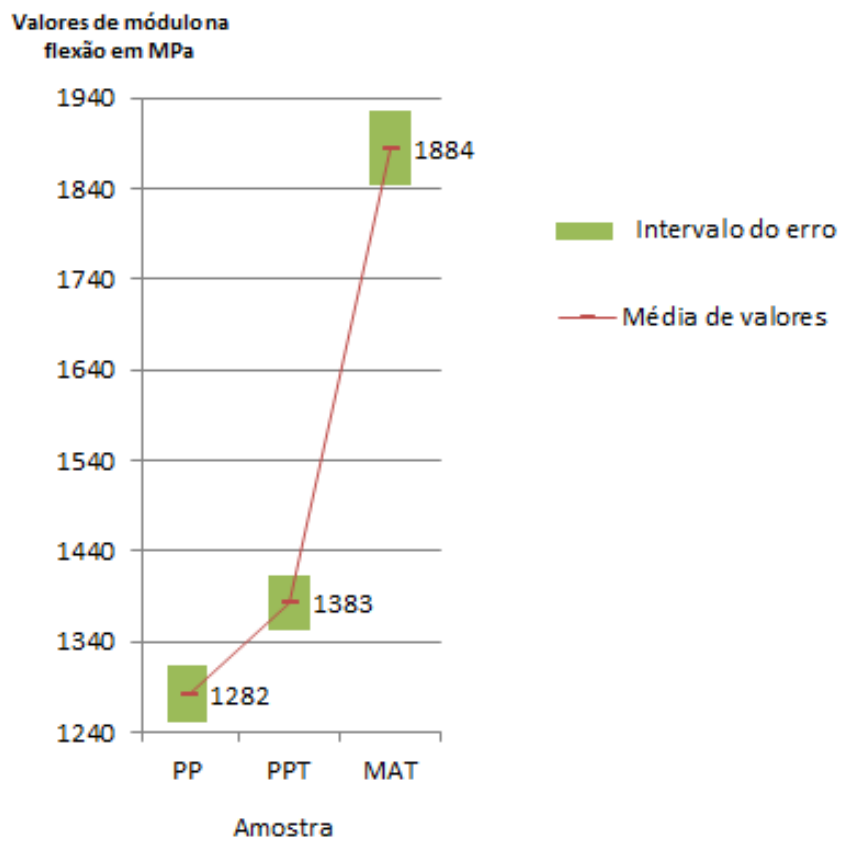

Figura 34: Gráfico dos resultados de módulo na flexão comparativa das amostras produzidas com PP + $\mathrm{CaCO}_{3}$ Mickhart 08T.

Módulo na flexão - v=2 mm/min - 150178 (MPa ) a $23^{\circ} \mathrm{C}$

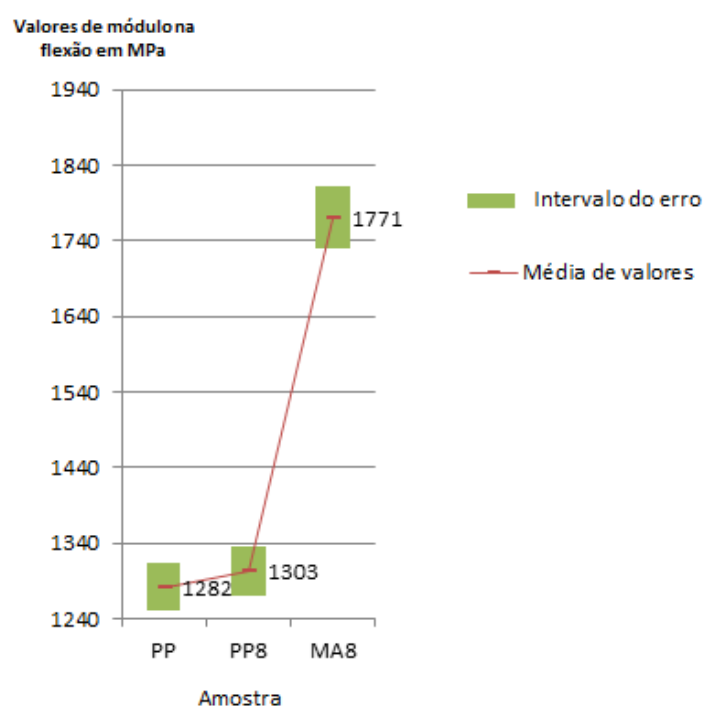

Figura 35: Gráfico dos resultados de módulo na flexão comparativa das amostras produzidas com PP + $\mathrm{CaCO}_{3}$ Mickhart 08. 


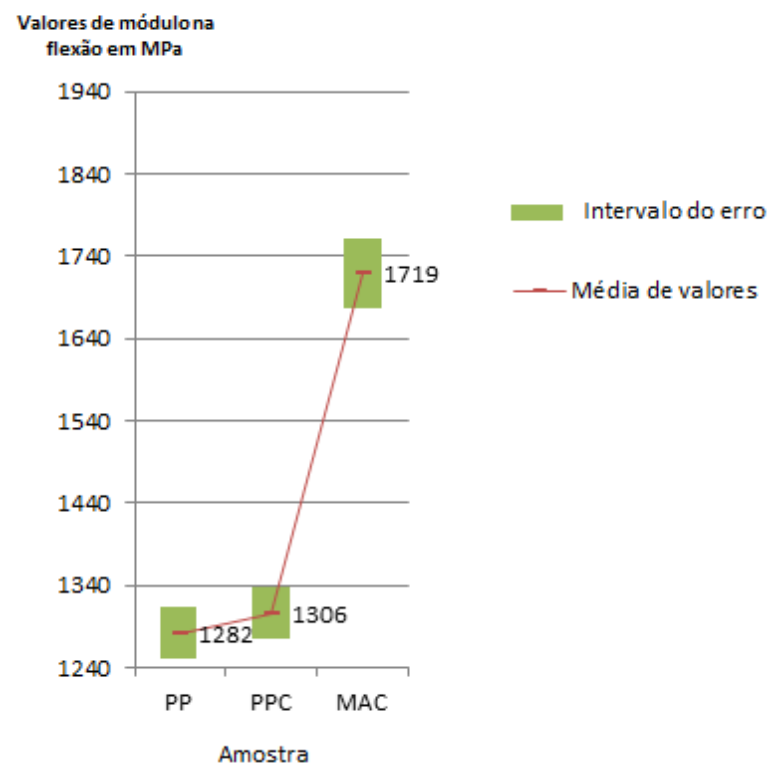

Figura 36: Gráfico dos resultados de módulo na flexão comparativa das amostras produzidas com PP + $\mathrm{CaCO}_{3}$ Mickhart C.

Módulo na flexão - v=2 mm/min - ISO 178 (MPa ) a $23{ }^{\circ} \mathrm{C}$

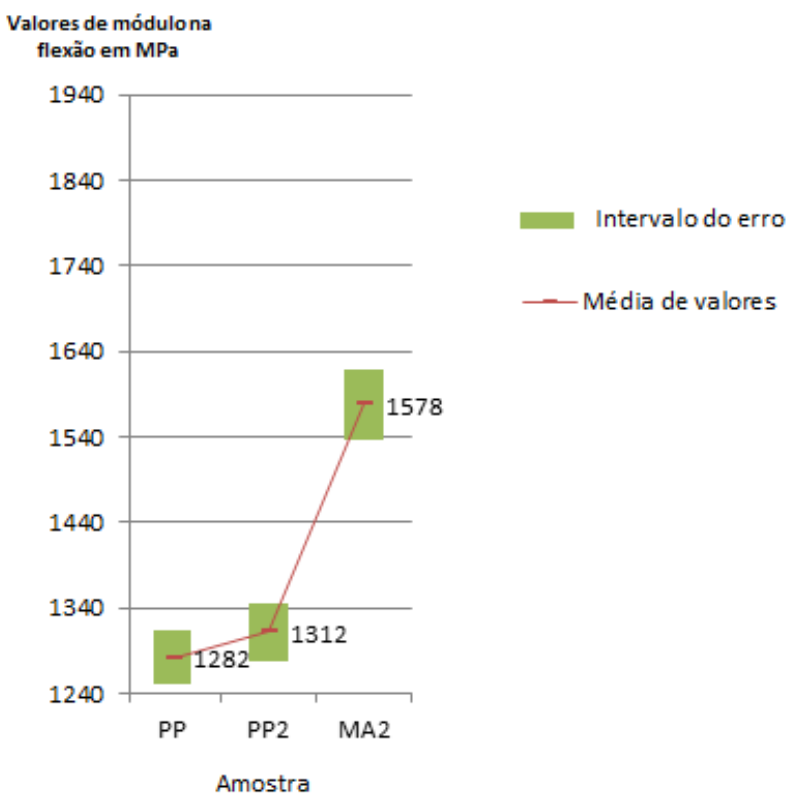

Figura 37: Gráfico dos resultados de módulo na flexão comparativa das amostras produzidas com PP + $\mathrm{CaCO}_{3}$ Mickhart 2. 
Tabela 13: Resultados de módulo na flexão e valores de incremento com a utilização do PP-g-MA no compósito.

\begin{tabular}{|c|c|c|c|}
\hline & \multicolumn{2}{|c|}{$\begin{array}{c}\text { Módulo na Flexão 2 } \mathbf{~ m m} / \mathbf{m i n} \text { at 23 }{ }^{\circ} \mathbf{C} \text { ISO 178 } \\
\text { (valores em MPa) }\end{array}$} \\
\hline tipo de $\mathrm{CaCO}_{3}$ & $\mathrm{~A}=\mathrm{PP}+5 \% \mathrm{CaCO}_{3}$ & $\begin{array}{c}\mathrm{B}=\mathrm{PP}+5 \% \mathrm{CaCO}_{3}+5 \% \\
\mathrm{PP}-\mathrm{g}-\mathrm{MA}\end{array}$ & $\begin{array}{c}\text { Incremento em \% } \\
\text { (B/A) }\end{array}$ \\
\hline Mickhart 08T & 1383 & 1884 & 36,23 \\
\hline Mickhart 08 & 1303 & 1771 & 35,92 \\
\hline Mickhart C & 1306 & 1719 & 31,62 \\
\hline Mickhart 2 & 1312 & 1578 & 20,27 \\
\hline
\end{tabular}

Estes mesmos valores da Tabela 13 podem ser vistos em modo gráfico na Figura 38 para melhor visualização.

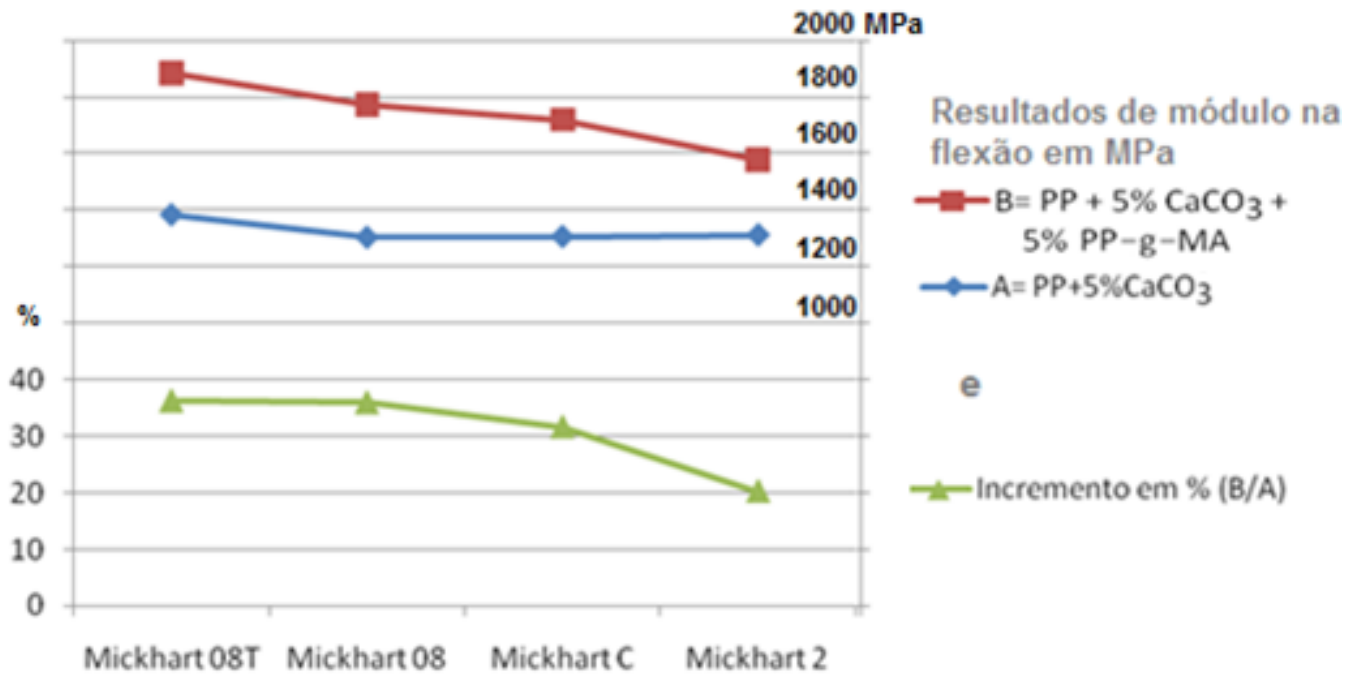

Figura 38: Gráfico dos resultados de módulo na flexão e visualização do incremento com a utilização do PPg-MA nos compósitos. 
A partir destes resultados, nota-se que a presença do PP-g-MA nos compostos aumenta de forma ainda mais considerável o módulo de flexão que a resistência à tração. Os aumentos significativos desta propriedade podem ser observados na Tabela 13 e na Figura 38. Observa-se também que, a partir dos resultados do Incremento em \% (B/A), os resultados de módulo na flexão são influenciados pelo o tamanho de partícula da carga. Ou seja, quanto menor o tamanho de partícula do $\mathrm{CaCO}_{3}$ utilizado, maior é o incremento na propriedade de módulo na flexão. Resultados observados nas amostras produzidas com Mickhart 08 e $08 \mathrm{~T}$ que tem tamanhos de partícula menores que o Mickhart C e Mickhart 2. Este último, maior de todos. 


\subsubsection{Análise dos resultados de resistência ao impacto a $23^{\circ} \mathrm{C}$ e a $-40{ }^{\circ} \mathrm{C}$}

Para que a análise de propriedades mecânicas fosse mais abrangente e mais conclusiva, foram feitas análises de impacto a temperatura ambiente $\left(23^{\circ} \mathrm{C}\right)$ e outra a baixa temperatura $\left(-40^{\circ} \mathrm{C}\right)$. Com esta análise podemos visualizar uma parte do comportamento da fase amorfa das amostras.

Vemos a partir da Figura 39 uma comparação geral das resistências ao impacto Izod com entalhe a $23^{\circ} \mathrm{C}$ das amostras produzidas.

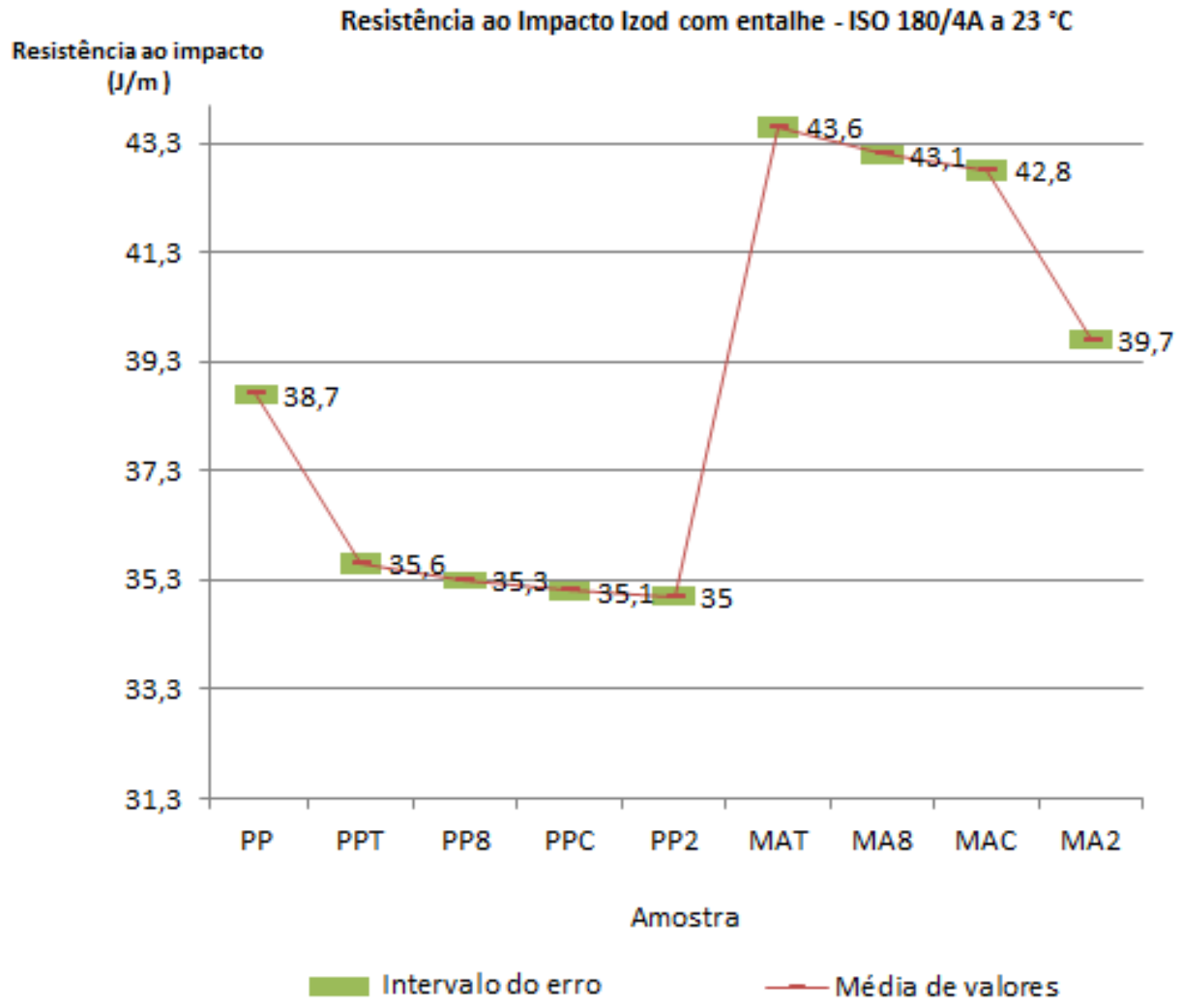

Figura 39: Gráfico dos resultados de resistência ao impacto a $23^{\circ} \mathrm{C}$ de todas as amostras dos compósitos de $\mathrm{PP}+\mathrm{CaCO}_{3}$

Nota-se que existe uma grande variação também para os resultados de resistência ao impacto Izod com entalhe a $23{ }^{\circ} \mathrm{C}$ quando é comparado as amostras produzidas com e sem PP-g-MA. Portanto, foi as informações foram divididas em dois grupos distintos para melhor visualização (Figuras 40 e 41) 


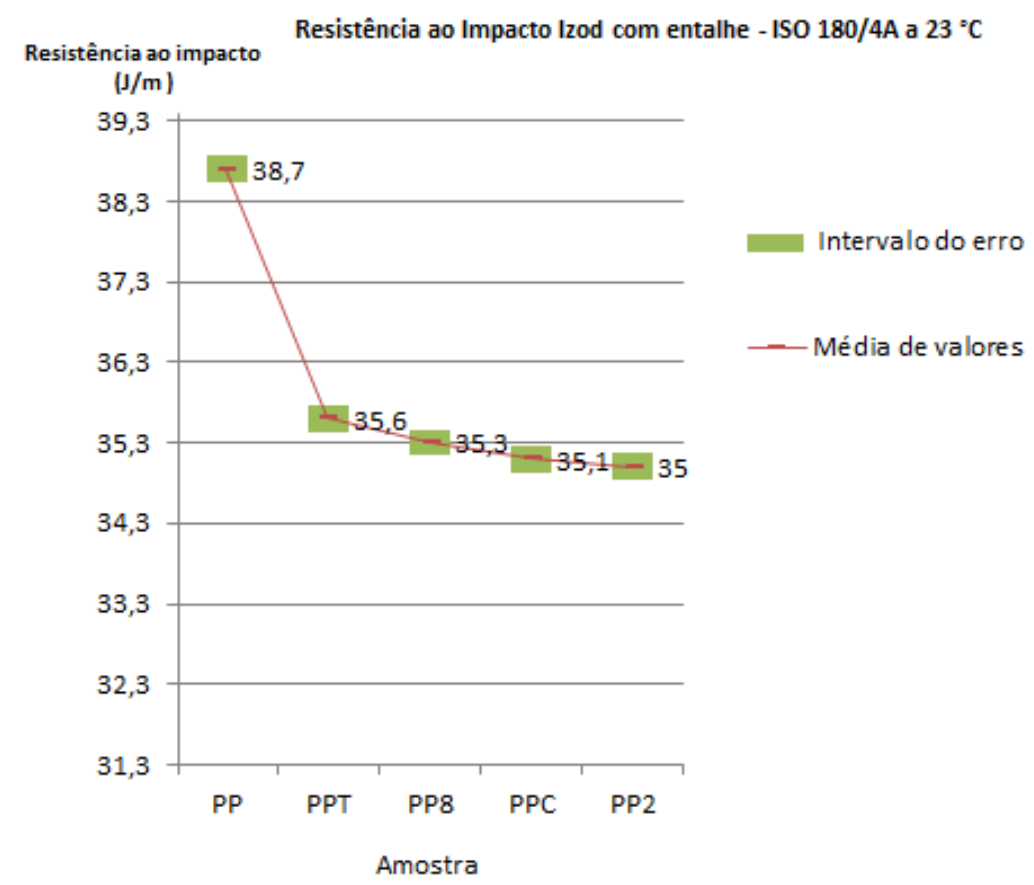

Figura 40: Gráfico dos resultados de resistência ao impacto a $23^{\circ} \mathrm{C}$ comparativa das amostras produzidas com PP $+\mathrm{CaCO}_{3}$.

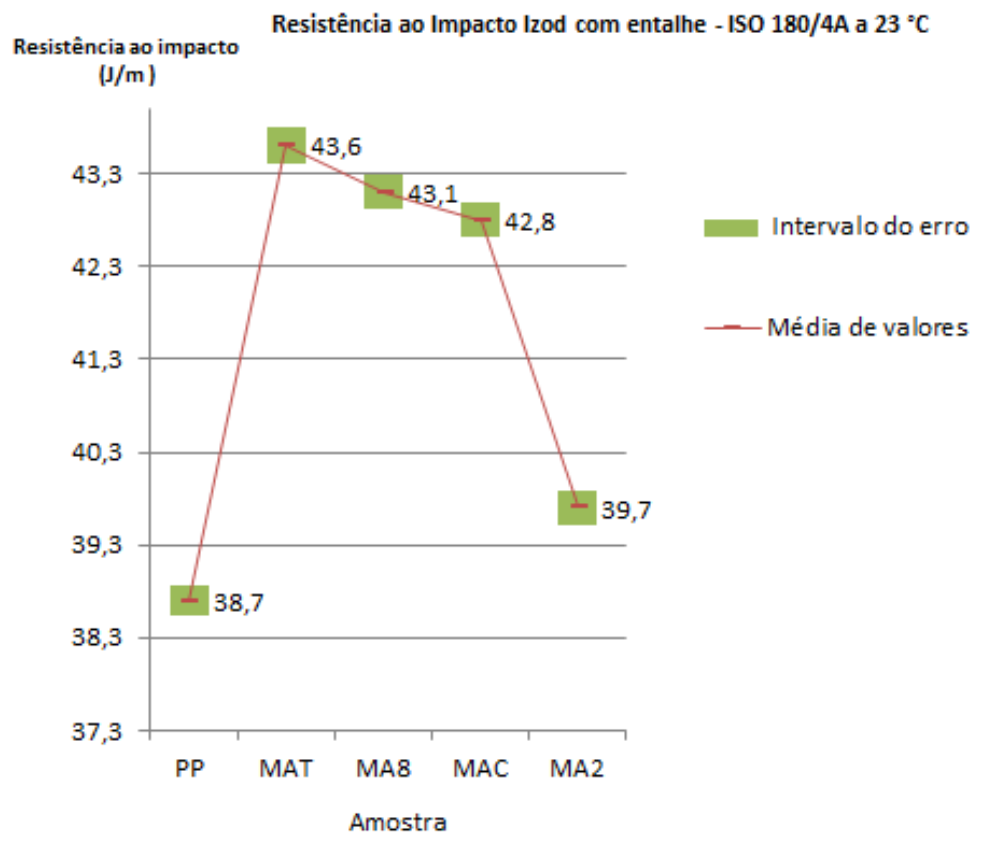

Figura 41: Gráfico dos resultados de resistência ao impacto a $23{ }^{\circ} \mathrm{C}$ das amostras de PP $+5 \% \mathrm{CaCO}_{3}+5 \% \mathrm{PP}$ g-MA.

Diferentemente dos resultados de resistência à tração e módulo na flexão, observa-se que o $\mathrm{CaCO}_{3}$ utilizado sem tratamento interfere negativamente nos resultados de impacto. Observa-se pela 
Figura 40 que a diferença, apesar de não ser tão significativa, é claramente observada quando comparamos os resultados com o PP puro. A maior diferença em relação ao PP puro é encontrada pela amostra PP2 (PP + 5\% Mickhart 2), e chega a um valor próximo a 10\% abaixo do valor do PP puro (valores respectivos: $35,0 \mathrm{~J} / \mathrm{m}$ e $38,7 \mathrm{~J} / \mathrm{m}$ ). Isto se deve ao aumento de propriedades mecânicas (resistência à tração e módulo na flexão) já observado anteriormente para estas amostras. Observase também que a influência da carga é mais impactante negativamente quanto maior o tamanho de partícula deste mineral.

Já para as amostras de PP $+\mathrm{CaCO}_{3}$ utilizando-se o PP-g-MA podemos ver pela Figura 41 que o comportamento é diferente comparado com os compostos de PP $+\mathrm{CaCO}_{3}$ sem PP-g-MA. Observa-se que, com relação ao tamanho de partícula, a tendência de queda da propriedade de impacto varia de acordo com o aumento do tamanho de partícula da carga mineral, mas podemos encontrar valores bastante acima do valor de referência $(38,7 \mathrm{~J} / \mathrm{m})$ se o tamanho de partícula do $\mathrm{CaCO}_{3}$ utilizado for pequeno o suficiente, conforme vemos pelas amostras MAT e MA8 da Figura 41.

O fato de que as amostras MAT, MA8, MAC e MA2 estejam com as propriedades de impacto maiores que a referência é um fator importante para uma análise mais minuciosa quanto à morfologia da matriz polimérica (PP). Por isso, após esta análise de propriedades é feito um estudo mais detalhado (itens 7.4 e 7.5) sobre a formação da fase cristalina beta destes materiais. 
Pelas Figuras 42 a 45 observa-se o incremento no valor de impacto a $23{ }^{\circ} \mathrm{C}$ com a utilização do PP-g-MA. Os resultados são comparativos com os respectivos pares de compósitos produzidos (PPT versus MAT, PP8 versus MA8, PP2 versus MA2 e PPC versus MAC).

Resistência ao Impacto Izod com entalhe - ISO $180 / 4 \mathrm{~A}$ a $23^{\circ} \mathrm{C}$

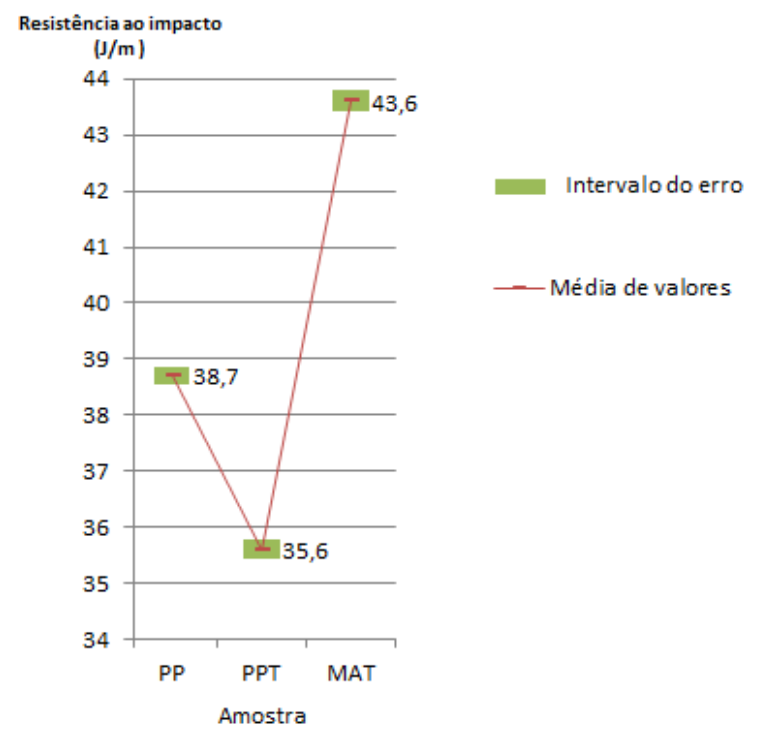

Figura 42: Gráfico dos resultados de resistência ao impacto lzod a $23^{\circ} \mathrm{C}$ comparativo das amostras produzidas com $\mathrm{PP}+\mathrm{CaCO}_{3}$ Mickhart $08 \mathrm{~T}$.

Resistência ao Impacto Izod com entalhe - ISO 180/4A a $23{ }^{\circ} \mathrm{C}$

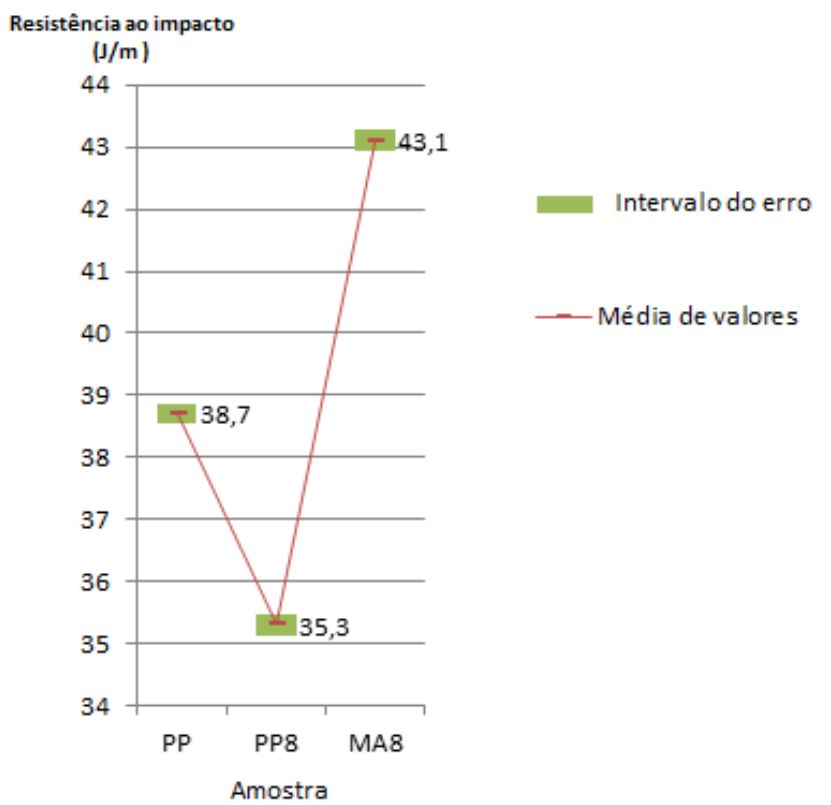

Figura 43: Gráfico dos resultados de resistência ao impacto lzod a $23{ }^{\circ} \mathrm{C}$ comparativo das amostras produzidas com PP + $\mathrm{CaCO}_{3}$ Mickhart 08. 


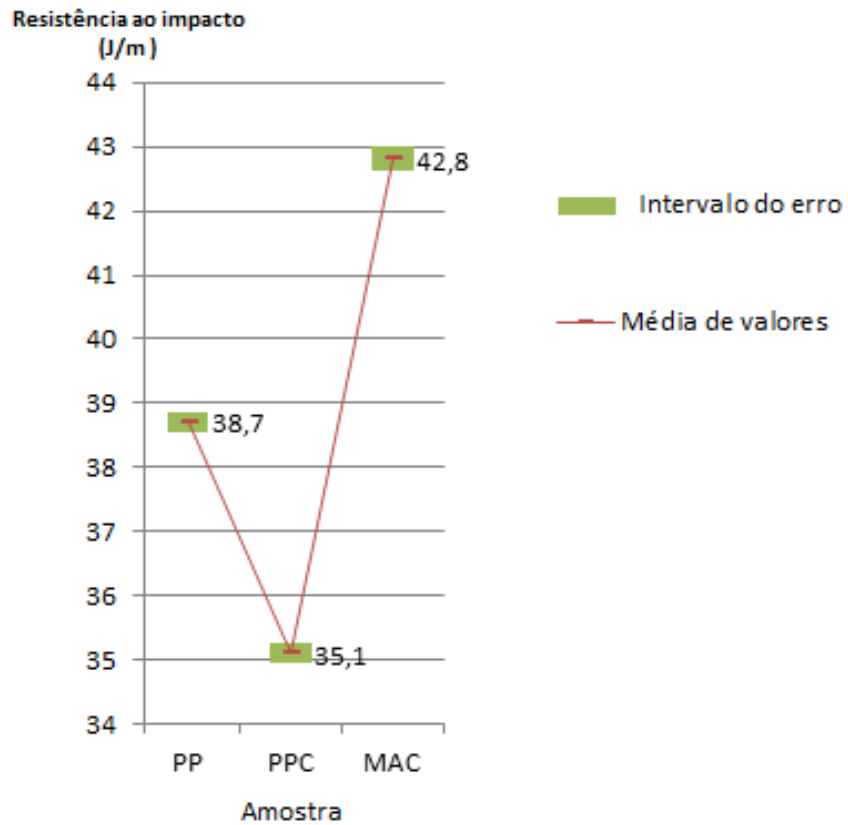

Figura 44: Gráfico dos resultados de resistência ao impacto lzod a $23{ }^{\circ} \mathrm{C}$ comparativo das amostras produzidas com $\mathrm{PP}+\mathrm{CaCO}_{3}$ Mickhart $\mathrm{C}$.

Resistência ao Impacto Izod com entalhe - ISO $180 / 4 \mathrm{~A}$ a $23^{\circ} \mathrm{C}$

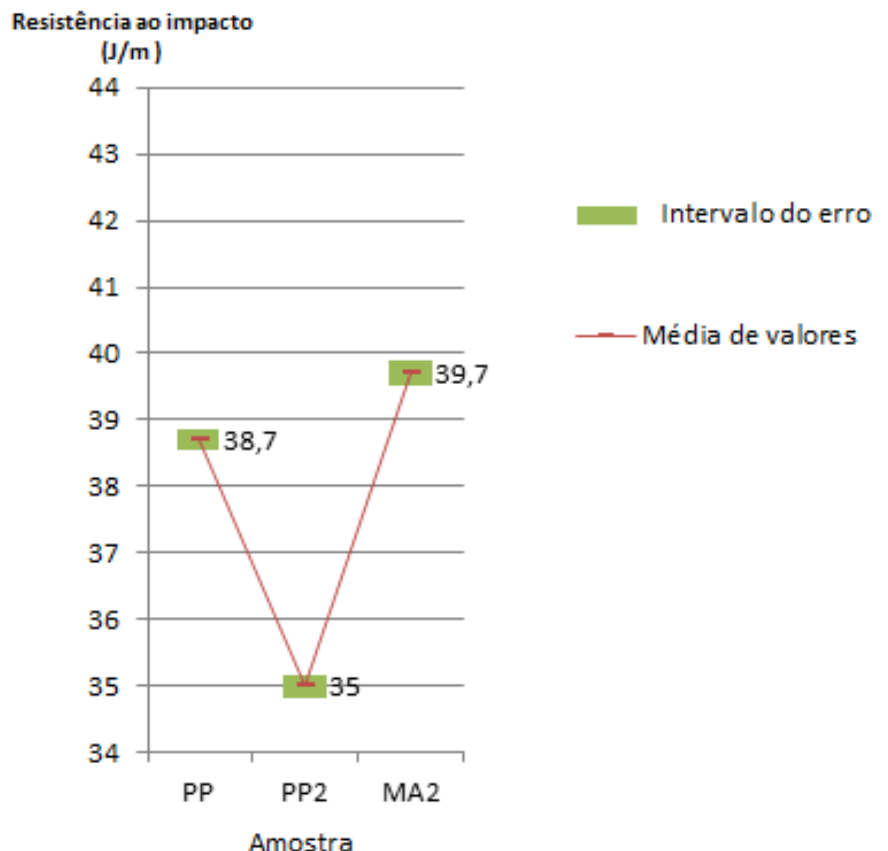

Figura 45: Gráfico dos resultados de resistência ao impacto lzod a $23{ }^{\circ} \mathrm{C}$ comparativo das amostras produzidas com $\mathrm{PP}+\mathrm{CaCO}_{3}$ Mickhart 2. 
Podemos observar, portanto que o PP-g-MA inserido melhora a propriedade de impacto das amostras estudadas.

A comparação entre os valores de resistência ao impacto das amostras $\mathrm{PP}+\mathrm{CaCO}_{3}$ e $\mathrm{PP}+$ $\mathrm{CaCO}_{3}+\mathrm{PP}-\mathrm{g}-\mathrm{MA}$, análoga ao que foi feito com a resistência à tração, podemos observar que o PPg-MA nos compostos também aumenta consideravelmente a resistência ao impacto a $23{ }^{\circ} \mathrm{C}$ do material com Carbonato de Cálcio. Nota-se novamente que esta substância foi capaz de alterar sinergicamente a polaridade do compósito melhorando as propriedades à temperatura ambiente das amostras estudadas.

Observa-se pela Tabela 14 e Figura 46 as informações sobre o percentual de aumento na propriedade de resistência ao impacto Izod com entalhe a $23 \stackrel{\circ}{\circ} \mathrm{C}$ compiladas de acordo com cada tipo de $\mathrm{CaCO}_{3}$ utilizado.

Tabela 14: Resultados de resistência ao impacto a $23{ }^{\circ} \mathrm{C}$ e valores de incremento com a utilização do PP-gMA no compósito.

\begin{tabular}{|c|c|c|c|}
\hline & \multicolumn{2}{|c|}{$\begin{array}{c}\text { Resultado de resistência ao impacto lzod com entalhe } \\
\text { a } 23^{\circ} \mathrm{C} \\
(\text { Valores em J/m) }\end{array}$} & \\
\hline tipo de $\mathrm{CaCO}_{3}$ & $\begin{array}{c}\mathrm{A}=\mathrm{PP}+5 \% \\
\mathrm{CaCO}_{3}\end{array}$ & $\begin{array}{c}\mathrm{B}=\mathrm{PP}+5 \% \mathrm{CaCO}_{3}+5 \% \text { PP-g-MA } \\
\text { Incremento em \% } \\
\text { (B/A) }\end{array}$ \\
\hline Mickhart 08T & 35,6 & 43,6 & 22,47 \\
\hline Mickhart 08 & 35,3 & 43,1 & 22,10 \\
\hline Mickhart C & 35,1 & 42,8 & 21,94 \\
\hline Mickhart 2 & 35,0 & 39,7 & 13,43 \\
\hline
\end{tabular}




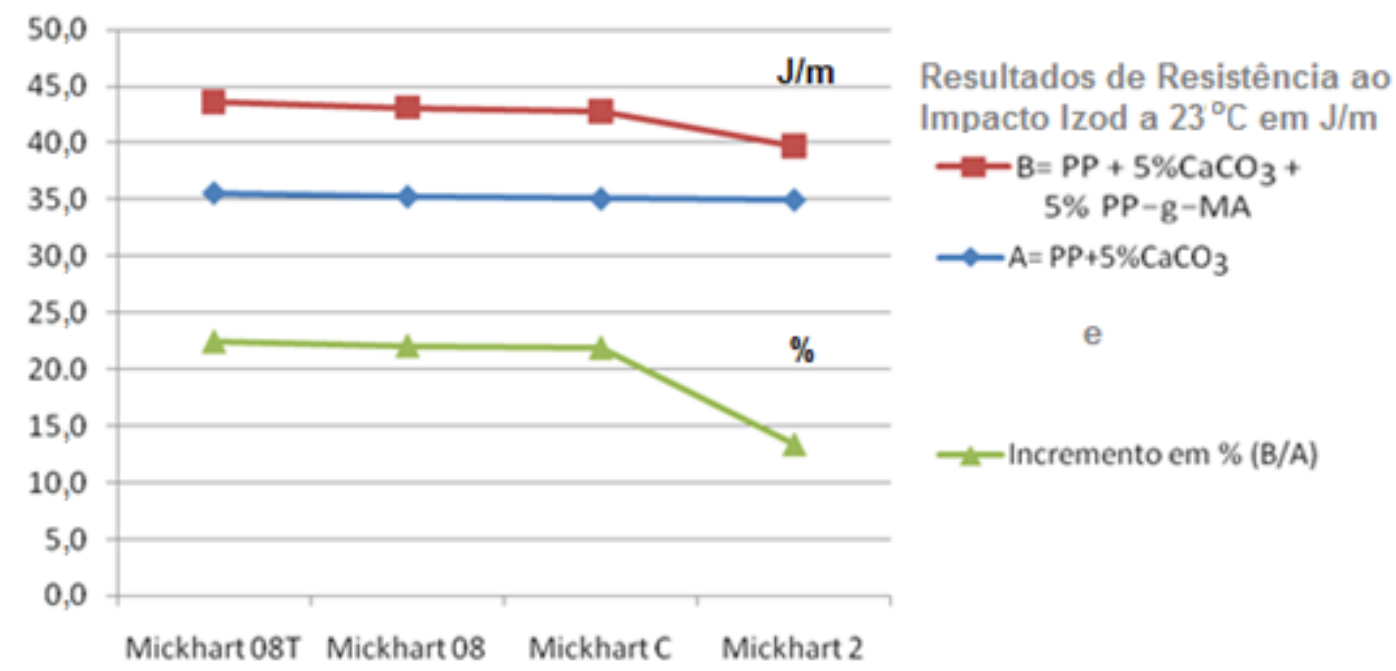

Figura 46: Gráfico dos resultados visuais de resistência ao impacto a $23{ }^{\circ} \mathrm{C}$ e valores de incremento com a utilização do PP-g-MA no compósito.

Identicamente aos resultados de tração, os incrementos na propriedade de impacto a temperatura ambiente sofrem a influência do tamanho de partícula da carga (Tabela 14 e Figura 46). Quanto menor o tamanho de partícula do $\mathrm{CaCO}_{3}$, maior o incremento nesta propriedade. É o que constatamos na amostra feita com Mickhart 08 que tem um tamanho de partícula menor que 0 Mickhart $\mathrm{C}$ e este menor que o Mickhart 2.

Para uma análise ainda mais abrangente, relacionada às propriedades mecânicas das amostras, a resistência ao impacto a baixa temperatura também foi avaliada utilizando-se as mesmas amostras. Observamos na Figura 47 as resistências ao impacto Izod com entalhe a $-40{ }^{\circ} \mathrm{C}$ para todas as amostras estudadas. 


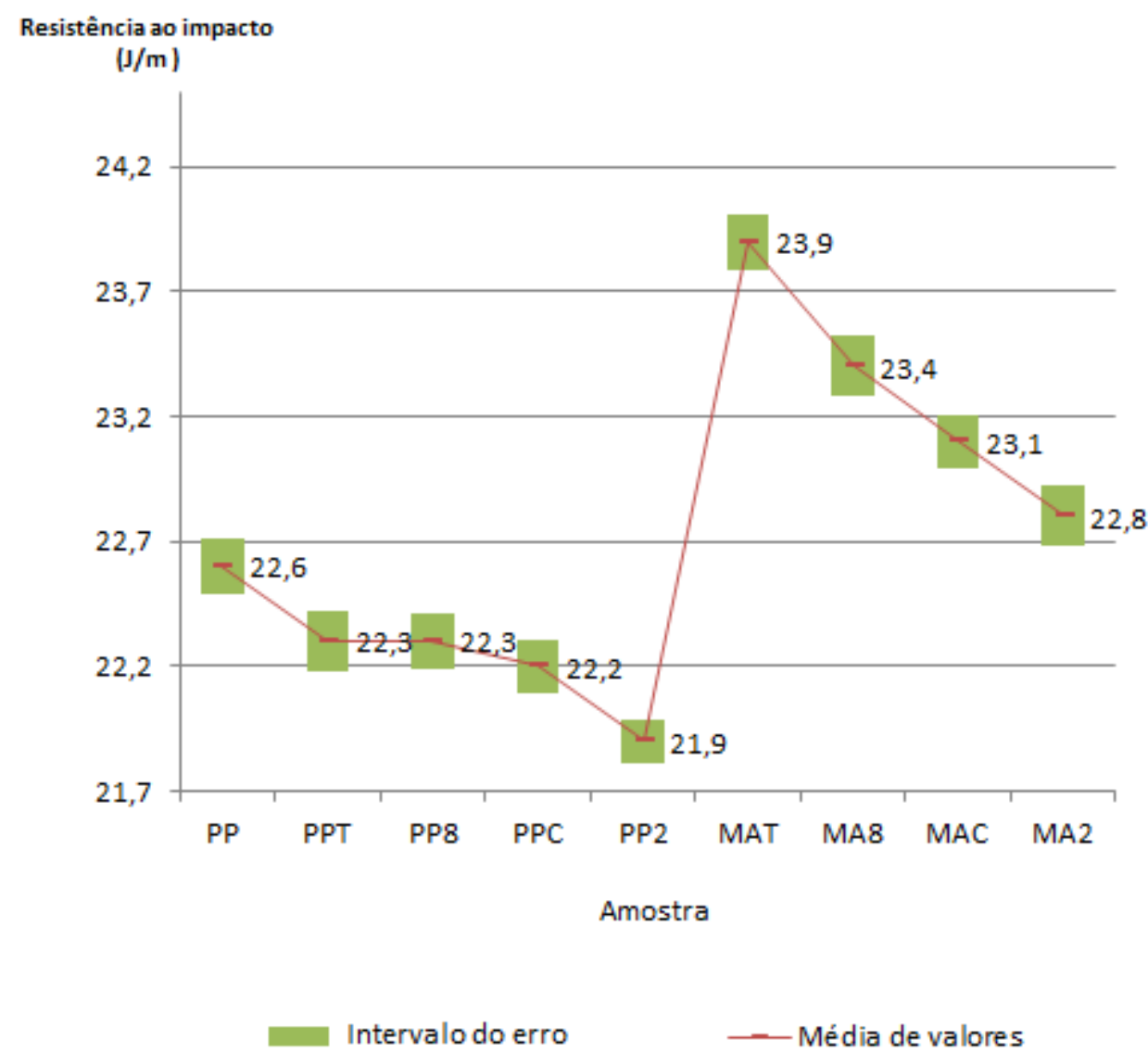

Figura 47: Gráfico dos resultados de resistência ao impacto a $-40{ }^{\circ} \mathrm{C}$ de todas as amostras dos compósitos de $\mathrm{PP}+\mathrm{CaCO}_{3}$.

Analogamente aos outros resultados encontrados, nota-se uma grande variação entre as amostras produzidas com e sem PP-g-MA. Portanto, observa-se pelas Figuras 48 e 49 os gráficos comparativos destas amostras separadas em grupos distintos para melhor visualização. 


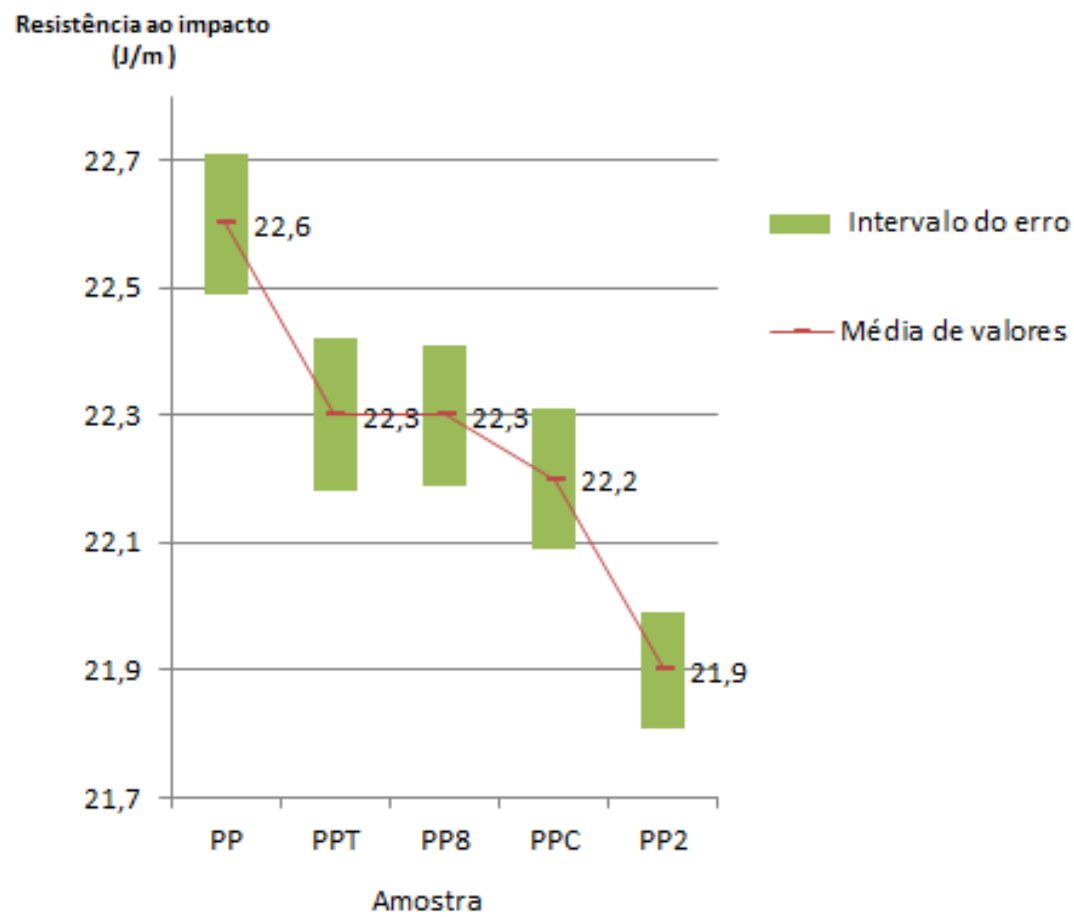

Figura 48: Gráfico dos resultados de resistência ao impacto a $-40{ }^{\circ} \mathrm{C}$ comparativa das amostras produzidas com PP + $\mathrm{CaCO}_{3}$.

Resistência ao Impacto Izod com entalhe - ISO $180 / 4 \mathrm{~A}$ a $-40^{\circ} \mathrm{C}$

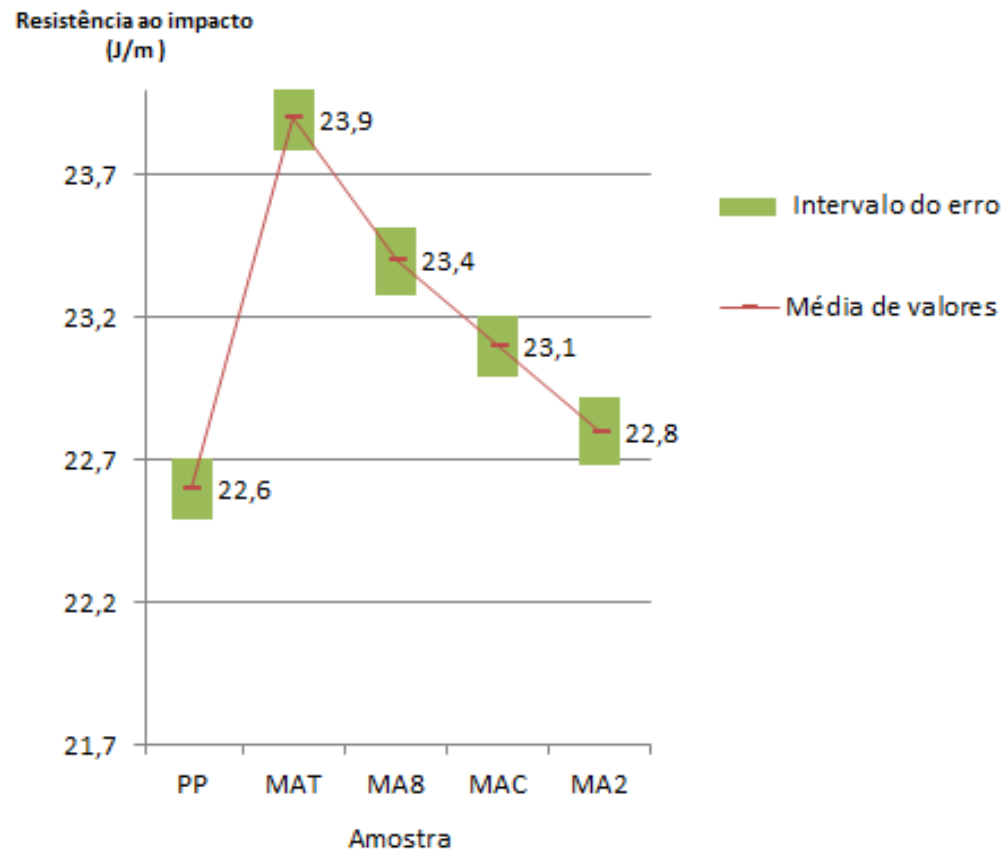

Figura 49: Gráfico dos resultados de resistência ao impacto a $-40{ }^{\circ} \mathrm{C}$ das amostras de PP $+5 \% \mathrm{CaCO}_{3}+5 \% \mathrm{PP}-$ g-MA. 
Assim como nas propriedades de resistência ao impacto a $23{ }^{\circ} \mathrm{C}$ foi observado uma diminuição da resistência ao impacto para as amostras sem PP-g-MA nas amostras (Figura 48).

Para as amostras de PP $+\mathrm{CaCO}_{3}+\mathrm{PP}-\mathrm{g}-\mathrm{MA}$ podemos ver pela Figura 49 que os resultados tiveram o resultado a $-40{ }^{\circ} \mathrm{C}$ aumentado. Porém, observa-se uma diminuição da resistência ao impacto à medida que é utilizado um $\mathrm{CaCO}_{3}$ de tamanho de partícula maior.

Analogamente ao que foi observado com a resistência ao impacto a $23^{\circ} \mathrm{C}$, as amostras MAT, MA8, MAC e MA2 resultaram em propriedades de impacto a $-40 \stackrel{\circ}{\mathrm{C}}$ maiores que a referência. Esta informação, mais uma vez, indica a necessidade de uma análise mais minuciosa quanto à morfologia da matriz polimérica (PP). Por isso, após esta análise de propriedades é feito um estudo mais detalhado (itens 7.4 e 7.5) sobre a formação da fase cristalina beta destes materiais.

Devido a grande diferença de resultados com a utilização do PP-g-MA nas amostras, as Figuras 50, 51, 52 e 53 são avaliados os respectivos pares de compósitos produzidos com e sem PP-g-MA (PPT versus MAT, PP8 versus MA8, PP2 versus MA2 e PPC versus MAC).

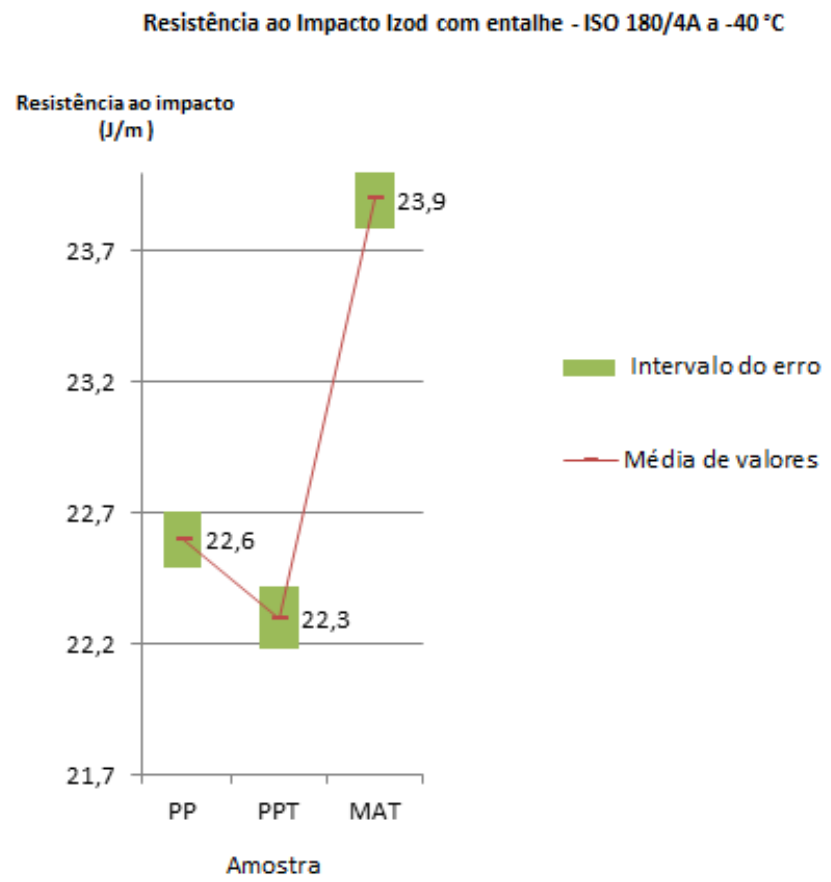

Figura 50: Gráfico dos resultados de resistência ao impacto Izod a $-40^{\circ} \mathrm{C}$ comparativo das amostras produzidas com PP $+\mathrm{CaCO}_{3}$ Mickhart 08T. 


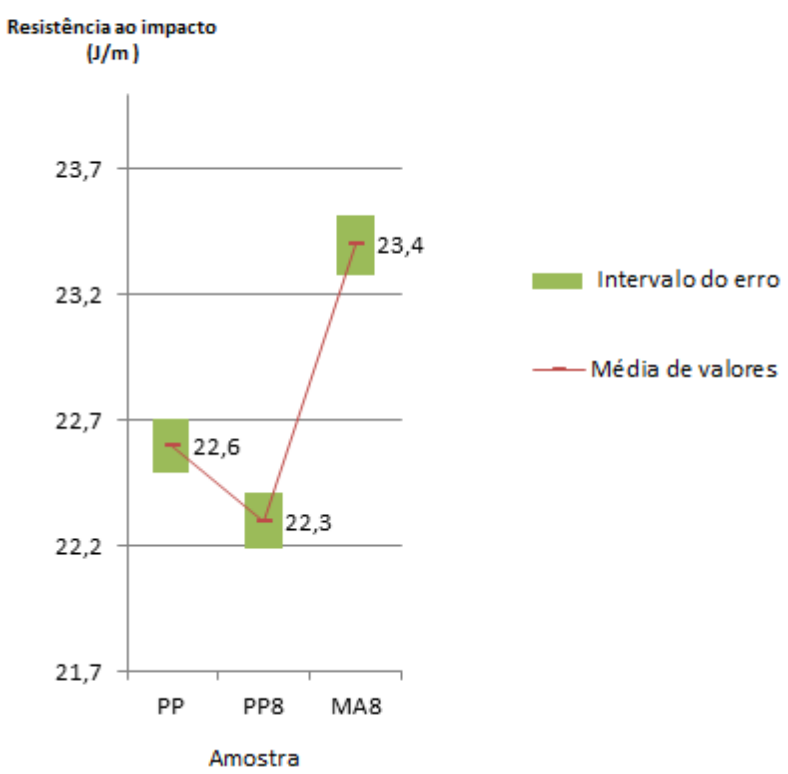

Figura 51: Gráfico dos resultados de resistência ao impacto Izod a $-40^{\circ} \mathrm{C}$ comparativo das amostras produzidas com PP $+\mathrm{CaCO}_{3}$ Mickhart 08.

Resistência ao Impacto Izod com entalhe - ISO 180/4A a $-40^{\circ} \mathrm{C}$

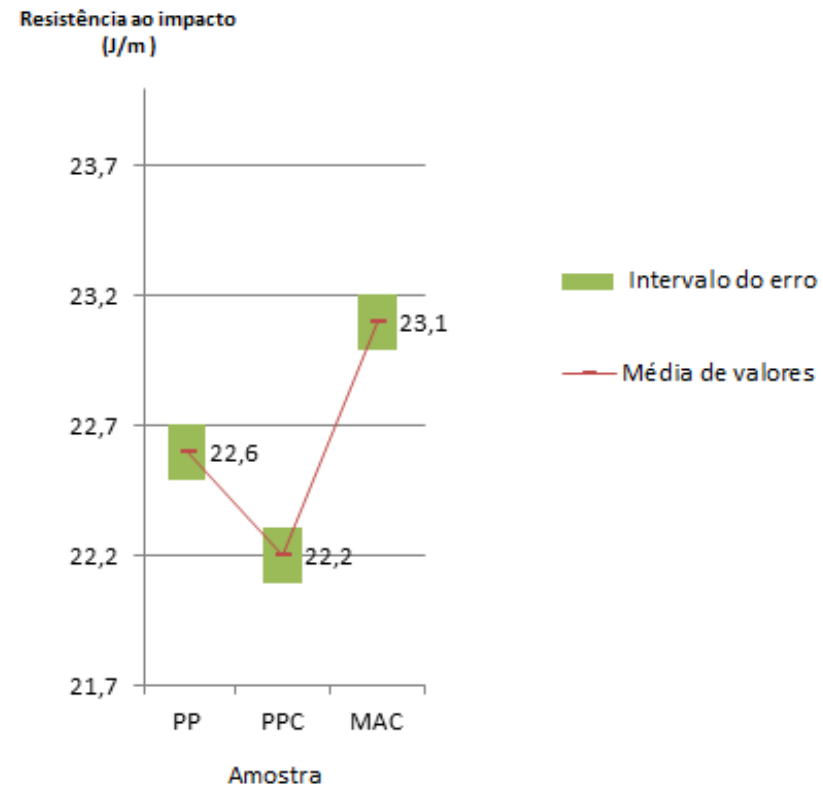

Figura 52: Gráfico dos resultados de resistência ao impacto lzod a $-40^{\circ} \mathrm{C}$ comparativo das amostras produzidas com $\mathrm{PP}+\mathrm{CaCO}_{3}$ Mickhart C. 


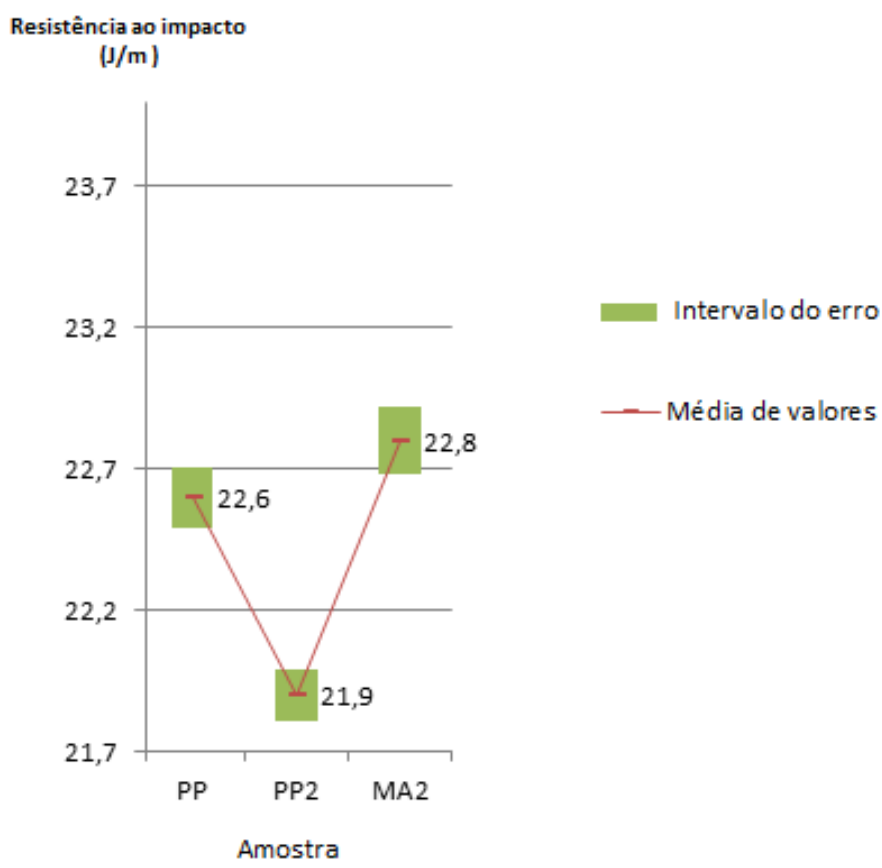

Figura 53: Gráfico dos resultados de resistência ao impacto Izod a $-40^{\circ} \mathrm{C}$ comparativo das amostras produzidas com $\mathrm{PP}+\mathrm{CaCO}_{3}$ Mickhart 2.

Analogamente aos resultados comparativos anteriores, as Figuras 50 a 53 mostram o aumento da resistência ao impacto Izod com entalhe a $-40{ }^{\circ} \mathrm{C}$ em todas as composições contendo PP-g-MA.

Observa-se pela Tabela 15 e Figura 54 as informações do percentual de aumento na propriedade de resistência ao impacto Izod com entalhe a $-40 \stackrel{\circ}{\circ}$ compiladas de acordo com cada tipo de $\mathrm{CaCO}_{3}$ utilizado. 
Tabela 15: Resultados de resistência ao impacto a $-40^{\circ} \mathrm{C}$ e valores de incremento com a utilização do PP-gMA no compósito.

\begin{tabular}{|c|c|c|c|}
\hline & \multicolumn{3}{|c|}{$\begin{array}{l}\text { Resultado de resistência ao impacto Izod com entalhe } \\
\mathrm{a}-40{ }^{\circ} \mathrm{C}(\mathrm{J} / \mathrm{m})\end{array}$} \\
\hline tipo de $\mathrm{CaCO}_{3}$ & $\begin{array}{c}\mathrm{A}=\mathrm{PP}+5 \% \\
\mathrm{CaCO}_{3}\end{array}$ & $\mathrm{~B}=\mathrm{PP}+5 \% \mathrm{CaCO}_{3}+5 \% \mathrm{PP}-\mathrm{g}-\mathrm{MA}$ & $\begin{array}{c}\text { Incremento em } \\
\%(\mathrm{~B} / \mathrm{A})\end{array}$ \\
\hline Mickhart 08T & 22,3 & 23,9 & 7,17 \\
\hline Mickhart 08 & 22,3 & 23,4 & 4,93 \\
\hline Mickhart C & 22,2 & 23,1 & 4,05 \\
\hline Mickhart 2 & 21,9 & 22,8 & 4,11 \\
\hline
\end{tabular}

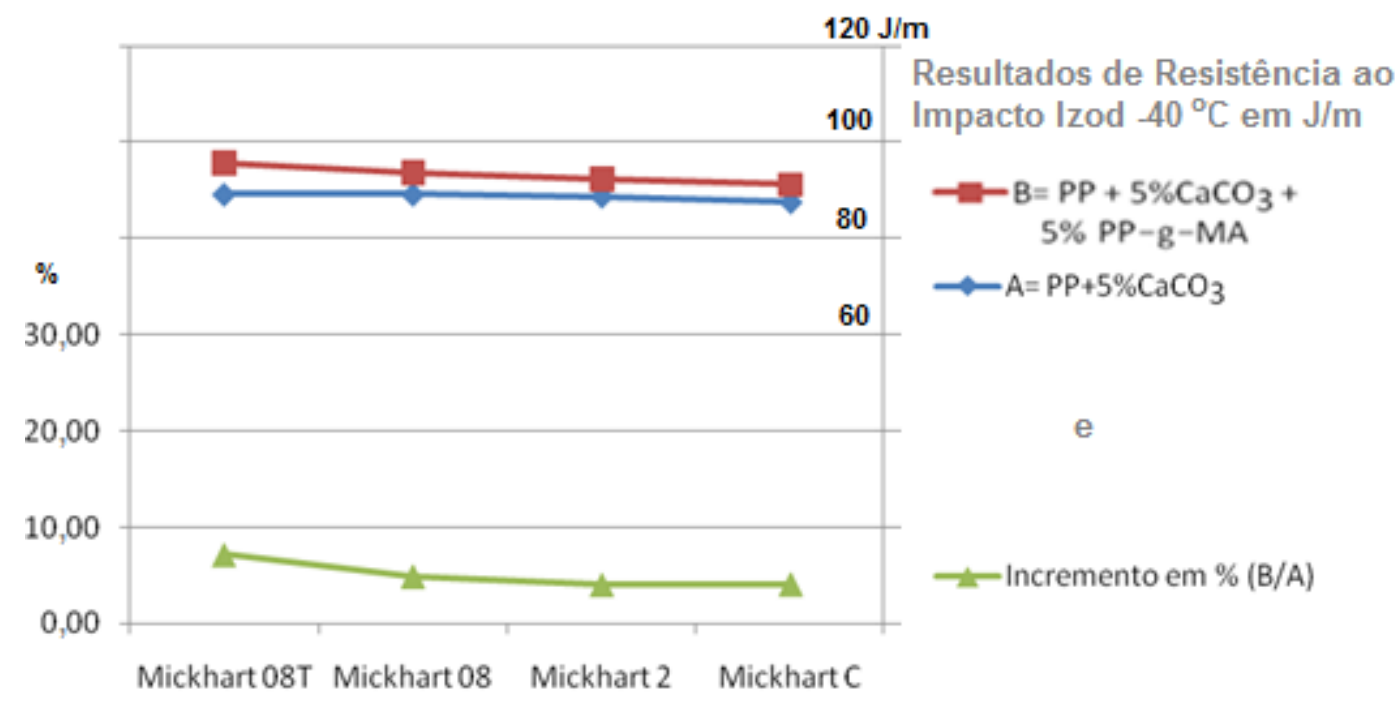

Figura 54: Gráfico dos resultados de resistência ao impacto a $-40{ }^{\circ} \mathrm{C}$ e valores de incremento com a utilização do PP-g-MA no compósito.

Nota-se, pela Tabela 15 e Figura 54, que o tamanho de partícula da carga influi no aumento da propriedade de impacto a $-40 \stackrel{\circ}{\circ}$. Observa-se que, pelo incremento em $\%(B / A)$, quanto menor 0 tamanho de partícula do $\mathrm{CaCO}_{3}$, maior o incremento também na propriedade de resistência ao impacto a $-40^{\circ} \mathrm{C}$. Constata-se a partir do valor decrescente comparado com as amostras produzidas com Mickhart 8T, Mickhart 08, Mickhart C e Mickhart 2 respectivamente. 


\subsection{Análise da influência do PP-g-MA no comportamento mecânico das amostras produzidas}

Todos os resultados mecânicos analisados mostraram claramente que há uma relação direta entre o tamanho de partícula do $\mathrm{CaCO}_{3}$ utilizado, bem como a adição do PP graftizado com anidrido maléico. Para uma melhor análise as informações do incremento \% (B/A) das Tabelas 12, 13, 14 e 15 foram compilados na Tabela 16 e Figura 55.

Tabela 16: Resultados comparativos do incremento em \% nas propriedades em função da inserção de PP-gMA nas amostras.

\begin{tabular}{|c|c|c|c|c|}
\hline $\begin{array}{l}\text { tipo de } \\
\mathrm{CaCO}_{3}\end{array}$ & $\begin{array}{l}\text { incremento na } \\
\text { resistência à tração }\end{array}$ & $\begin{array}{l}\text { Incremento no Módulo } \\
\text { na flexão }(\mathrm{MPa})\end{array}$ & $\begin{array}{l}\text { incremento no } \\
\text { impacto a } 23^{\circ} \mathrm{C}\end{array}$ & $\begin{array}{l}\text { incremento no } \\
\text { impacto a }-40^{\circ} \mathrm{C}\end{array}$ \\
\hline $\begin{array}{l}\text { Mickhart } \\
\text { 08T }\end{array}$ & 10,09 & 36,23 & 22,47 & 7,17 \\
\hline $\begin{array}{l}\text { Mickhart } \\
08\end{array}$ & 10,16 & 35,92 & 22,10 & 4,93 \\
\hline $\begin{array}{l}\text { Mickhart } \\
\text { C }\end{array}$ & 9,21 & 31,62 & 21,94 & 4,05 \\
\hline $\begin{array}{l}\text { Mickhart } \\
2\end{array}$ & 4,11 & 20,27 & 13,43 & 4,11 \\
\hline
\end{tabular}

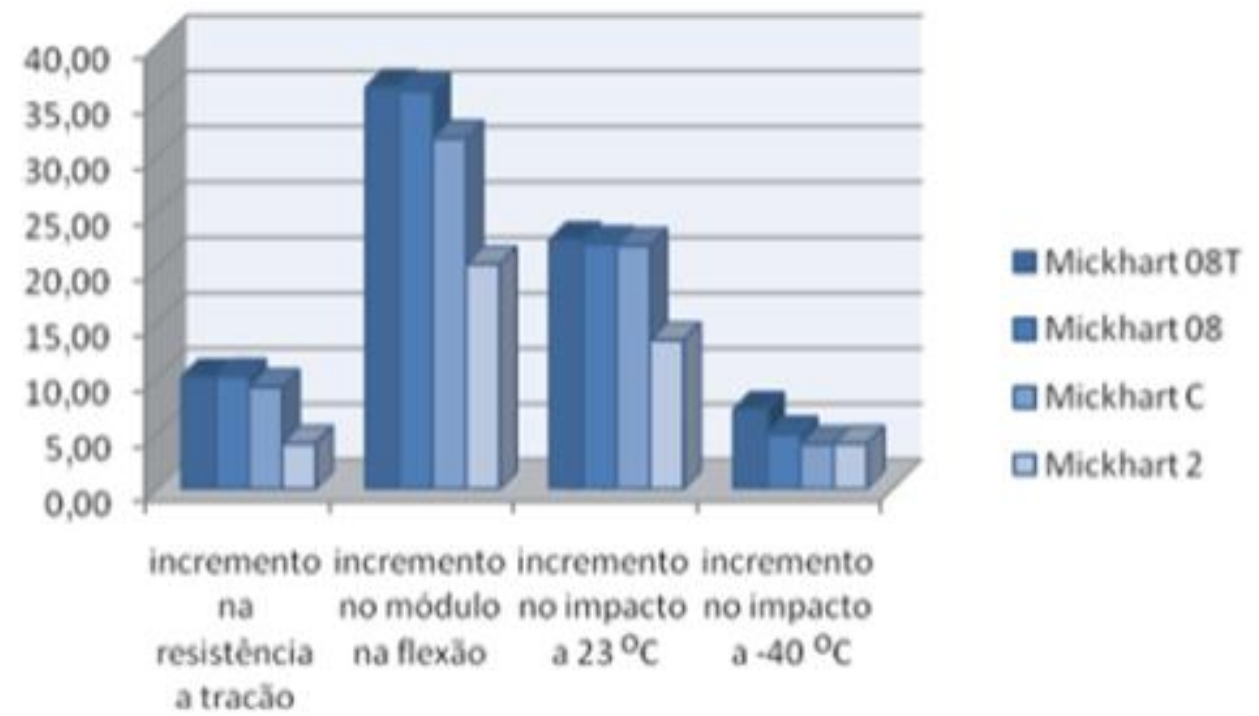

Figura 55: Gráfico dos resultados comparativos do incremento em \% nas propriedades em função da inserção de PP-g-MA nas amostras. 
A partir dos resultados da Tabela 16 e Figura 55, observou-se os incremento em percentual para cada tipo de $\mathrm{CaCO}_{3}$ utilizado comparativamente para as propriedades de resistência à tração, módulo na flexão, resistência ao impacto Izod a $23^{\circ} \mathrm{C}$ e resistência ao impacto Izod a $-40 \stackrel{\circ}{ } \mathrm{C}$.

Com estes resultados de comportamento mecânico podemos visualizar melhor os aspectos relacionados ao tamanho de partícula do $\mathrm{CaCO}_{3}$ e a influência do polipropileno graftizado com anidrido maléico pode gerar nas amostras testadas. Para as próximas análises, portanto, estas informações serão muito importantes para o direcionamento, discussão e conclusão geral do estudo.

Observa-se que quanto menor o tamanho de partícula da carga, o incremento de PP-g-MA torna-se maior para todas as propriedades. Esta informação pode ser confirmada a partir dos resultados maiores de incremento em \% com a utilização do $\mathrm{CaCO}_{3}$ Mickhart $08 \mathrm{~T}$ e Mickhart 08 (ambos com tamanho de partícula 0,9 um) comparados com o incremento em \% das amostras produzidas com Michhart C e Mickhart 2. (Tabela 16 e Figura 55)

\subsection{Análise das propriedades de resistência mecânica (resistência à tração e módulo na flexão) em comparação com os resultados de resistência ao impacto dos compósitos produzidos}

Observa-se que as amostras produzidas com PP $+\mathrm{CaCO}_{3}+\mathrm{PP}-\mathrm{g}-\mathrm{MA}$ resultaram gráficos em formato crescente sequenciais para todas as propriedades, portanto, foram analisadas estas amostras separadamente com mais detalhamento nesta parte do trabalho.

Foi inserido graficamente os resultados relativos a resistência mecânica primeiramente das amostras MAT, MA8, MAC e MA2 conforme a Figura 56. 


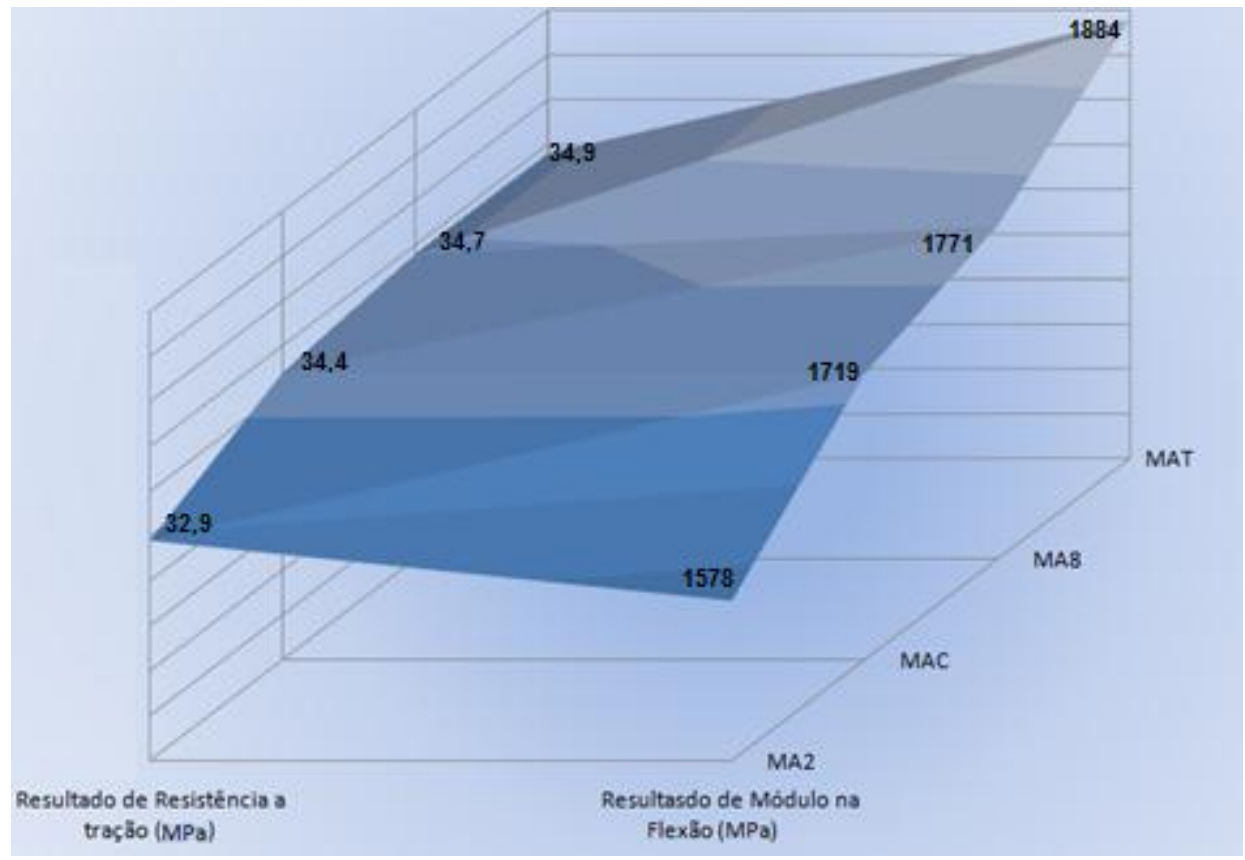

Figura 56: Resultados gráficos combinados de resistência à tração e módulo na flexão das amostras MAT, MA8, MAC E MA2.

Observa-se que há uma tendência lógica para estes dois resultados, onde a amostra MAT tem maiores resultados e a amostra MA2 tem menores resultados.

De acordo com os princípios de comportamento mecânico, os resultados relativos à ductilidade e ao impacto deveriam gerar exatamente o inverso destes últimos resultados relativos à resistência mecânica de tração e módulo na flexão. Ou seja, a amostra MAT geraria um resultado menor de impacto e a amostra MA2 geraria resultado maior. Pois, as propriedades de resistência mecânica relacionado à rigidez (resistência à tração, módulo e dureza) são diametralmente oposta às propriedades relativas à ductilidade (impacto e alongamento). Porém, contraditoriamente a estes princípios encontramos resultados de impacto da amostra MAT maiores e MA2 menores, conforme vemos através da Figura 57. 


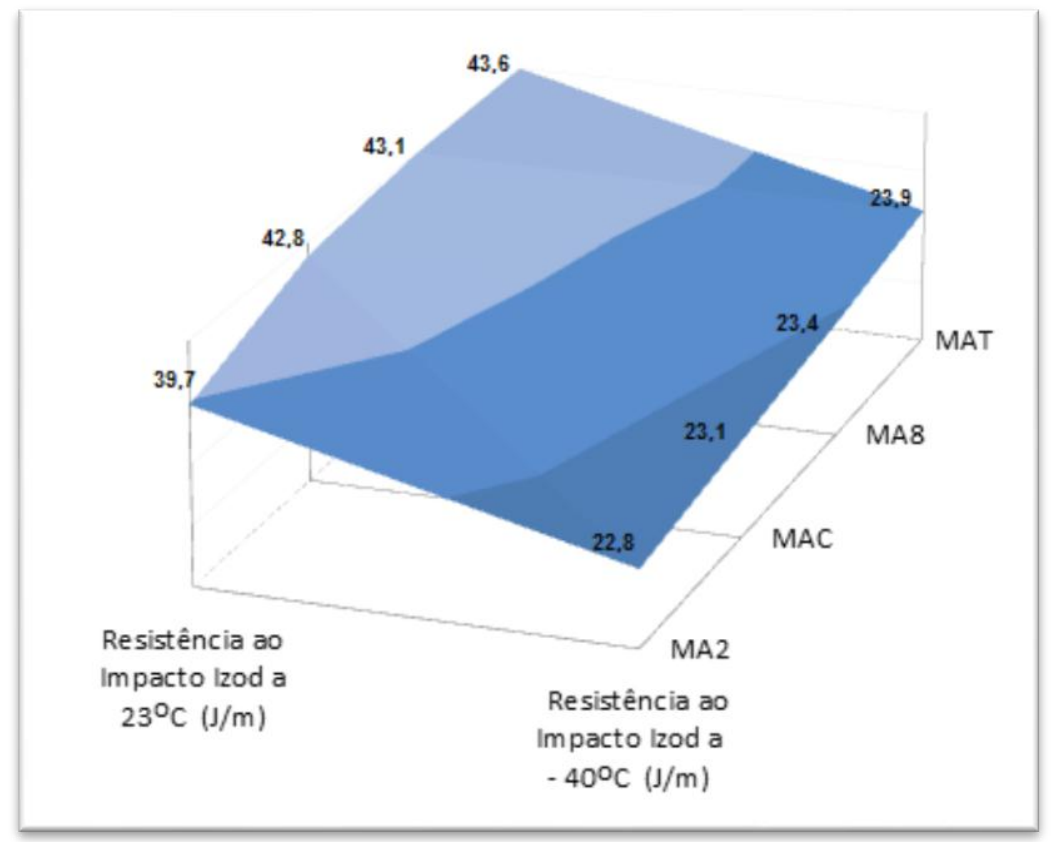

Figura 57: Resultados de resistência ao impacto lzod a $23{ }^{\circ} \mathrm{C} \mathrm{e}-40^{\circ} \mathrm{C}$ das amostras MAT, MA8, MAC e MA2.

Todos estes resultados foram compilados em dois formatos gráficos em três dimensões para facilitar a visualização deste fenômeno específico (Figuras 58 e 59).

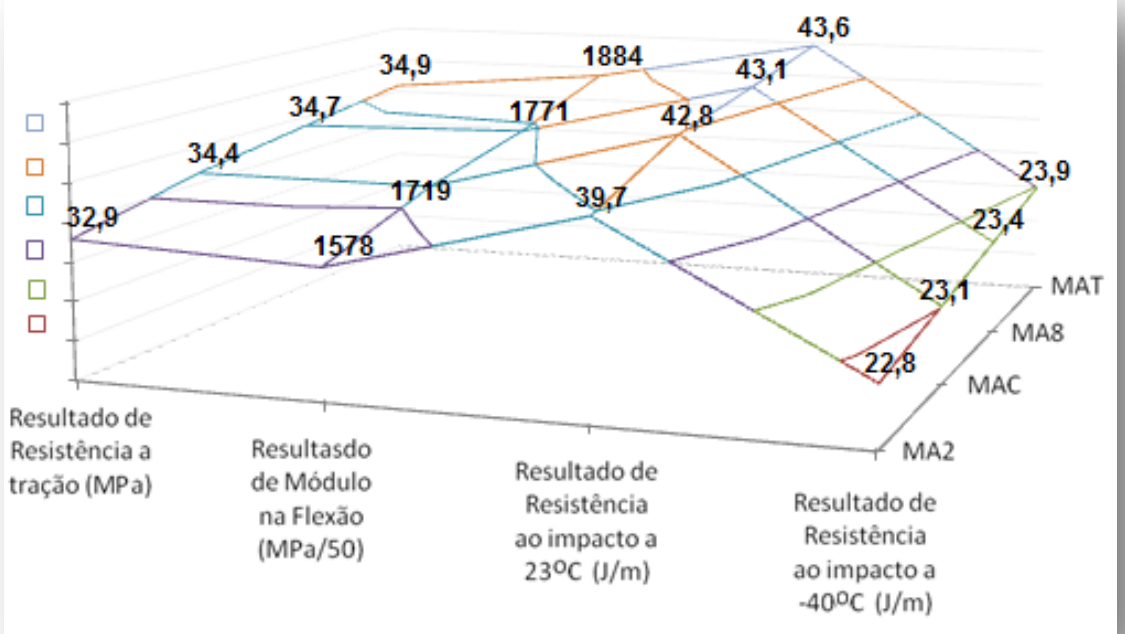

Figura 58: Resultados combinados de resistência à tração, módulo na flexão e resistência ao impacto lzod a $23{ }^{\circ} \mathrm{Ce}-40{ }^{\circ} \mathrm{C}$ das amostras MAT, MA8, MAC e MA2. 
Estes mesmos resultados da Figura 58 são mostrados na Figura 59 em formato gráfico radar.

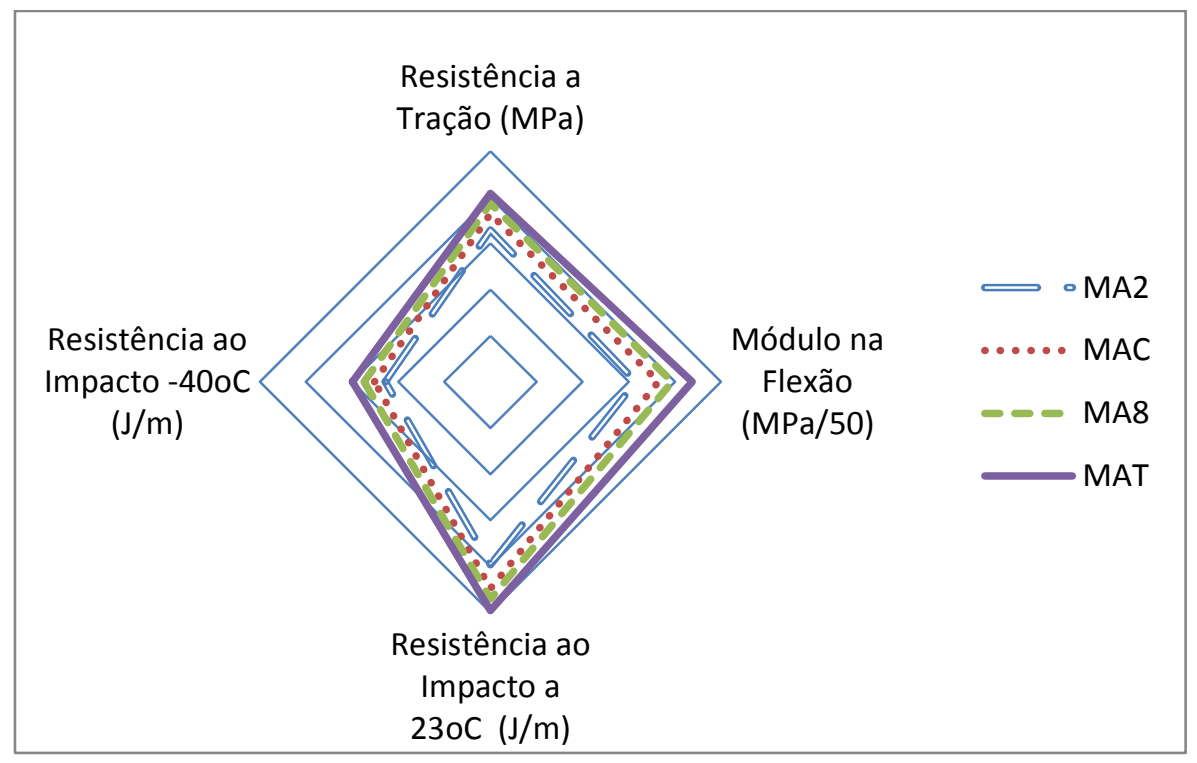

Figura 59: Gráfico radar dos resultados combinados de resistência à tração, módulo na flexão e resistência ao impacto lzod a $23^{\circ} \mathrm{C}$ e $-40^{\circ} \mathrm{C}$ das amostras MAT, MA8, MAC e MA2.

Os resultados numéricos destas amostras seguem descritos na Tabela 17.

Tabela 17: Resultados numéricos combinados de resistência à tração, módulo na flexão e resistência ao impacto lzod a $23^{\circ} \mathrm{Ce}-40^{\circ} \mathrm{C}$ das amostras MAT, MA8, MAC e MA2.

\begin{tabular}{|c|c|c|c|c|}
\hline & $\begin{array}{l}\text { Resultado de } \\
\text { resistência à } \\
\text { tração (MPa) }\end{array}$ & $\begin{array}{l}\text { Resultasdo de } \\
\text { módulo na } \\
\text { flexão (MPa) }\end{array}$ & $\begin{array}{l}\text { Resultado de } \\
\text { resistência ao } \\
\text { impacto a } 23{ }^{\circ} \mathrm{C} \\
(\mathrm{J} / \mathrm{m})\end{array}$ & $\begin{array}{l}\text { Resultado de } \\
\text { resistência ao } \\
\text { impacto a }-40{ }^{\circ} \mathrm{C} \\
(\mathrm{J} / \mathrm{m})\end{array}$ \\
\hline MAT & 34,9 & 1884 & 43,6 & 23,9 \\
\hline MA8 & 34,7 & 1771 & 43,1 & 23,4 \\
\hline MAC & 34,4 & 1719 & 42,8 & 23,1 \\
\hline MA2 & 32,9 & 1578 & 39,7 & 22,8 \\
\hline
\end{tabular}

Conforme havíamos observado pelas análises de cada propriedade (itens 7.1.1, 7.1.2 e 7.1.3) observa-se o aumento de todas as propriedades para as amostras produzidas com tamanho de partícula menores (MAT e MA8). Além disso, todas as amostras produzidas com PP-g-MA tiveram todas as propriedades melhoradas com relação à amostra de PP virgem (referência). Esta melhora 
em todas as propriedades é uma informação contraditória se for avaliado em termos de comportamento mecânico. Desta forma, foi analisada a fase cristalina beta no item 7.4. Visto que alguns estudos de outros autores também indicaram este fenômeno de aumento de todas as propriedades relacionadas à formação da fase cristalina beta [14] [15]. Ou seja, os $\mathrm{CaCO}_{3}$ utilizados juntamente com o PP-g-MA nas condições descritas neste trabalho estaria agindo como nucleante de fase cristalina beta nestas amostras. 


\subsection{Análise da fase cristalina beta dos compósitos}

\subsubsection{Análise da fase cristalina beta através do ensaio de DSC (Varredura diferencial de calorimetria)}

Com o indício de que as melhoras nas propriedades estaria relacionado com a fase cristalina beta tomou-se a providência da análise neste sentido; iniciando, portanto, pela análise de resultados de DSC.

A análise de DSC é comumente utilizada para observação das temperaturas de transição de fases ou cristalinidade dos materiais. No caso específico na atual conjuntura do trabalho o intuito foi a análise da curva calorimétrica em função de alguma alteração devido à cristalinidade beta do material. Desta forma, a Figura 60 mostra a análise apenas das amostras: PP (como referência), MAT, MA8, MAC e MA2, pois foram as amostras que tiveram aumento substancial em todas as propriedades mecânicas avaliadas.

Como descrito anteriormente (item 5.1.1), as análise das curvas de DSC deste trabalho foram obtidas a partir do segundo aquecimento. Ou seja, as amostras foram primeiramente aquecidas a 10 ${ }^{\circ} \mathrm{C}$ por minuto até $230{ }^{\circ} \mathrm{C}$ com o intuito de padronização da história térmica de todos os materiais e depois resfriadas até $-40^{\circ} \mathrm{C}$ a $10^{\circ} \mathrm{C}$ por minuto. As curvas ilustradas (Figura 60) foram obtidas a partir de um segundo aquecimento de $10{ }^{\circ} \mathrm{C}$ por minuto até $200{ }^{\circ} \mathrm{C}$. Os pontos foram extratificados e compilados em conjunto para melhor visualização e análise. 


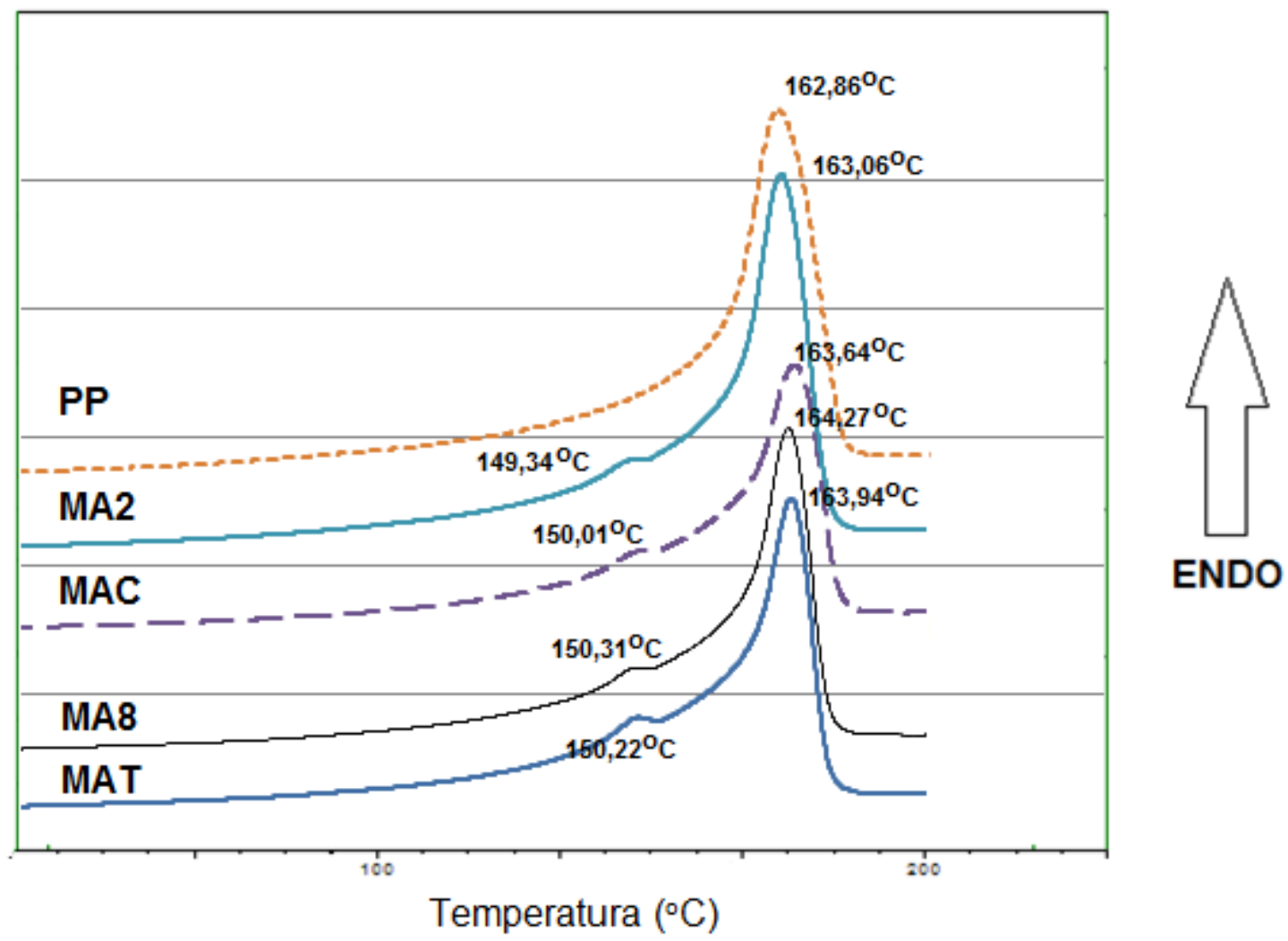

Figura 60: Resultado das curvas de aquecimento por DSC para as amostras de: PP (referência), MA2, MAC, MA8 e MAT.

O primeiro pico gerado (próximo a $150^{\circ} \mathrm{C}$ ) está relacionado a fusão $(\mathrm{Tm})$ da fase cristalina beta e o segundo pico (próximo a $164^{\circ} \mathrm{C}$ ) é relativo a fase cristalina alfa $[14,15]$.

Embora haja meios e procedimentos para o cálculo de quantificação das fases cristalinas (alfa e beta) por meio da análise do calor de fusão e entalpia, o cálculo não gera valores reais, visto que a fase cristalina beta é uma fase metaestável e altera a curva de DSC o que contribui para uma quantificação maior de fase alfa e distorções neste tipo de cálculo quantitativo. Portanto, o estudo de quantificação da fase cristalina beta é medida diretamente das amostras injetadas, utilizando-se o método de difração de raios-X. 


\subsubsection{Análises do percentual de fase cristalina beta por difração de Raios-X (WAXD)}

Esta técnica é bastante utilizada quando é necessária a identificação de estruturas cristalinas em uma gama de materiais. No caso específico deste trabalho, esta análise foi importantíssima, pois, como o ensaio permite a observação de espectros de difração característicos decorrentes dos seus parâmetros de rede cristalina, pôde-se comparar o polipropileno virgem com todas as amostras de PP com $\mathrm{CaCO}_{3}$ produzidas neste trabalho. Numa análise ainda mais detalhada, foi possível a determinação por comparação da fração cristalina e a formação de diferentes fases cristalinas do polipropileno em algumas das amostras. Ou seja, por esta análise podemos evidenciar a fase cristalina alfa, que é mais comum e também observar se há indícios da formação da fase cristalina beta.

$\mathrm{Na}$ Figura 62 seguem os resultados obtidos a partir dos difratogramas de Raios-x e na Figura 63 observam-se os mesmos resultados da Figura 62, porém para as amostras MAT, MA8, MAC e MA2 com pontos adaptados e convertidos para melhor visualização

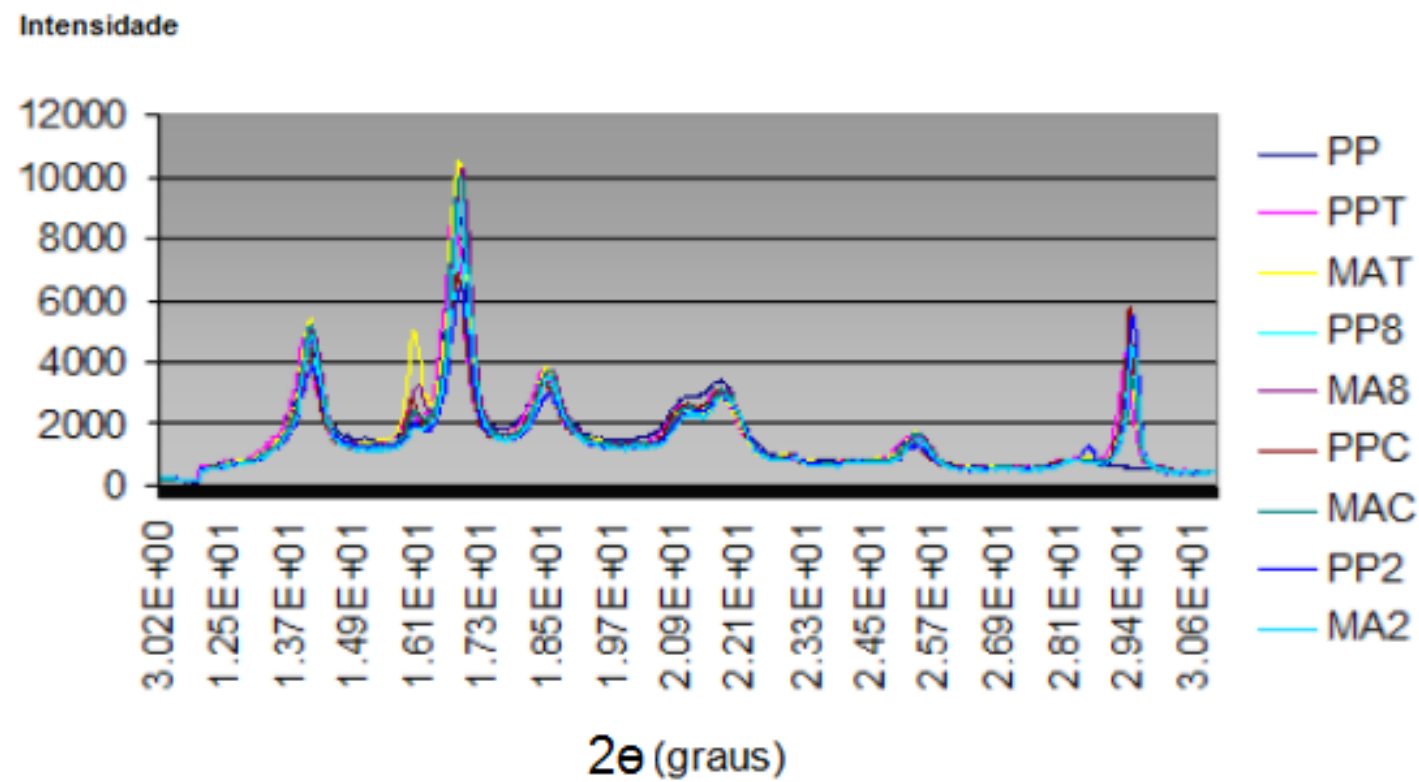

Figura 61: Difratogramas de raios-x para todas as amostras de $\mathrm{CaCO}_{3}$ produzidas. 


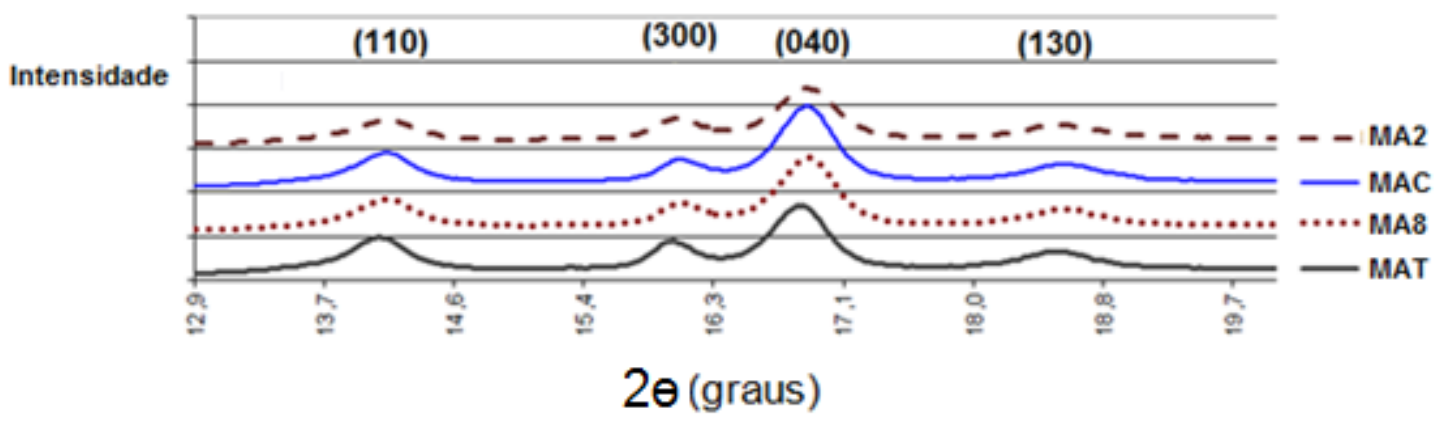

Figura 62: Difratogramas de raios-x extratificados com pontos adaptados e convertidos apenas das amostras MAT, MA8, MAC e MA2 para melhor visualização.

A região compreendida entre $2 \Theta$ igual a $X$ e $Y$ foi analisada. Destaca-se a formação de uma fase cristalina beta no ângulo (2e) $16,1^{\circ}$ [15]. Este pico de difração neste ângulo corresponde ao plano de Miller (300). Também encontramos picos de difração intensos nos ângulos $(2 \Theta) 13,9^{\circ}, 17,0^{\circ}$ e 18,6 $6^{\circ}$ atribuídos aos planos (110), (040) e (130) respectivamente, da forma cristalina alfa [16, 34 e 35].

Uma quantificação de fase cristalina beta pode ser feita utilizando-se a equação empírica descrita pela Equação 4 [15].

$$
K=I(300) \text { beta } /[I(300) \text { beta }+I(110) \text { alfa }+I(130) \text { alfa }+I(040) \text { alfa }]
$$

Equação 4: Equação empírica da quantificação da fase cristalina beta por dados de difração de Raios-x.

Onde: $\mathrm{K}$ é $\mathrm{o}$ índice de fase cristalina beta presente na amostra que varia entre 0 a 1. Correspondentes à fração cristalina da forma beta, ou seja, 0\% a 100\%, respectivamente.

Os resultados deste valor estão mostrados na Tabela 18 e em seguida em forma gráfica na Figura 64 
Tabela 18: Resultados do valor de fase cristalina beta gerada (K) e os respectivos valores para iniciais utilizados para seu cálculo.

\begin{tabular}{cccccc}
\hline PLANO $\Rightarrow$ I(300)beta & I(110)alfa & I(130)alfa & I(040)alfa & K \\
\hline PP & 1806 & 4764 & 3739 & 8944 & 0,09 \\
\hline PPT & 2476 & 4923 & 3745 & 8733 & 0,12 \\
\hline MAT & 5071 & 5396 & 3850 & 10448 & 0,20 \\
\hline PP8 & 2068 & 4387 & 3275 & 7324 & 0,12 \\
\hline MA8 & 3290 & 5124 & 3710 & 10255 & 0,15 \\
\hline PPC & 2040 & 4520 & 3382 & 6877 & 0,12 \\
\hline MAC & 2361 & 5271 & 3783 & 10084 & 0,11 \\
\hline PP2 & 1640 & 3896 & 3027 & 6383 & 0,11 \\
\hline MA2 & 1832 & 4854 & 3625 & 9267 & 0,09 \\
\hline Ângulo=> & $\mathbf{1 6 , 1}$ & $\mathbf{1 3 , 9}$ & $\mathbf{1 8 , 6}$ & $\mathbf{1 7 , 0}$ & \\
\hline
\end{tabular}

\section{Resultados do percentual de fase cristalina beta} (índice $\mathrm{K}$ multiplicado por $100=\%$ )

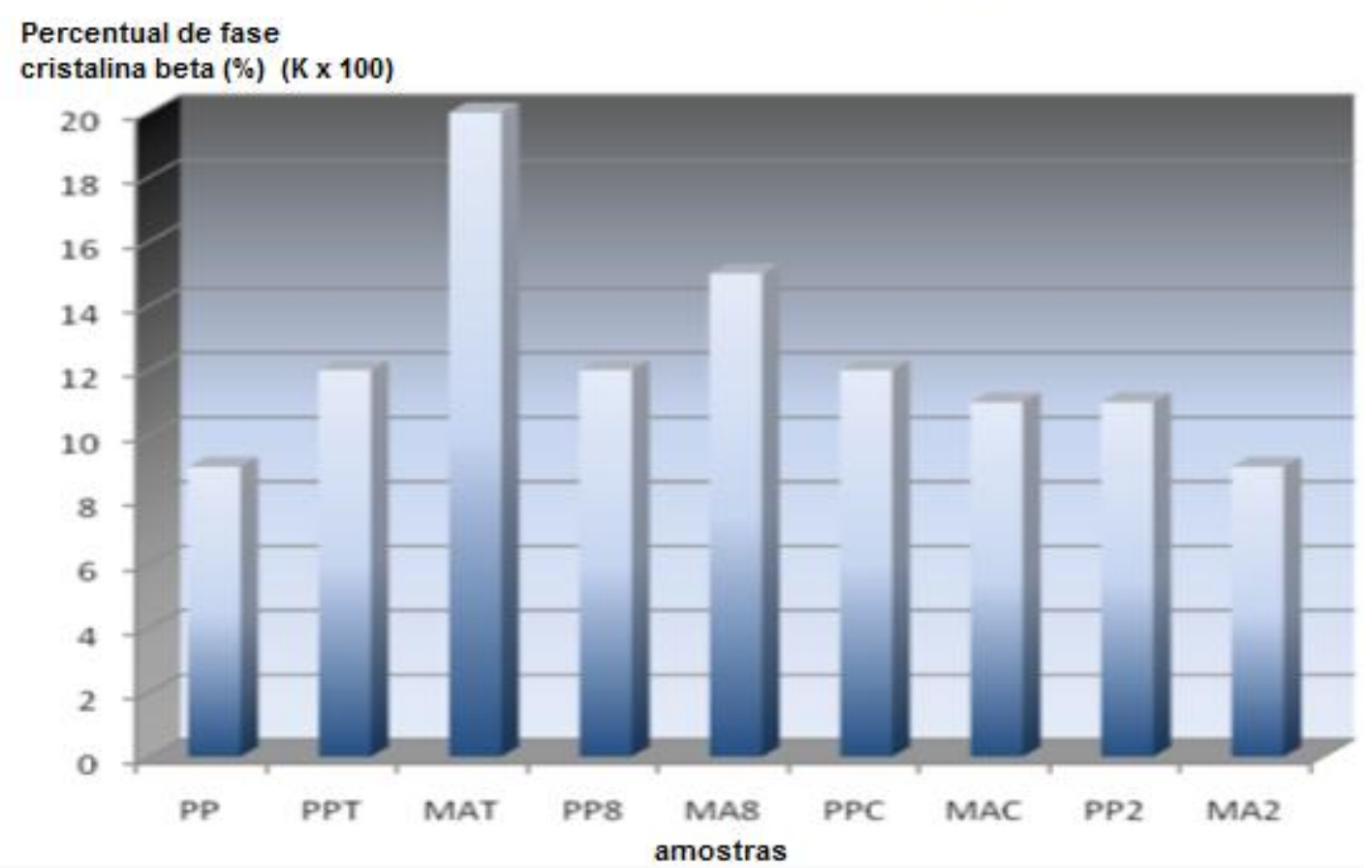

Figura 63: Gráfico dos resultados percentuais de fase cristalina beta gerado nas amostras estudadas.

Observa-se claramente que a amostra MAT com 5\% de Mickhart 08T e 5\% de PP-g-MA foi o que mais gerou a fase cristalina beta. Observa-se também que as amostras produzidas com PP-g- 
MA seguem uma tendência descrescente de acordo com o tamanho de partícula do $\mathrm{CaCO}_{3}$, portanto, as Figuras 65 e 66 as amostras foram separadas em grupos para melhor análise.

\section{Resultados do percentual de fase cristalina beta (índice $\mathrm{K}$ multiplicado por $\mathbf{1 0 0}=\%$ )}
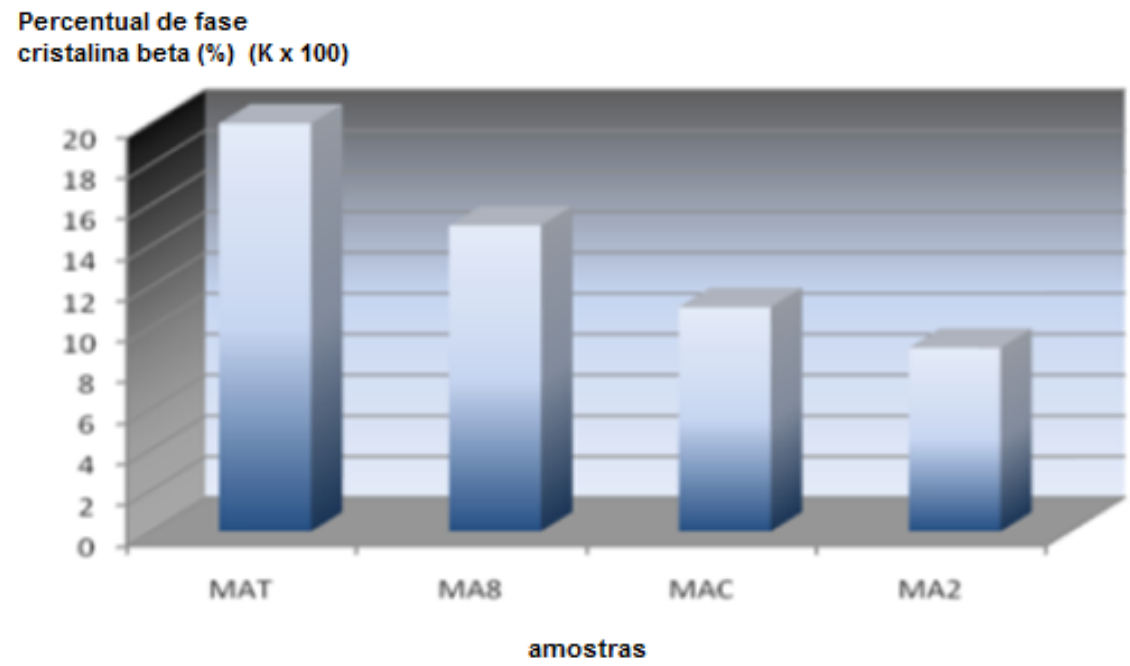

Figura 64: Gráfico dos resultados percentuais de fase cristalina beta gerada nas amostras produzidas com PP-g-MA.

\section{Resultados do percentual de fase cristalina beta} (índice $\mathrm{K}$ multiplicado por $100=\%$ )
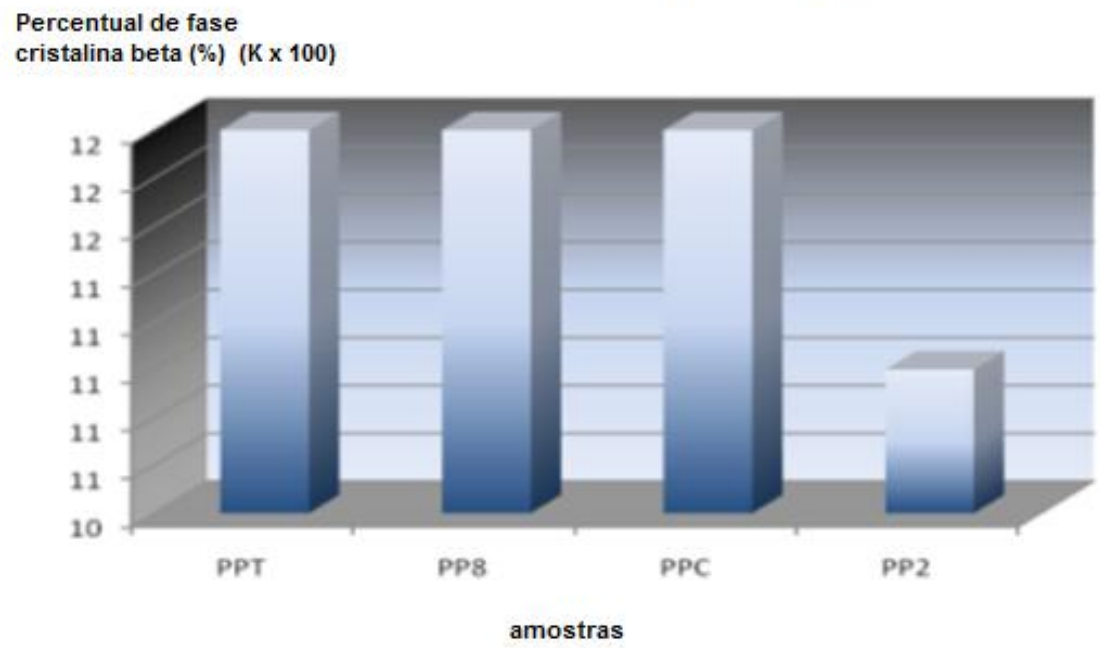

Figura 65: Gráfico dos resultados percentuais de fase cristalina beta gerada nas amostras produzidas sem PP-g-MA. 
Observa-se pela Figura 65 que as amostras com PP-g-MA apresentaram maior tendência à formação da fase, dependendo do tamanho de partícula do $\mathrm{CaCO}_{3}$ utilizado. Além disso, a tendência mostrou-se inversamente proporcional; ou seja, quanto menor, maior a tendência à formação da fase cristalina beta.

Observa-se que as amostras MAT e MA8, produzidas respectivamente com os carbonatos de cálcio Mickhart 08T e Mickhart 08, tiveram quantificações de fase cristalina beta distintas apesar destes produtos terem tamanhos de partícula semelhantes. Isso nos leva a concluir que o tratamento superficial prévio do fabricante foi suficiente para uma melhora no efeito nucleante deste carbonato de cálcio (Mickhart 08T).

Observa-se pela Figura 66 que houve uma formação aproximada de 12 a 11\% para as amostras produzidas sem PP-g-MA. O que indica que o tamanho de partícula não influencia para este grupo de amostra.

A partir destes resultados de percentual de fase cristalina beta seria necessário fazer uma correlação com os resultados das propriedades analisadas (resistência à tração, módulo na flexão e resistência ao impacto) das amostras produzidas com PP-g-MA. Estas informações são mostradas na Tabela 19 e nas Figuras 67, 68 e 69.

Tabela 19: Correlação de todas as propriedades e o percentual de fase cristalina formada nas amostras produzidas com PP $+\mathrm{CaCO}_{3}+\mathrm{PP}-\mathrm{g}-\mathrm{MA}$.

\begin{tabular}{|c|c|c|c|c|c|}
\cline { 2 - 6 } & $\begin{array}{c}\text { Resultado } \\
\text { de } \\
\text { Resistência } \\
\text { a tração } \\
\text { (MPa) }\end{array}$ & $\begin{array}{c}\text { Resultado } \\
\text { de Módulo } \\
\text { na Flexão } \\
(\mathrm{MPa} / 50)\end{array}$ & $\begin{array}{c}\text { Resultado } \\
\text { de } \\
\text { Resistência } \\
\text { ao impacto } \\
\text { a 23oC } \\
(\mathrm{kJ} / \mathrm{m} 2)\end{array}$ & $\begin{array}{c}\text { Resultado } \\
\text { de } \\
\text { Resistência } \\
\text { ao impacto } \\
\text { a-400C } \\
(\mathrm{kJ} / \mathrm{m} 2)\end{array}$ & $\begin{array}{c}\text { Percentual } \\
\text { de fase } \\
\text { cristalina } \\
\text { beta }\end{array}$ \\
\hline -MA2 & 32,9 & 1578 & 39,7 & 22,8 & 9,0 \\
\hline -MAC & 34,4 & 1719 & 42,8 & 23,1 & 11,0 \\
\hline -MA8 & 34,7 & 1771 & 43,1 & 23,4 & 15,0 \\
\hline -MAT & 34,9 & 1884 & 43,6 & 23,9 & 20,0 \\
\hline
\end{tabular}




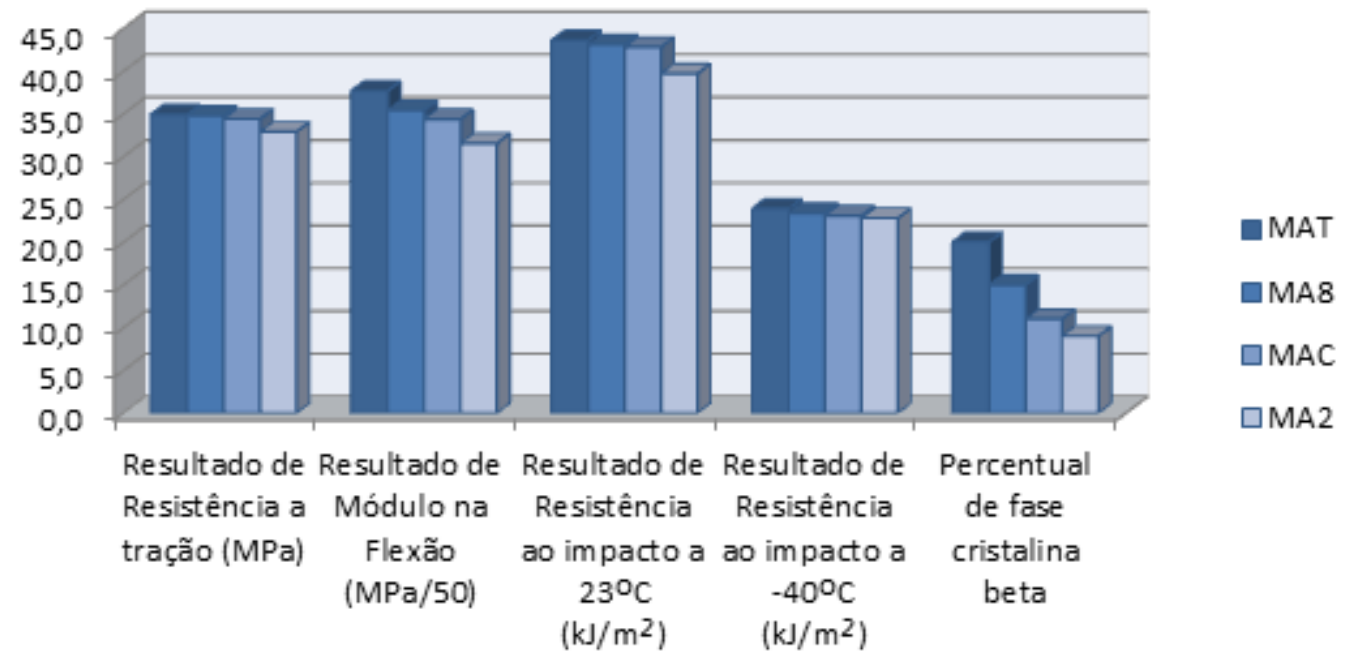

Figura 66: Gráfico da correlação de todas as propriedades e o percentual de fase cristalina formada nas amostras produzidas com PP + $\mathrm{CaCO}_{3}+$ PP-g-MA.

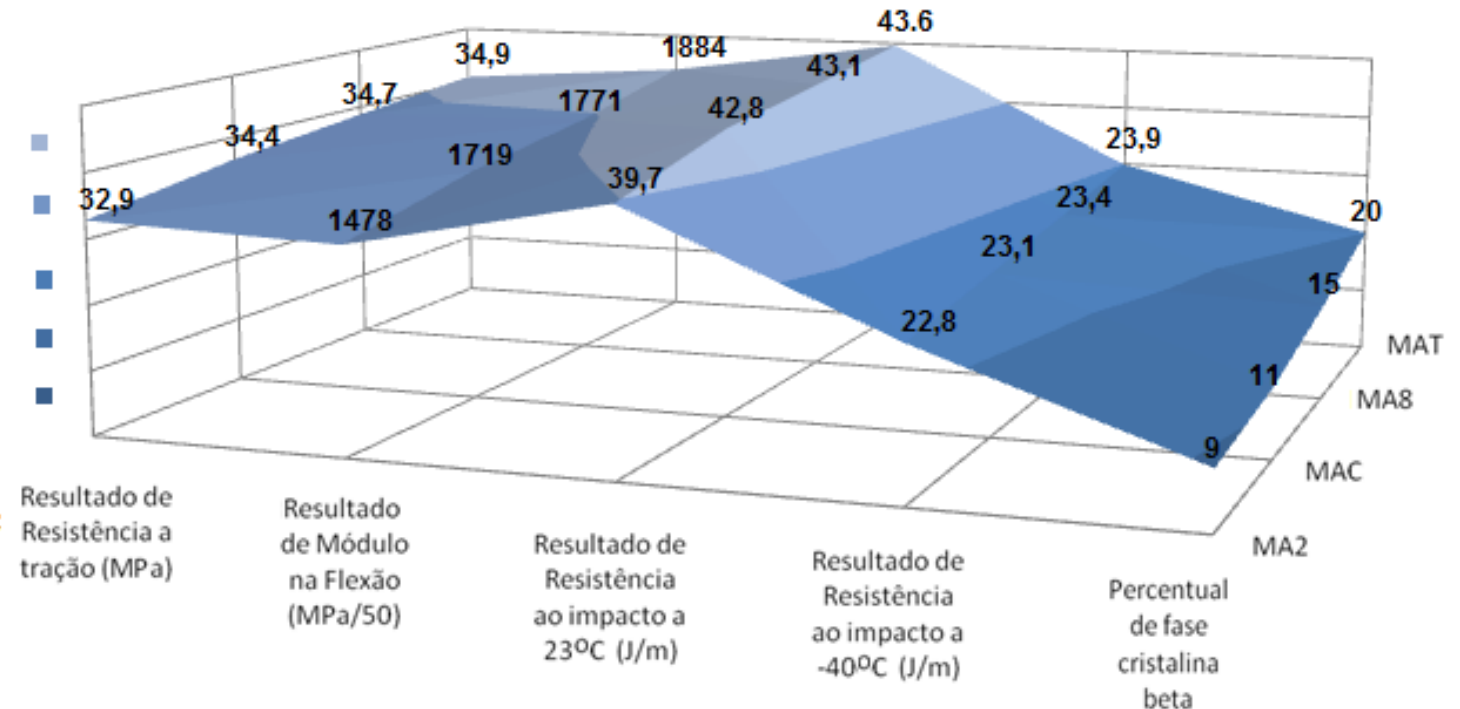

Figura 67: Gráfico da correlação tridimensional de todas as propriedades e o percentual de fase cristalina formada nas amostras produzidas com PP + $\mathrm{CaCO}_{3}+$ PP-g-MA. 


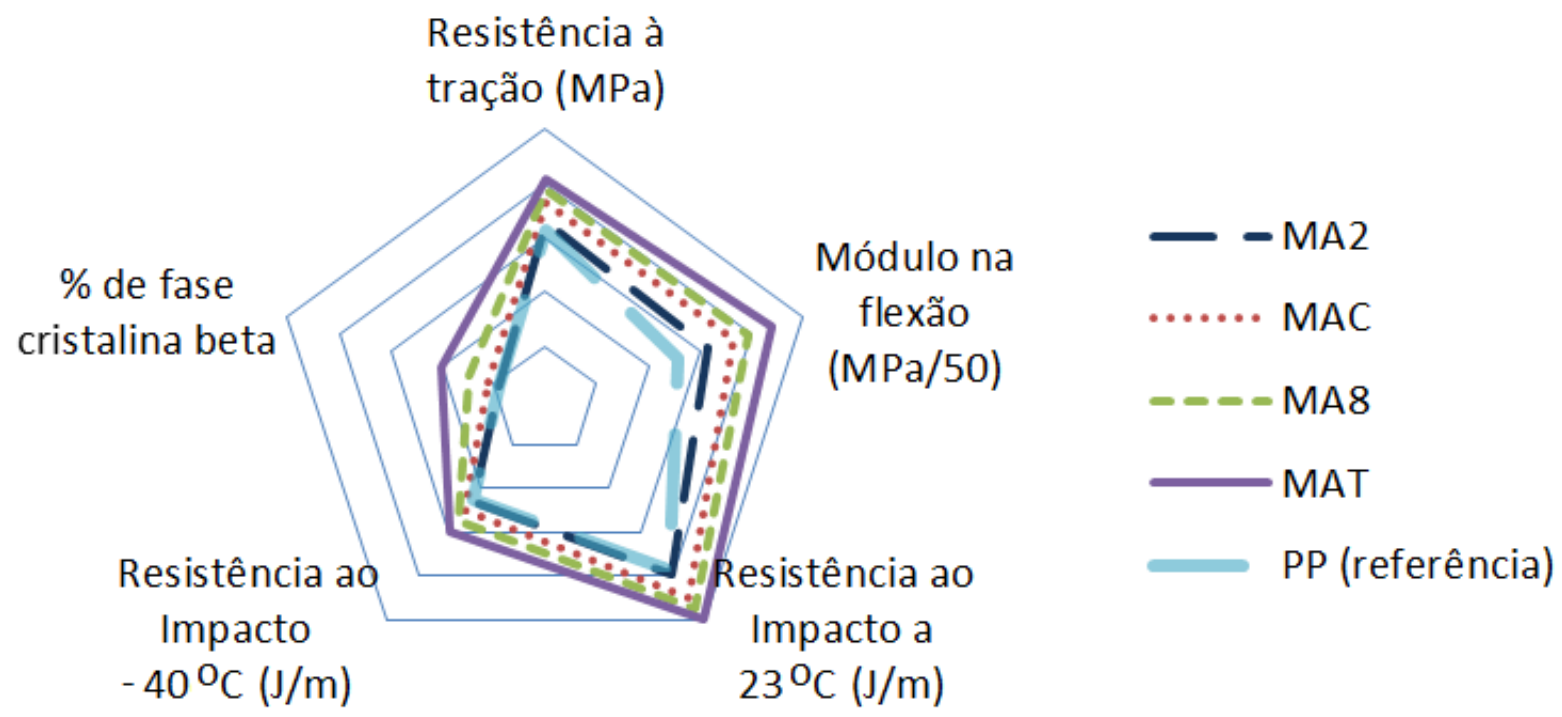

Figura 68: Gráfico radar da correlação de todas as propriedades e o percentual de fase cristalina formada nas amostras produzidas com PP + $\mathrm{CaCO}_{3}+$ PP-g-MA.

Com estes resultados mostrados na Tabela 19, bem como nas Figuras 67, 68 e 69 observa-se uma clara correlação diretamente proporcional entre o percentual de fase cristalina beta com os resultados das propriedades de resistência à tração, módulo na flexão e resistência ao impacto Izod com entalhe.

Para uma análise minuciosa destes efeitos potencializados, pôde-se observar a partir dos resultados da amostra MAT. Observa-se que esta amostra resultou em melhores propriedades de resistência à tração e módulo na flexão em função do uso do PP-g-MA e do tipo de $\mathrm{CaCO}_{3}$ utilizado. E, melhores propriedades de resistência ao impacto (a $23{ }^{\circ} \mathrm{C}$ e a $-40{ }^{\circ} \mathrm{C}$ ) ocorreram em função direta do aumento da fase cristalina beta. Ou seja, o carbonato de cálcio utilizado (Mickhart 08T) somado ao PP-g-MA teve: a. uma função de carga mineral de reforço no compósito, que resultou melhores propriedades de resistência à tração e módulo na flexão e $\boldsymbol{b}$. uma função de nucleante de fase cristalina beta, que proporcionou um aumento significativo para os resultados de impacto (a $23 \stackrel{\circ}{\mathrm{C}}$ e a $-40 \stackrel{\circ}{\circ})$ 
7.5 Análise da influência do tamanho de partícula dos carbonatos de cálcio inseridos nas amostras e sua influência no percentual de fase cristalina beta

Esta análise foi possível com a comparação dos resultados das amostras produzidas com Mickhart 08, Mickhart $\mathrm{C}$ e Mickhart 2, os quais tem tamanhos de partícula os de 0,9 $\mu \mathrm{m}, 2,5 \mu \mathrm{m}$ e 3,0 $\mu \mathrm{m}$ respectivamente, conforme vemos na tabela 20 e Figuras 70 e 71.

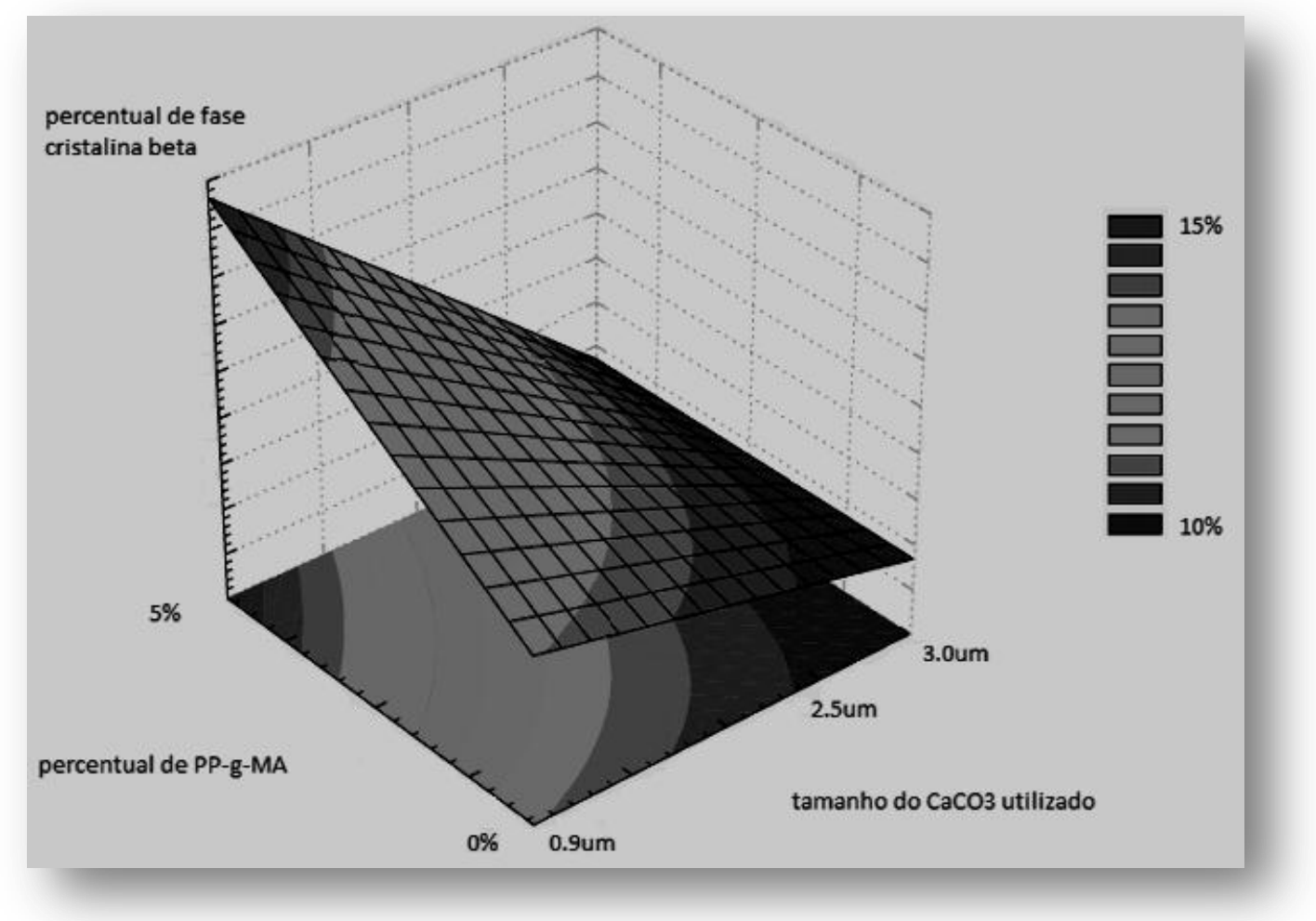

Figura 70: Gráfico da análise visual tridimensional da formação da fase cristalina beta de acordo com as variáveis: tamanho de partícula do $\mathrm{CaCO}_{3}$ e percentual de PP-g-MA utilizado (o máximo de $5 \%$ de PP-g-MA correspondente a $0,05 \%$ de anidrido maléico graftizado)

Tabela 20: Resultados numéricos da formação da fase cristalina beta de acordo com a correlação do tamanho de partícula do $\mathrm{CaCO}_{3}$, com e sem a utilização de $5 \%$ de PP-g-MA (0,05\% de anidrido maléico graftizado).

\begin{tabular}{|c|c|c|}
\cline { 2 - 3 } \multicolumn{1}{c|}{} & $\begin{array}{c}\text { percentual de fase cristalina beta } \\
\text { formado nas amostras sem anidrido } \\
\text { male ico }\end{array}$ & $\begin{array}{c}\text { percentual de fase cristalina beta } \\
\text { formado nas amostras com } 0,05 \% \text { de } \\
\text { anidrido male ico }\end{array}$ \\
\hline 3 & 11,00 & 9,00 \\
\hline 2,5 & 12,00 & 11,00 \\
\hline 0,9 & 12,00 & 15,00 \\
\hline
\end{tabular}


Resultados do percentual de fase cristalina beta

(indice $\mathrm{K}$ multiplicado por $100=\%$ )

Percentual de fase

cristalina beta $(\%)(\mathrm{K} \times 100)$

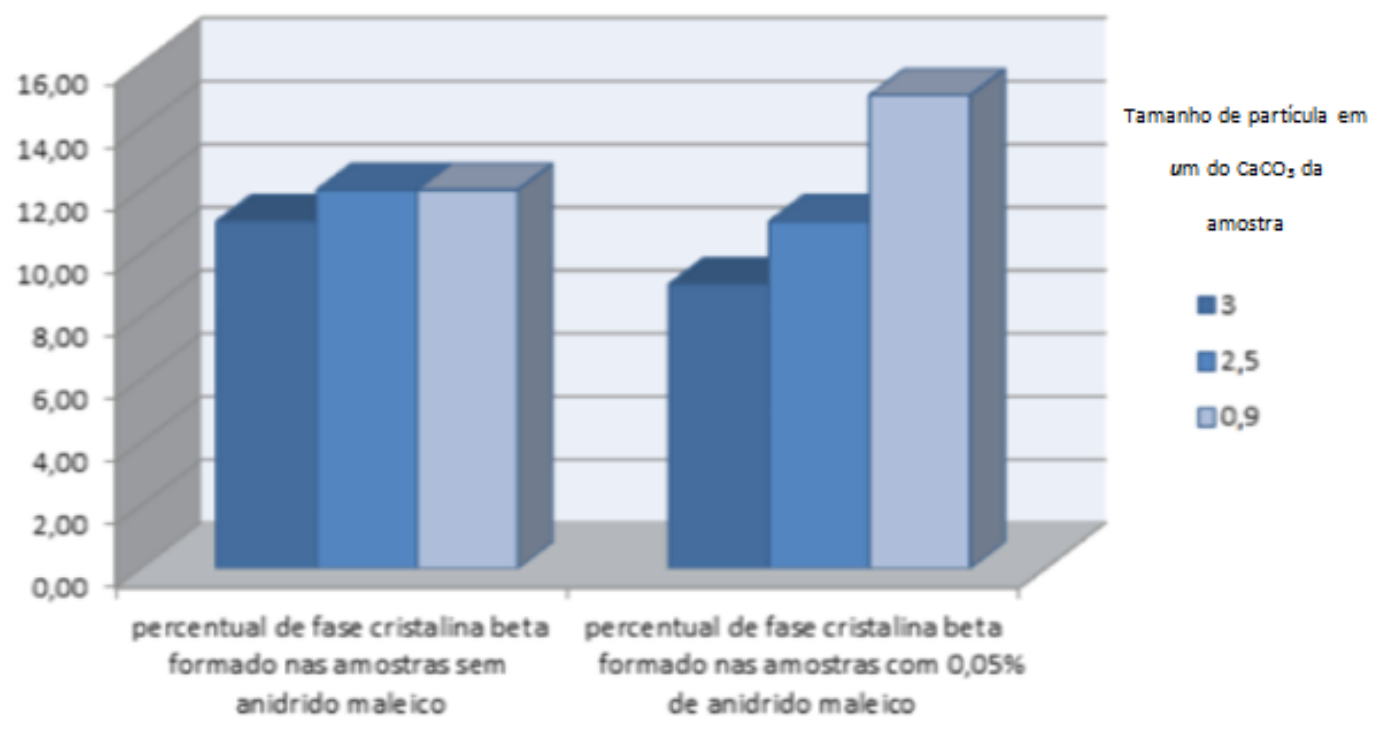

Figura 71: Análise visual da formação da fase cristalina beta de acordo com a correlação do tamanho de partícula do $\mathrm{CaCO}_{3}$, com e sem a utilização de 5\% de PP-g-MA (0,05\% de anidrido maléico graftizado).

As amostras produzidas com Mickhart 08T não foram analisadas neste item 7.5 , pois este $\mathrm{CaCO}_{3}$ é comercializado com prévio tratamento superficial pelo fornecedor. Por motivos comerciais, a tecnologia envolvida neste tratamento superficial prévio não foi revelada e não se encontra neste trabalho.

A partir da Tabela 20 e das Figuras 70 e 71, observa-se que há uma correlação proporcionalmente inversa entre o tamanho de partícula utilizado e a formação da fase cristalina beta. Quanto menor a partícula, observou-se um maior percentual de fase cristalina beta formado. Observa-se também que esta correlação entre o tamanho de partícula e a formação da fase cristalina beta é evidenciado de forma mais visível com a utilização do PP-g-MA.

Indicamos como sugestão para trabalhos futuros um estudo mais abrangente da Figura 70, pois a quantidade de pontos utilizados foi insuficiente para maiores detalhamentos e conclusões sobre a influência destas variáveis de tamanho de partícula e quantidade de PP-g-MA na formação da fase cristalina beta. 


\subsection{Análise da aderência superficial entre o $\mathrm{PP}$ e $\mathrm{CaCO}_{3}$ e sua influência no percentual de fase cristalina beta}

Esta análise foi possível, pois temos quatro amostras nas quais foram utilizados $\mathrm{CaCO}_{3}$ de tamanho de partícula 0,9 $\mu \mathrm{m}$ : PP8, PPT, MA8 e MAT. Ou seja, a amostra PP8 é uma amostra de PP + 5\% Mickhart $08(0,9 \mu \mathrm{m})$, a amostra PPT trata-se de PP + 5\% Mickhart 08T $(0,9 \mu \mathrm{m}$ previamente tratada pelo fabricante), a amostra MA8 trata-se de PP $+5 \%$ Mickhart $08+5 \%$ de PP-g-MA e por fim, a amostra MAT é o PP + 5\% Mickhart 08T + 5\% de PP-g-MA.

Podemos afirmar, dessa forma, que estas quatro amostras são diferenciadas apenas pela variável de adesão superficial entre $\circ \mathrm{CaCO}_{3}$ e a matriz de PP. A amostra PP8 tem menor adesão superficial e a amostra MAT, maior adesão. O aumento de adesão superficial tem a sequência: PP8 $<$ PPT $<$ MA8 $<$ MAT.

Desta forma, a Figura 72 traz o percentual de fase cristalina beta formado para estas amostras.

Resultados do percentual de fase cristalina beta

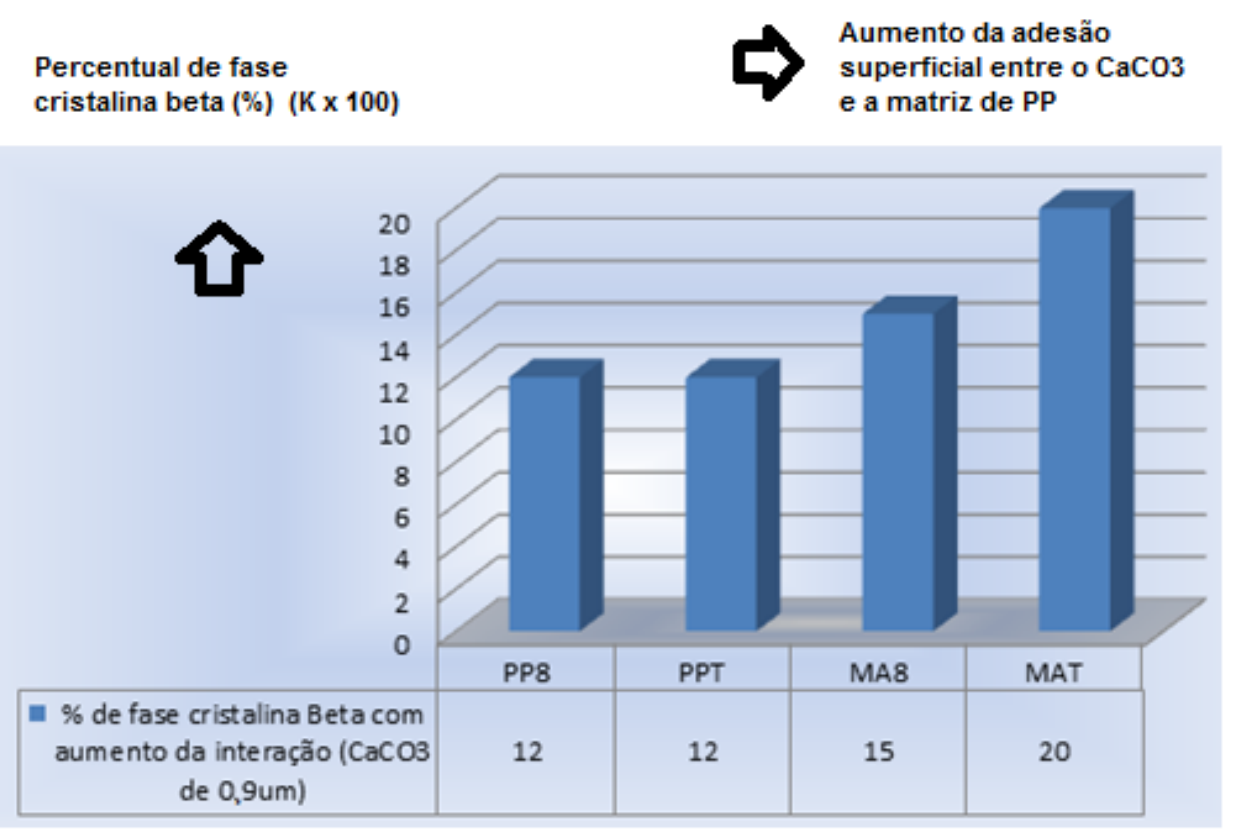

Figura 72: Gráfico e valores numéricos de fase cristalina formada variando-se a adesão superficial entre 0 $\mathrm{CaCO}_{3}$ de $0,9 \mu \mathrm{m}$ e a matriz de PP. 
Observa-se pela Figura 72 que a adesão superficial entre $\circ \mathrm{CaCO}_{3}$ e a matriz de PP é diretamente proporcional à formação da fase cristalina beta. Ou seja, quanto maior a adesão superficial entre o $\mathrm{CaCO} 3$ e a matriz de $\mathrm{PP}$, maior o aumento percentual da fase cristalina beta nos compósitos produzidos com $5 \%$ de carbonatos de cálcio de tamanho de partícula 0,9 $\mu \mathrm{m}$.

A partir desta informação, tornou-se necessária uma análise mais detalhada com os resultados de propriedades mecânicas estudadas até aqui.

As Figuras 73 e 74 correlacionam os resultados mecânicos (resistência à tração, módulo na flexão e resistência ao impacto a $23^{\circ} \mathrm{C}$ e a $-40 \stackrel{\circ}{\circ}$ ) com os resultados de percentual de fase cristalina beta para estas amostras (PP8, PPT, MA8 e MAT).

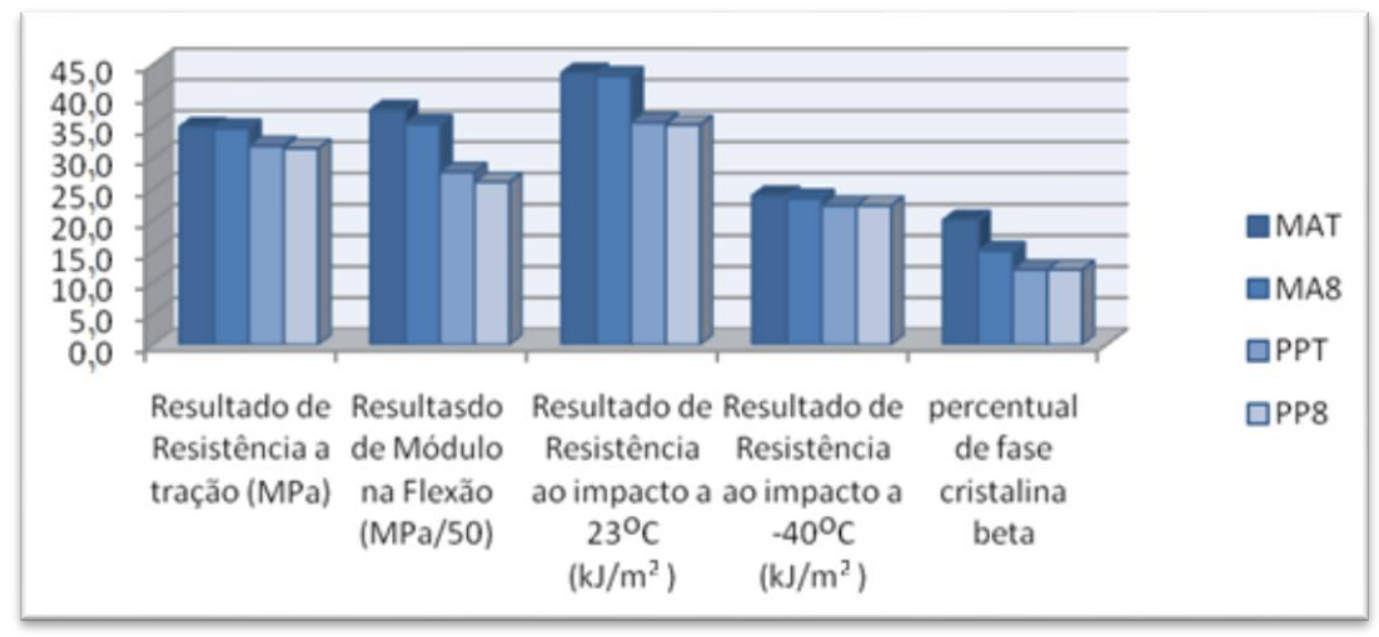

Figura 73: Gráfico dos resultados da formação da fase cristalina beta e resultados físicos de acordo com a variação da interação entre a carga e os $\mathrm{CaCO}_{3}$ de $0,9 \mu \mathrm{m}$.

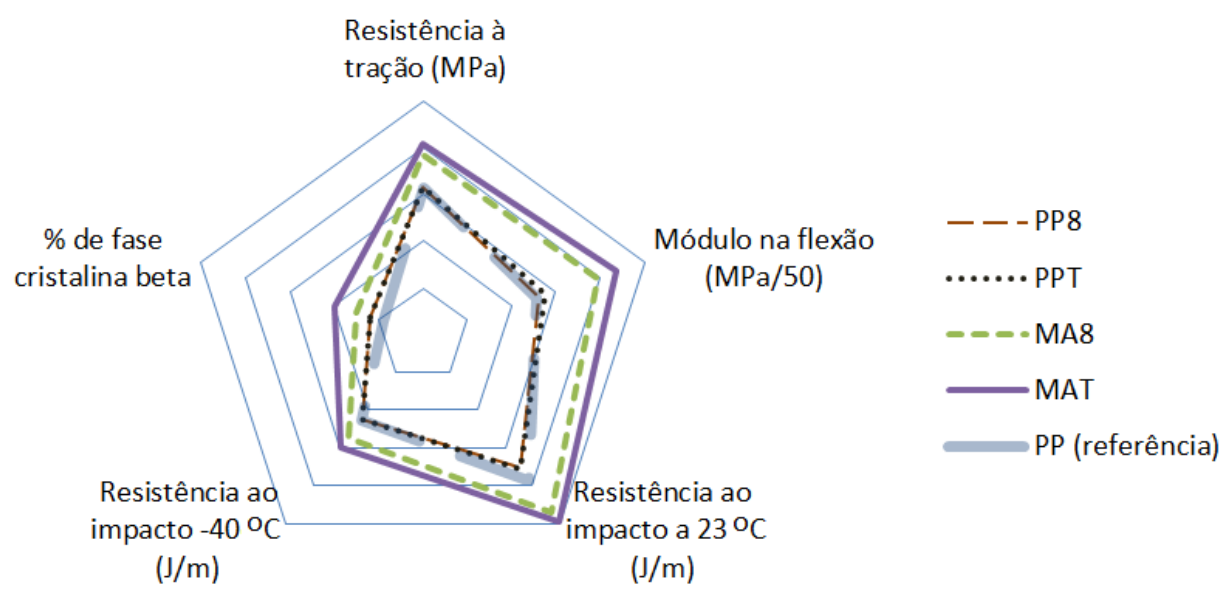

Figura74: Análise gráfica (radar) do aumento da formação da fase cristalina beta e dos resultados físicos com o aumento da interação superficial entre a carga e todos os $\mathrm{CaCO}_{3}$ de $0,9 \mu \mathrm{m}$. 
A partir das Figuras 73 e 74 observa-se a importância do aumento da adesão interfacial entre a carga $\left(\mathrm{CaCO}_{3}\right.$ de tamanho de partícula $\left.0,9 \mu \mathrm{m}\right)$ e a matriz (PP) na melhora das propriedades mecânicas estudadas (resistência à tração, módulo na flexão e resistência ao impacto a $23{ }^{\circ} \mathrm{C}$ e a $40 \stackrel{\circ}{ } \mathrm{C})$.

Apesar de visualmente observarmos que todos os resultados estão todos diretamente proporcionais e correlacionados, há duas informações importantes que devem ser discutidas:

1. Observa-se que o aumento da adesão interfacial nos compósitos estudados (PP8, PPT, MA8 e MAT) auxiliou a função do $\mathrm{CaCO}_{3}$ como carga mineral de reforço nos compósitos, que resultou em melhores propriedades de resistência à tração e módulo na flexão. Observa-se também a importância da adesão superficial para este efeito (como carga mineral de reforço), pois não se observou o aumento das propriedades de rigidez (resistência à tração e módulo na flexão) nas amostras PP8 e PPT.

2. Observa-se também que o aumento da adesão interfacial nos compósitos PP8, PPT, MA8 e MAT proporcionou o aumento do efeito nucleante de fase cristalina beta nestes compósitos. Este aumento no percentual de fase cristalina beta proporcionou o aumento dos resultados de impacto (a $23^{\circ} \mathrm{C}$ e a $-40 \stackrel{\circ}{\circ}$ ) [14, 15]. Isto é observado através da comparação entre estes dois resultados que são diretamente proporcionais (Figuras 73 e 74). 


\subsection{Análise de resultados de MEV (microscopia eletrônica de varredura)}

Foram feitas análises das superfícies de fratura criogênica das amostras. As superfícies foram tratadas previamente em ácido clorídrico para retirada do $\mathrm{CaCO}_{3}$ superficial. Observa-se o resultado das micrografias através das Figuras 75 e 76.

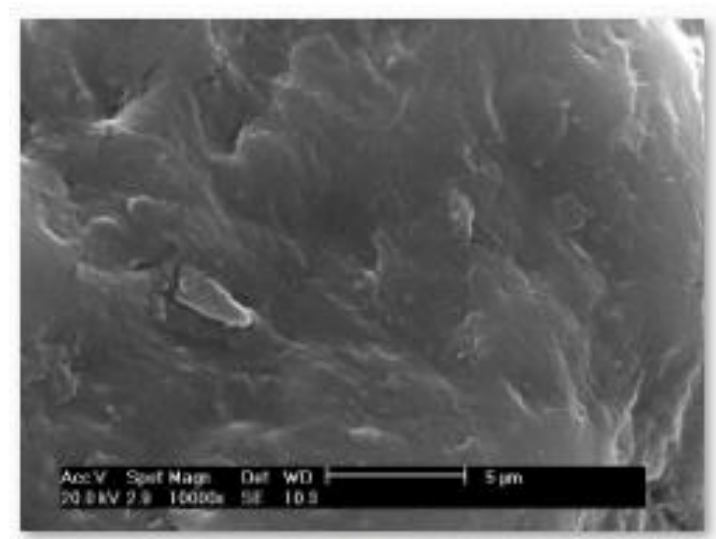

MAT

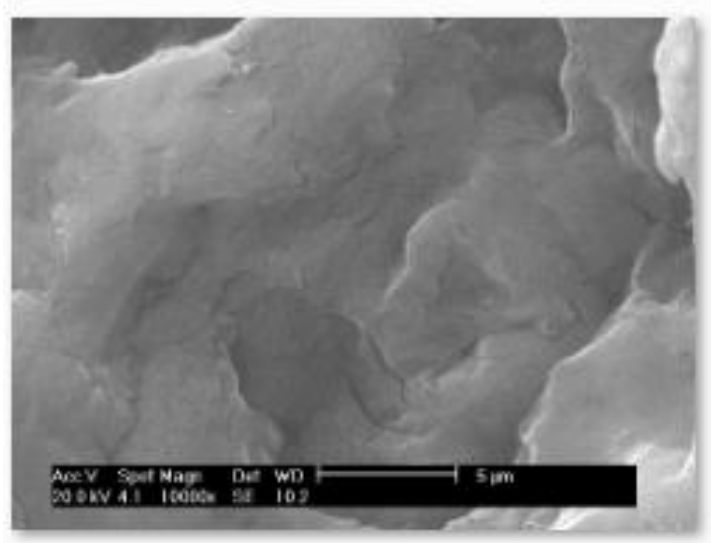

MAC

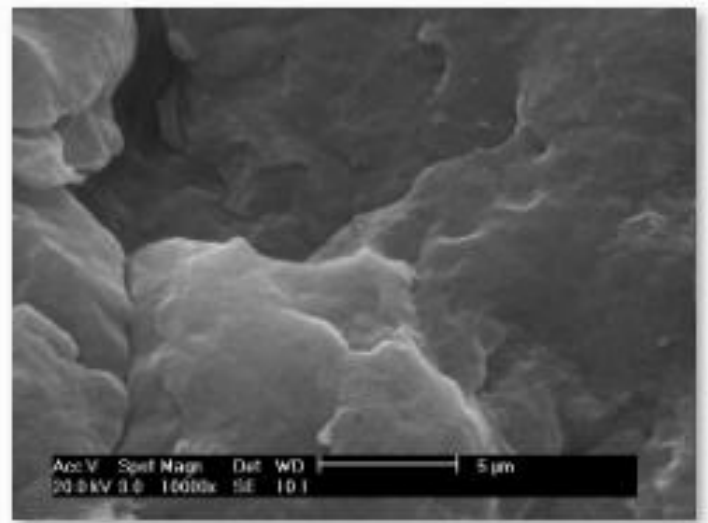

MA8

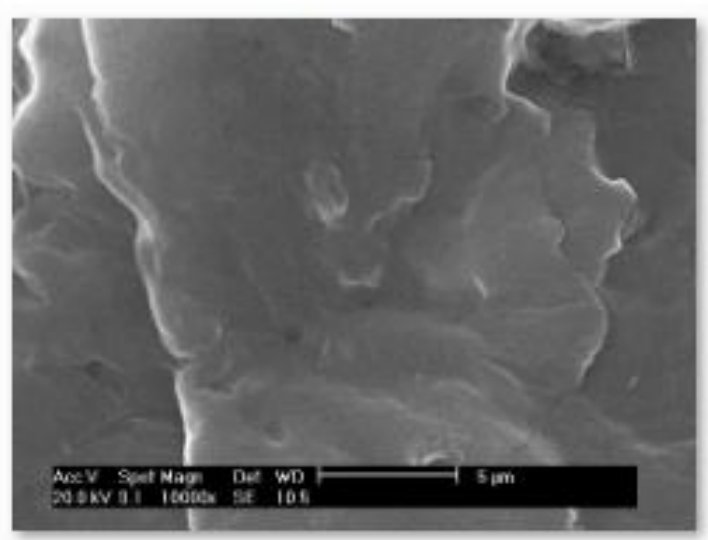

MA2

Figura 75: Microscopias das amostras de PP + $\mathrm{CaCO}_{3}+$ PP-g-MA. 


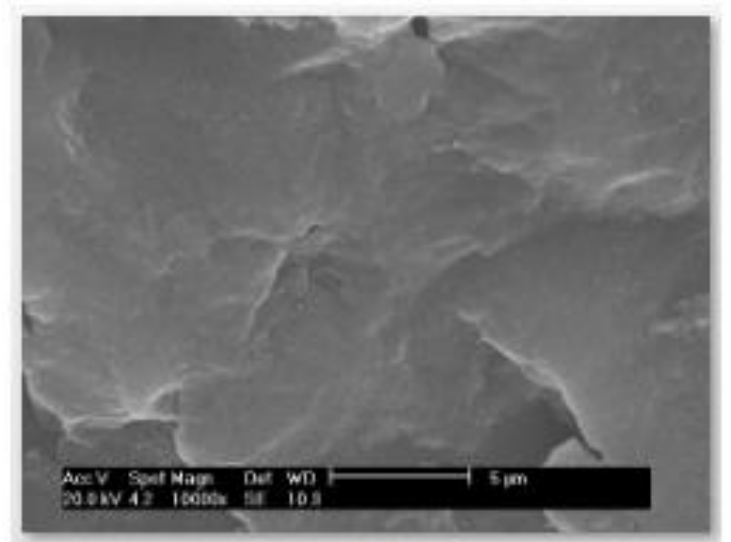

PPT

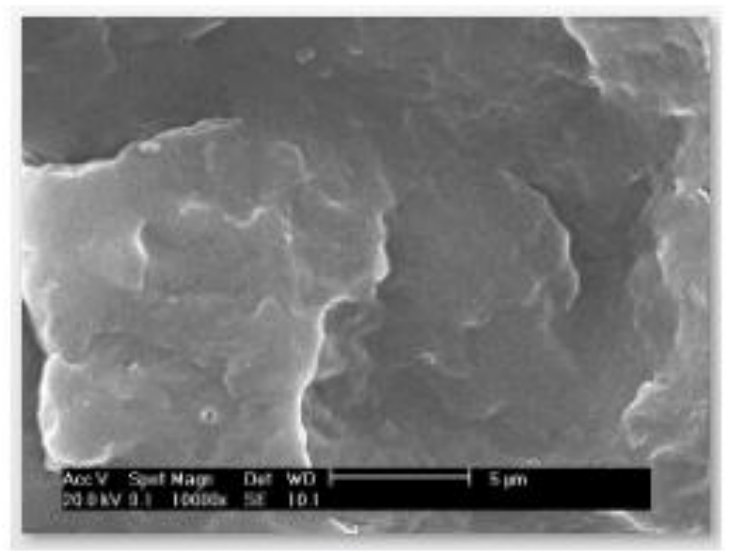

PPC

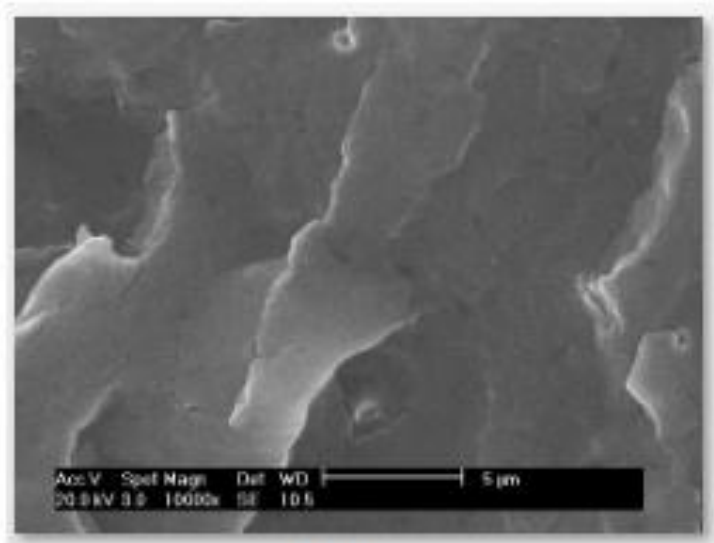

PP8

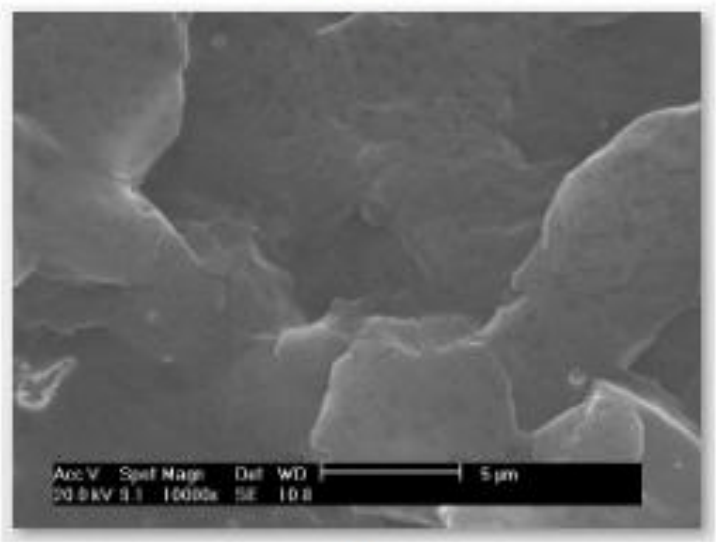

PP2

Figura 76: Microscopias das amostras de PP $+\mathrm{CaCO}_{3}$.

O nível de aumento foi de 20000 vezes, o que não foi suficiente para análise quanto à diferenciação das fases presentes nas amostras. Nota-se uma ligeira diferença na amostra MAT quanto à superfície que apresenta mais rugosidades em comparação com as outras amostras. Porém como a superfície é bastante sensível ao manuseio durante a fratura criogênica (quebra após 2 horas em nitrogênio líquido) esta diferença pode estar relacionada ao preparo prévio da amostra. Não foram encontradas, portanto, informações de grande relevância por este método. 


\section{CONCLUSÕES}

A reação de graftização realizada neste estudo demonstrou grande eficácia de reação com baixo rendimento no processo por batelada (em balão) de reaço e pequena eficácia no processo contínuo (extrusão reativa), entretanto com grande rapidez. No primeiro caso, foram obtidas amostras com elevada graftização, como mostraram os seus espectros FTIR e EDS, nos quais não se observou a presença de oxigênio. Na extrusão reativa, infelizmente, o método não foi homogêneo devido à dificuldade no controle da alimentação de matérias primas, resultando em amostras com diferenças no aspecto físico e na cor e a baixa eficácia de graftização observada pelos espectros FTIR e presença de oxigênio por EDS.

O baixo rendimento de produção observado pelo método de balão volumétrico e a baixo índice de graftização observado pelo método de extrusão reativa fez com que descidíssimos utilizar o PP-g-MA pronto e já comercializado (Polibond 3200 da Chemtura).

Foram produzidos as duas séries de compósitos de polipropileno contendo carbonato de cálcio $\left(\mathrm{CaCO}_{3}\right)$ com PP-g-MA presente ou ausente. Para isto foi utilizada uma pré-etapa de produção de masterbatchs garantindo uma incorporação uniforme do $\mathrm{CaCO}_{3}$ nos compósitos produzidos.

Os $\mathrm{CaCO}_{3}$ de tamanhos na faixa de unidades de micron necessitam de uma grande adesão interfacial com a matriz de PP para serem utilizadas eficazmente. Caso não exista um terceiro componente que aumente a interação entre a carga e a matriz (PP-g-MA), as propriedades que exigem resistência mecânica são afetadas negativamente. Esta informação é confirmada pelos baixos resultados de resistência à tração e módulo na flexão da amostra PP8 (PP $\left.+5 \% \mathrm{CaCO}_{3}\right)$.

Foi possível aumentar propriedades diametralmente opostas como a resistência à tração e módulo na flexão sem que ocorressem perdas nas propriedades de resistência ao impacto. A partir das análises DRX, pôde-se concluir que este fenômeno é devido à formação da fase cristalina beta na matriz de polipropileno. Este comportamento já havia sido estudado por outros autores [14] [15] e foi confirmado através deste trabalho.

Pôde-se concluir que a fase cristalina beta induzida com o uso do $\mathrm{CaCO}_{3}$ é o fator determinante para o fenômeno de aumento nos valores de resistência mecânica. Ou seja, nas 
amostras com maior incremento em todas as propriedades mecânicas analisadas encontrou-se a maior concentração da fase cristalina beta. Estas informações também foram confirmadas pelos resultados das propriedades da amostra MAT, principalmente, em comparação com o aumento do percentual de fase cristalina beta.

Apesar de observarmos que todos os resultados estão todos diretamente proporcionais e correlacionados com o aumento da fase cristalina beta, existem dois direcionamentos distintos e importantes que devem ser analisados para a explicação deste fenômeno:

1. Observa-se que o aumento das propriedades de resistência à tração e módulo de flexão está relacionado com a eficiência da carga mineral utilizada como reforço dentro da matriz de PP.

2. Observa-se que o aumento das propriedades de resistência ao impacto (a $23^{\circ} \mathrm{C}$ e a -40 ${ }^{\circ}$ C) está relacionado com a eficiência da carga mineral utilizada como nucleante de fase cristalina beta do PP.

Quanto à formação da fase cristalina beta, pôde-se concluir que o tamanho de partícula do $\mathrm{CaCO}_{3}$ é um fator determinante. Quanto menor o tamanho de partícula desta carga mineral, maior a formação da fase beta.

Pôde-se observar também que um terceiro componente, PP-g-MA, potencializou a formação da fase cristalina beta. Esta informação pôde ser observada através da análise da fase cristalina beta por DRX. Observou-se que as amostras que não continham este componente (PPT, PP8, PPC e PP2) resultaram em baixos percentuais de fase cristalina beta.

Pôde-se concluir, finalmente, que o aumento do percentual de fase cristalina beta do PP é mais eficaz quando existe a união destes dois fatores: 1. Quando se utiliza o $\mathrm{CaCO}_{3}$ de tamanho de partícula reduzido, próximos à escala manométrica e 2. Quando existe um aumento da adesão interfacial entre esta carga $\left(\mathrm{CaCO}_{3}\right)$ e a matriz de polipropileno. 


\section{SUGESTÕES PARA TRABALHOS FUTUROS}

A seguir são apresentadas algumas sugestões para trabalhos futuros:

- Continuar o estudo da adesão superficial entre $0 \mathrm{CaCO}_{3}$ e a matriz de PP. Para isso será necessário não somente variar a quantidade de PP-g-MA nas amostras, mas também estudar, entender e variar o tratamento prévio superficial do $\mathrm{CaCO}_{3}$.

- Estudar e trabalhar com parâmetros mais controlados da extrusão reativa, pois sabemos que um processo de extrusão reativa é alterado facilmente por estes parâmetros. Neste quesito, é importante também adaptar estas variáveis de forma eficiente com o tempo/temperatura de meia vida do peróxido utilizado para graftização.

- Trabalhar com $\mathrm{CaCO}_{3}$ de tamanhos nanométricos e compará-los com resultados de tamanhos próximos aos apresentados neste trabalho.

- As análises de DSC feitas neste trabalho tiveram fins específicos e não foram estudados com todos os detalhamentos que as informações da análise podem suprir, portanto segue como primeira sugestão o estudo mais aprofundado dos resultados de DSC

- Neste trabalho foi utilizado uma etapa de produção de masterbatchs utilizando-se um equipamento drays para melhorar a inserção do $\mathrm{CaCO}_{3}$, para trabalhos futuros seria importante avaliar a eliminação desta etapa para melhorar o custo de produção e desta forma tornar os compósitos mais atrativos economicamente. Porém, para que haja a eliminação dessa etapa os parâmetros de extrusão devem ser melhorados. Deve-se estudar, entender e trabalhar com várias combinações destes parâmetros: tipo de extrusora (monorosca ou dupla rosca) e combinação maximizada do desenho da rosca. 


\section{REFERÊNCIA BIBLIOGRÁFICA}

[1]. Naqvi, M.K.; Choudhary, M.S.; J.M.S. - Ver. Macromol. Chem. Phys. (1996), C36 (3), 601-629.

[2]. Fritz, H. - G.; Cai, Q.; Q.; Bölz, U.; Kuntstoffe German Plastics (1993), 83 (6), 8-10.

[3]. Borsig, E.; J.M.S. - Pure Appl. Chem. (1999), A36 (11), 1699-1715.

[4]. McLoughlin, K.M.; ET AL.; ANTEC'97, Polymer Modifiers and Additives Division, Polyolefins I Polypropylene, 733; Society of Plastics Engineers: Toronto (1997).

[5]. Ruggeri, G.; et al.; Polymers Neworks Blends (1992), 2 (3), 167-171.

[6]. Tedesco, A.; Dissertação apresentada no programa de pós-graduação em Química, Universidade Federal do Rio Grande do Sul, como requisito parcial para obtenção de título de mestre em Química, Polipropileno graftizado com metacrilato de glicidila como agente compatibilizante em blendas de PP e Nylon 6 (2001).

[7]. Lu, B.; Chung, T.C.; Macromolecules (1999), 32, 2525-2533.

[8]. Gartner, C.; Suárez, M.; López, B. L. - "Grafting of maleic anhydride on polypropylene and its effect on blending with poly(ethylene terephthalate)" - Grupo Ciência de los Materiales, Universidad de Antioquia, Sede de Investigaciones Universitarias(SIU), Calle 62 \# 52-59 Torre 1 Laboratorio 310, Medellín, Colômbia (2008).

[9]. Campbell, D.; .Pathrick, R.A.; White, J.R. Polymer characterization - physical techniques. 2ª Ed. Stainley thornes (2000).

[10]. Riessen, R.; Schawer, J. The glass transition temperature measured by different TA techniques. Cataloque Metller Toledo thermal analysis (2003).

[11]. JAMSHIDI, K.; HYON, S.H.; IKADA, Y. Thermal characterization of polylactides. Polymer (1998), v.29, p.2229-2234. 
[12]. UserCom-information for users of mettler Toledo thermal analysis systems.

[13]. C. G. Mothé; A. D. Azevedo, Análise Térmica de Materiais, leditora, São Paulo (2002)

[14]. C. Mathieu, A. Thierry, J.C. Wittmann, and B. Lotz, J. Polymer Sci.; Polymer Physics (2002), Vol. 40, 2504.

[15]. P. Jacoby; Plastics Additives and Compounding (2007), Volume 9, Issue 3, pp 32-35.

[16]. Hermans, P.H.; Weidinger, A. Estimation of crystallinity of some polymers from X-ray intensity measurements. J. polym.sci (1949), v.4, p.709-723.

[17]. Krey, P. F. Dissertação apresentada no programa de pós-graduação em Química, Universidade Federal do Rio Grande do Sul, como requisito parcial para obtenção de título de mestre em Química, Polipropileno graftizado com metacrilato de glicidila e anidrido maléico como agente compatibilizante em blendas de PP e PET (2002).

[18]. Adamson, A., "Physical Chemistry of Surfaces", 3rd ed., New York, John-Wiley \& Sons (1976), $698 \mathrm{p}$.

[19]. Bigg, D. M. Mechanical properties of particulate filled polymers. Polymer Composites, Brookfield (2004).

[20]. Bilmeyer, F.; 'Textbook of Polymer Science', Wiley, 2 ed. (1971)

[21]. Bretas, Rosário, Reologia de Polímeros Fundidos, 2 ed, EDUFSCar (2005), 257 páginas

[22]. Cowie J.M.G. - Polymers: Chemistry and Physics of Modern Materials, Interte Books, $2^{\mathrm{a}}$ Ed. (1993)

[23]. Katz, H.S. e Milewski, J.K., "Handbook of fillers and reinforcements for plastics", 1st ed., New York, Van Reinhold Co. (1978).

[24]. Plueddemann, E. P. Interfaces in polymer matrix composites. In: BROUTMAN, L. J.; KROCK, R. H. (Ed.). Composite materials. New York: Academic Press (1974) v. 6.

[25]. Rauwendaal, C. Polymer mixing: a self-study guide. Munich: Hanser/Gardner Publishers (1998). 
[26]. Richard C; Hing, K e Schreiber H.P. Interaction Balances and Properties of Filled Polymers. Polymer Composites, v. 6, n. 4 (2004).

[27]. Rothon, R. Particulate Filled Polymer Composites. Londres. Longman Scientific and Technical, (1995).

[28]. Stumm, W. e Morgan, J.J., "Aquatic chemistry: chemical equilibria and rates in natural waters", Third edition, John Wiley \& Sons, New York (1995).

[29]. Nachtigall, S. M.B.; Baumhardt neto, R.; Mauler, R. S.; Polymer Eng. And Science (1999), 39 (4), 630 .

[30]. Sun, Y.J.; Hu, G.H.; Lambla, M.; Die Angew. Makromol. Chem. (1995), 229 (39820), 1-13.

[31]. Zhao, L, "Síntese e caracterização do copolímero tribloco anfifílico biodegradável Poli(L, Llactídeo-Stat-e-Caprolactona)-BlocoPoli(Óxido de Etileno)-Bloco-Poli(L,L=Lactídeostat-eCaprolactona) (2008).

[32]. Natta, G. Une Nouvelle classe de polymeres d'a-olefines ayant une régularité de structure exceptionnelle. Journal of Polymer Science (1995), v.16, p. 143-154.

[33]. Ruland, W. Crystallinity and disorder parameters in nylon 6 and nylon 7, Polymer (1964), v.5, p.89-102.

[34]. Weidinger, A.; Hermans, P.H. On the determination of the crystalline fraction of isotactic polypropylene from X-ray diffraction. Makromol.Chem (1961), v.50, p.98-115.

[35]. Hermans, P.H.; Weidinger, A. On the determination of the crystalline fraction of isotactic polypropylene from X-ray diffraction. Makromol. Chem. (1961), p.44-46, 24-36.

[36]. Lopes, P. E. \& Sousa, J. A. - "Influência das Condições de Processamento nas Propriedades Mecânicas de Compósitos de Polipropileno com Fibras de Vidro", Polímeros: Ciência e Tecnologia da Associação Brasileira de Polímeros (ABPol), São Carlos-SP, v.IX (1), Jan/Mar, p. 85-96 (1999).

[37]. Lopes, P. E. \& Sousa, J. A. "Modificação nas Características da Interface/Interfase em Compósitos de Polipropileno/Fibras de Vidro com Compatibilizante PP-g-MAH e sua Influência nas 
Propriedades Mecânicas" Polímeros: Ciência e Tecnologia da Associação Brasileira de Polímeros (ABPol), São Carlos-SP Out/Dez, p. 98 - 103 (1999).

[38]. P.G.S. Campos, M.C.A. Fantini, and D.F.S.Petri, J.Braz. Chem. Soc., 15, 523 (2004).

[39]. S.H.P. Bettini and J.A.M. Agnelli, Polym. Test. 19, 3 (2000).

[40]. E.A. Murillo and B.L. López, Macromol. Symp., 242, 131 (2006).

[41]. M. Sclavons, P. Franquinet, V. Carlier, G. Verfaillie, I. Fallais, R. Legras, M. Laurent, F.C. Thyrion. Polymer, 41, 1989-1999. Qualification of the maleic anhydride grafted onto polypropylene by chemical and viscosimetric fitration and FTIR spectroscopy.(2000).

[42]. D.R. Burfield and P.P.T. Loi. JAPS (1988), 36, 279-293. The use of infrared spectroscopy for determination of stereoregularity (1988).

[43]. J.M. Garcia Martínez, O. Laguna, S. Areso, E.P. Collar. Journal of Applied Polymer Science 1999, 73, 2839-2849. FTIR Quantitative Characterization of Chemically Modified Polypropylene Containing Succinic Grafted Groups (1999).

[44] Lewin, M; Mey Maron, A; Frank, R. Surface free energies of polymeric materials, additives and minerals. Polymers for Advanced Technologies, New York, v.16, n.6, p. 429-441 (2005).

[45] Ciminelli, R.R. Critério para formulação de cargas e reforços minerais em termoplásticos. In: Congresso Brasileiro do Plástico Reforçado, 5., 1988, São Paulo. Anais. São Paulo: Associação Brasileira de Plástico Reforçado (1988), P.71-73.

[46] Guimarães, A.M.F.; Ciminelli, V.S.T.; Vasconcelos, W.L. Organically modified layered silicates obtained by grafting of amino-mecapto silane coupling agent. In: Encontro da Sociedade Brasileira de Pequisas de Materiais, 5. (2006), Florianópolis, SC. [Anais]. Rio de Janeiro: SBPMat, 2006. P. 94-96.

[47] Dana, J.D. Manual de mineralogia. Rio de Janeiro: Livros Técnicos e Científicos Editora (1974).

[48] Betejtin, A. Curso de mineralogia. $3^{\text {a }}$ Ed. Moscou: Editorial MIR (1977).

[49] Explicação do equipamento de mistura tipo banbury - Página da internet acessada dia 11/abr/2012 às $11 \mathrm{~h}$ http://www.ctb.com.pt/?page_id=6153 
[50] homogeneizadores de laboratório tipo drays, página acessada dia 11/abr/2012 às 13h http://www.mh.ind.br/lab_homog.asp

[51] prensa hidráulica para produção de filmes de espessura controlada, página acessada dia 11/abr/2012 'às $13 \mathrm{~h} 30$ http://www.mh.ind.br/lab_prensa.asp

[52] Kun Yang, Qi Yang, Guangxian Li, Yajie Sun, Decai Feng, Polym Comp (2006), 27, 443-450.

[53] S. Bruckner, S. V. Meille, V. Petraccone, B. Pirozzi, Prog. Polym. Sci. (1991), 16, 361.

[54] Moore, E. P. Polypropylene Handbook; Ohio: Haser Publisher (1996); p 113.

[55] Trongtosak, K.; Supapol, P.; Tantayanon, S. Polym Test (2004), 23, 533.

[56] Zhang, P.; Liu, X.; Li, Y. Mater Sci Eng A (2006), 434, 310.

[57] Cho, K.; Seheb, D. N.; Choi, J.; Yang, H. Polymer (2001), 43, 1407.

[58] Chi-Ming Chan, Jingshen Wu, Jian-Xiong Li, Ying-Kit Cheung, Polymer (2002), 43, 2981-2992.

[59] W.C.J Zuiderduin, C Westzaan, J Huétink, R.J Gaymans, Polymer (2003), 44, 261-275.

[60] Y.S. Thio and A.S. Argon, Polymer (2002), 43, 3661-3674.

[61] Q. X. Zhang, Zhong-Zhen Yua, Xiao-Lin Xiea, Yiu-Wing Mai, Polymer (2004), 45, 5985-5994.

[62] S. C. Tjong, R. K. Y. Li, T. Cheung, Polym Eng Sci (1997), 37, 166-172.

[63] K. Premphet, P. Horanont, J Appl Polym Sci (1999), 74, 3445-3454.

[64] Informações sobre talco e pirofilita, página da internet acessada dia 5/nov/2012 às 23h: http://www.dnpm.gov.br/assets/galeriadocumento/balancomineral2001/talco.pdf

[65] Informações e detalhes da máquina extrusora da marca Miotto, página da internet acessada dia 10/nov/2012 às 11h: http://www.miotto.com.br/monorosca1.php 